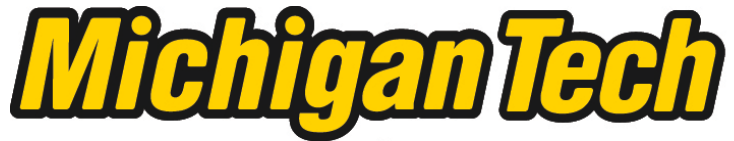 \\ Michigan Technological University Create the Future Digital Commons @ Michigan Tech
}

Dissertations, Master's Theses and Master's Reports - Open

Dissertations, Master's Theses and Master's

Reports

2014

\section{ON THE DIGITAL-POLITICAL TOPOGRAPHY OF MUSIC}

Daniel William Lawrence

Michigan Technological University

Follow this and additional works at: https://digitalcommons.mtu.edu/etds

Part of the Music Commons, and the Rhetoric Commons

Copyright 2014 Daniel William Lawrence

\section{Recommended Citation}

Lawrence, Daniel William, "ON THE DIGITAL-POLITICAL TOPOGRAPHY OF MUSIC", Dissertation, Michigan Technological University, 2014.

https://doi.org/10.37099/mtu.dc.etds/785

Follow this and additional works at: https://digitalcommons.mtu.edu/etds

Part of the Music Commons, and the Rhetoric Commons 


\title{
ON THE DIGITAL-POLITICAL TOPOGRAPHY OF MUSIC
}

By

Daniel William Lawrence

\begin{abstract}
A DISSERTATION
Submitted in partial fulfillment of the requirements for the degree of DOCTOR OF PHILOSOPHY

In Rhetoric and Technical Communication

MICHIGAN TECHNOLOGICAL UNIVERSITY

2014
\end{abstract}

(C) 2014 Daniel William Lawrence 
This dissertation has been approved in partial fulfillment of the requirements for the Degree of DOCTOR OF PHILOSOPHY in Rhetoric and Technical Communication.

Department of Humanities.

Dissertation Advisor:

Committee Member:

Committee Member:

Committee Member:

Department Chair:
Dr. Stefka Hristova

Dr. Robert Johnson

Dr. Karla Kitalong

Mr. Christopher Plummer

Dr. Ronald Strickland 


\section{Table of Contents}

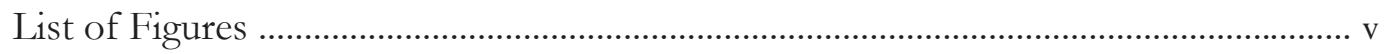

Acknowledgments ..................................................................................................... vi

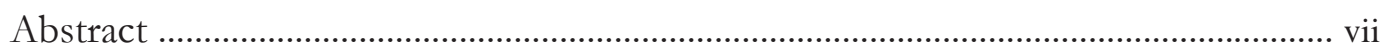

\section{Chapter 1}

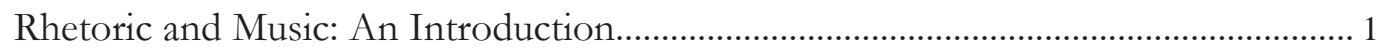

Sonic Studies and the Soundscape …............................................................... 1

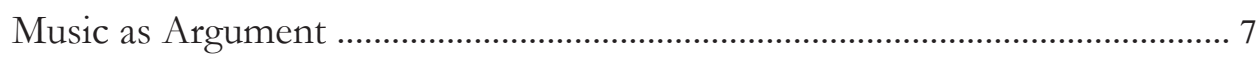

The Pedagogy of Music in Ancient Greece ................................................... 17

Music Beyond its Affective Dimension .......................................................... 25

The Exigency for Such a Work …................................................................... 32

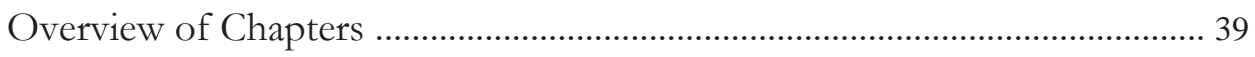

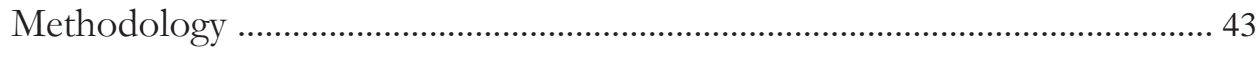

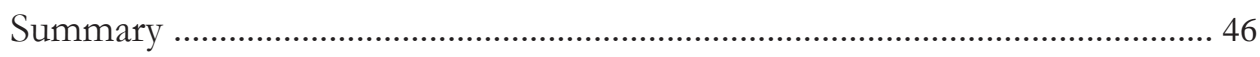

\section{Chapter 2}

Rhetorical-Musical Invention Through the Material and Immaterial Properties of

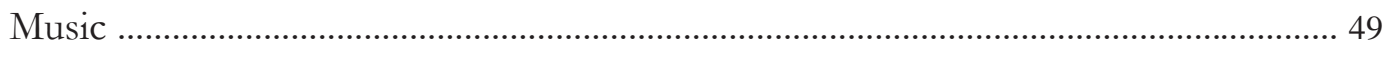

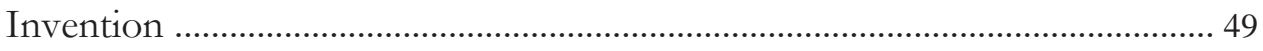

Audience, Invention, Rhetorician ................................................................... 53

Madness and the Ghost: The Non-Presence of Self in Invention ................. 63 


\section{Chapter 3}

The Digital Music Commodity: Memory, Notation, and Reproduction ...................... 70

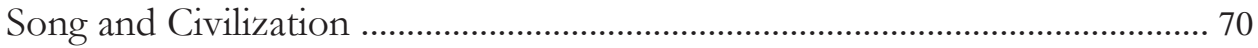

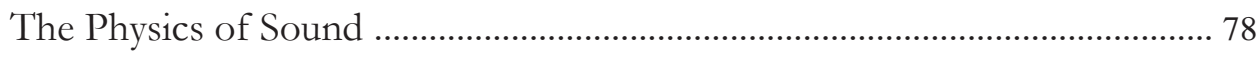

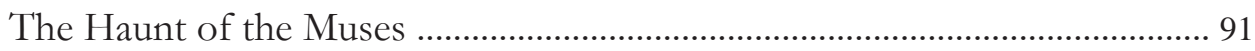

The Archivization of Sound ......................................................................... 105

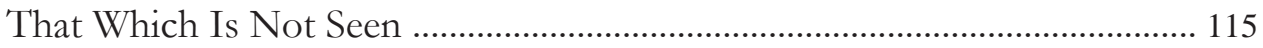

\section{Chapter 4}

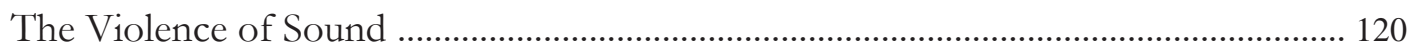

Sonic Bullets and Objective Violence ………..................................................... 120

Who Orchestrates Musical Torture? ................................................................ 128

The Political Spaces of Sound ........................................................................ 132

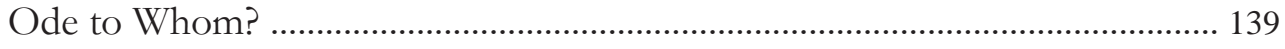

\section{Chapter 5}

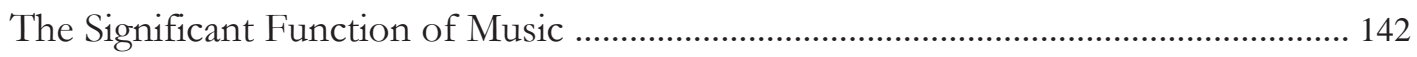

Beyond "Figures of Rhetoric" .......................................................................... 142

Rhetorical Listening ....................................................................................... 153

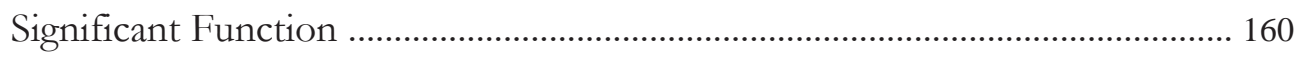

Conclusion: Musical Locality in the Digital Age ............................................... 166 


\section{List of Figures}

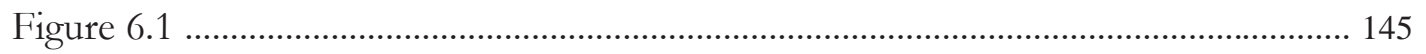

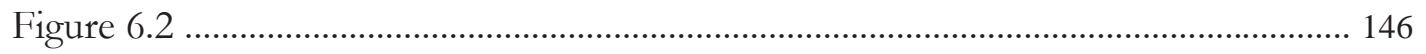

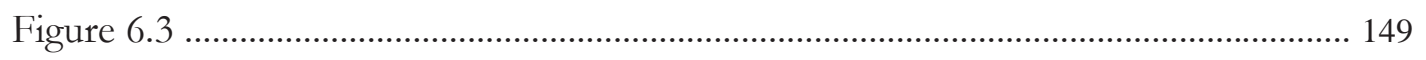




\section{Acknowledgments}

I endlessly thank my advisor, Stefka Hristova, for her genuine excitement in my project and for the care and attention given to my work. This dissertation would not have been possible without the open and exploratory venue you created for my writing.

Many thanks to my committee: Robert Johnson for his advice and guidance, Karla Kitalong for her positive feedback, and Christopher Plummer for sharing his expertise in music composition and production.

I thank Tarun Tapas Mukherjee, editor of The Rupkatha Journal on Interdisciplinary Studies in Humanities, for permission to include here portions of my article "Singing Specters: Phenomenology in the Performance of Music," which first appeared in their October 2013 special issue on Performance Studies.

I also thank Kate Comer and the editorial team at Harlot: A Revealing Look at the Arts of Persuasion for permission to include here portions of my article "The Quiet, Wintry North: Digital Folk of the Upper Peninsula" from their April 2013 special issue on Sonic Rhetorics.

And my family: no words are worthy to thank you for all the love and support through the years. 


\begin{abstract}
The persuasive power of music is often relegated to the dimension of pathos: that which moves us emotionally. Yet, the music commodity is now situated in and around the liminal spaces of digitality. To think about how music functions, how it argues across media, and how it moves us, we must examine its material and immaterial realities as they present themselves to us and as we so create them. This dissertation rethinks the relationship between rhetoric and music by examining the creation, performance, and distribution of music in its material and immaterial forms to demonstrate its persuasive power. While both Plato and Aristotle understood music as a means to move men toward virtue, Aristotle tells us in his Laws, through the Athenian Stranger, that the very best kinds of music can help guide us to truth. From this starting point, I assess the historical problem of understanding the rhetorical potential of music as merely that which directs or imitates the emotions: that which "Soothes the savage breast," as William Congreve writes. By furthering work by Vickers and Farnsworth, who suggest that the Baroque fascination with applying rhetorical figures to musical figures is an insufficient framework for assessing the rhetorical potential of music, I demonstrate the gravity of musical persuasion in its political weight, in its violence-the subjective violence of musical torture at Guantanamo and the objective, ideological violence of music — and in what Jacques Attali calls the prophetic nature of music. I argue that music has a significant function, and as a non-discursive form of argumentation, works on us beyond affect. Moreover, with the emergence of digital music distribution and domestic digital recording technologies, the digital music commodity in its material and immaterial forms allows for ruptures in


the former methods of musical composition, production, and distribution and in the political potential of music which Jacques Attali describes as being able to foresee new political realities. I thus suggest a new theoretical framework for thinking about rhetoric and music by expanding on Lloyd Bitzer's rhetorical situation, by offering the idea of "openings" to the existing exigence, audience, and constraints. The prophetic and rhetorical power of music in the aleatoric moment can help provide openings from which new exigencies can be conceived. We must, therefore, reconsider the role of rhetorical-musical composition for the citizen, not merely as a tool for entertainment or emotional persuasion, but as an arena for engaging with the political. 
On the Digital-Political Topography of Music 
We read of how various harmonic modulations have the power to instill diverse effects in the listener: moving them from hysteria to a pacified state;

$$
\begin{aligned}
& \text { from lust to chastity; } \\
& \text { from a serious illness to good health; }
\end{aligned}
$$

from being beset with demonic forces to being freed of them;

from all we can gather concerning rhetoric, its effects are never so extensive as those of music.

There is a great power yet still latent within music - a greater energy and capacity to influence effectively the human mind, than that possessed by rhetoric.

-Athanasius Kircher, Musurgia Universalis (1650) 


\title{
Chapter 1
}

\section{Rhetoric and Music: An Introduction}

\author{
Song to mortals of all things the sweetest.
}

-Museaus

\section{Sonic Studies and the Soundscape}

In this chapter I introduce the persuasive power of music. From the epigraph provided from Kircher's Musurgia Universalis, we begin to see the sometimes confrontational, often muddled ideas of the place of music in argumentation, and argumentation in music. I begin, here, by introducing the field of sonic studies, a recent field of study which engages with the sounds of the world. Sonic studies emerged as a grouping of academic work that is interdisciplinary in nature. It encompasses acoustics, listening and sound cognition, noise and architectural planning, media studies, and much else that is related to not only sounds that humans decisively make, but sounds that occur from, for example, our footsteps, or the crack of a branch in winter, laden with heavy snow. Herein we begin to understand the distinction from musicology, which is primarily concerned with the theory, application, and analysis of organized musical composition. The term soundscape comes from work by R. Murray Schafer, in his The Tuning of the World (1977). Soundscapes constitute a sort of acoustic ecology; they are made up of all the sounds of an environment. Bernie Krause adds 
specifications on Schafer's framework to develop such dimensions as anthrophonous, biophonous, and geophonous sounds (2012).

Humans make all sorts of sounds. And they aren't all pleasant. Two neuroscientists, Pawel and Margaret Jastreboff, have been studying what they call misophonia, a certain neurological disorder which causes sufferers great anxiety and distress over hearing certain sounds (2002) It's also known as selective sound sensitivity. We clank spoons on ceramic bowls. We tap our fingers rhythmically in boredom and unconsciously let our uvulas ripple around in latenight snoring. Yet, we also sing in harmony with one another. We hear a bird song and replicate it in a whistle. ${ }^{1}$ Biophonous sounds are those produced by other living species. There's no doubt a bit of anthropocentricism in this framework, but we must admit: humans are undoubtedly the loudest of all animals, with our engines and mining blasts, fireworks and space shuttles and planes and war. Then again, the perception of loudness varies depending on the particular auditory receptive structures of a species, and can of course vary from member to member of a given species. And loudness in human perception varies based on frequencies and relative noise levels: the Decibel or $\mathrm{dB}$ is not a universal unit of measurement, but rather a relative way of measuring apparent

${ }^{1}$ Granted, it should be noted, too, that the sound of a whistle is unpleasant to many. Herein we see in plain view the problem of the aesthetics of music, and are faced with a subjective-objective problem. Why is it that we have cross-cultural musical tropes such as descending melodies or minor tonalities that almost always move the listener to an affect akin to melancholy, while much else is case-by-case? Andrew Schultz, Professor of Music at UNSW, in a lecture titled "The Minor Fall and the Major Lift: Music, Power, and the Composer's Black Art," tells us there should be a division between psychoacoustics, or "the logic of music," against culturally shaped perceptions of aesthetics for "individuals." (Oct. 2010). This "aesthetic position," the combination of the subject and objective influence, constitutes the ever-changing, "organic" nature of what we might call musical taste according to Schultz. 
amplitude. I imagine that earthworms do not think we are very loud, until we start digging them up and the world is rumbling all around them. Sounds made by animals other than the human — this category of biophonous sounds - appear to us as both structured and unstructured, much like anthrophonous sounds. Richard Dawkins notes in his Selfish Gene that bird songs are apt to change from generation to generation, working somewhat like mutations in genes, and these songs then go through a sort of memetic transference (1976). There are some age-old questions regarding the songs of birds. It's entertaining to wonder: do human musical structures reflect the melodic phrasing of winged life? Did we derive some scales from our friends in the trees? On the other hand, we know too well the caw of the crow at 5 am on a Saturday when a little extra sleep is needed. But Geoffrey A. Keller, in his studies of the American crow, has found at least twenty different caws that seem to have definitive purposes in crow communities, such as signaling for danger (2014). So a rattling, disturbing caw that heralds the discovery of a fresh feed is likely to sound of music to a murder of crows.

Lastly in these ideas we have geophonous sounds, which are the sounds of the earth, roughly. Wind, waves. We run into some trouble, which we can note for entertainment: if I step on crunchy Autumn leaves in October, is the earth sounding, or am I sounding? We're sounding together, I think. When avalanchial ice starts cracking and a group of snowshoers dives for cover and startles a mountain goat, or some young couple in love hears a warm breeze sweep over them on a sandy beach with lapping waves but wearily eyes the seagulls gurgling overhead, we can start to see how soundscapes are put together. And they are infinitely intricate. The addition I make here is to note that there are certainly extra-geophonous sounds, or sounds that are not 
made by earth, but beyond it. Some of these sounds are made by humans and their technologies, some by astronomical objects. We might call them cosmophonous sounds. Colonel Chris Hadfield made field recordings of the sounds of the International Space Station (ISS), such as "Sleep Station - Fan on High," "Caution Alarm," and "Sounds from the Dining Table," as well as his own musical creations such as "Jewel in the Night," which he has classified as belonging to the Space Folk genre on his SoundCloud page where he published these recordings. Granted, we can call these anthrophonous sounds, as they are produced by humans and the machines they have built. But what do we make of, for example, a volcanic eruption on a distant world, perhaps in altogether different galaxy? We can call these sounds cosmophonous, from the Latin cosmos and what became the Middle English "cosmos" and remains today as synonymous with "the universe." Pythagoras is thought to be the first to use kosmos as a way to mean the entirety of the universe, including the earth, though it then carried a meaning of order and arrangement: the universe, yes, but the universe and all of its interweavings and interconnectedness, all of its harmonies and its mathematical machinery (Uzdavinys 2004, p. 4). ${ }^{2}$

There is a paradox that has been jostled around for some time: "If a tree falls in the forest, and no one's there to hear it, does it make a sound?" We can trace this

\footnotetext{
${ }^{2}$ NASA, too, has been using the plasma wave science instrument on Voyager I to "listen" to the sounds of space as Voyager I leaves the heliosphere- the sun's great magnetic field - and traverses into interstellar space. Humans themselves cannot "hear" plasma waves, but because those recorded by Voyager I were in the range of audible human frequencies, between a few hundred a few thousand $\mathrm{Hz}$, they can be played back and turned into the pressure waves which humans recognize as sound (Gurnett). Thus, the addition of cosmophonous sounds to the field of sonic studies may not only better help us understand human music, but could aid us in far-distant research in inter-stellar communication and translation.
} 
particular phrasing to Twiss and Mann's Physics from 1910, though such a strain of inquiry has been floating around and considered seriously for some time. It's a philosophical thought experiment with which many of us are familiar. The human ear-as well as many other animals' ears_-detects sound not as vibration, immediately and directly, but as differentiations of pressure in the air. Inner ear bones and cochlear hairs process this input into pitch (frequency) and loudness (amplitude), as well as directionality (location) by a quick calculation that we perform with our binaural set of ears. I imagine this is why we tilt our heads to the side as a sign of confusion. Our domestic pets do this, too, but it's not because they picked up on the symbolism of the gesture: tilting the head adds a vertical difference between ears as well as the preexisting horizontal difference, and better helps to locate the source of a sound by sending more information to the brain. So if a distant civilization that lives in a similar frequency range as humans on a planet halfway across the Milky Way sings a song, does that civilization make a sound? It does. They're making all sorts of sound, I imagine. And beyond that: sounds we just can't hear, yet, or may never. Sounds in other ranges and using different mechanisms. Sounds we might never hear, and that we might not be able to perceive given our particular anatomy, or our particular situation in time and space. Or perhaps they'll sing along with us someday. While this may seem at first like a trivial consideration—what should we care about the sounds and goingons of places we know nothing about? —we should always be mindful of that which is around us, beyond the simple bounds of a geocentric worldview. We might call this tendency to disregard the extraterrestrial going-ons of the universe as the "geocentric conceit": whether in sonic studies, philosophy, or even in some STEM fields, we forget 
our size and place in our academic work. On the other hand, we can remember the Golden Record placed aboard the Voyager I spacecraft that, at the time of writing this work, is thought to have left the heliosphere to travel beyond our solar system. On the Golden Record is a collection of human understanding, composed in a way that was thought might be universally legible. Yet, on the Golden Record, too, are the sights and sounds of earth and its species, from Blind Willie Johnson, Beethoven, traditional Senegalese percussion, and a wealth of other human musical works. To consider the addition of cosmophonous sound to the soundscape is to open up our understanding of sound to be more inclusive in an age when humans are, through the aid of technology, exploring other worlds. It also allows us to understand that sound is not bound to the conventions we have limited it to: our understanding of sound is always changing. Indeed, as Jacques Attali tells us, music can even be prophetic (2009).

There are many lenses through which we study the sounds of our world and in our work toward identifying the sounds that occur beyond the limitations of the geocentric worldview. What has been lost in the study of sound is the way in which we structure music to make arguments, in particular contexts, for particular purposes. The purpose of this project is to re-introduce rhetoric to the theory of music and thus contribute to the growing body of work emerging as sonic studies, and to suggest for rhetorical scholars an attention to be paid toward music and its persuasive abilities beyond emotion. Music is too often passed off as a segment of a soundscape, as a passive source of enjoyment. And we are too often left with the notion from ancient Greek theories of music that our songs are merely that which plays with pathos, that which stirs the emotions. This work seeks to examine the ways in which music 
persuades us through its political appropriations, through its subsumption into capitalism as the digital music commodity, and in its material and immaterial properties. So, too, does this work hope to bring some light to the political potential of music in its ability to bolster political revolution and to foresee new political realities, in what, as above mentioned, Jacques Attali calls the "prophetic" nature of music (2009).

\section{Music as Argument}

On earth, here, humans have started organizing their sounds into complex patterns using arrangements that feature multiple sounding sources to create unified entities. We have our English "music" from the Latina musica, but the etymological train follows back to ancient Greece, at least, from mousikê. Music is often seen as the lengthy organization of multiple sounds for particular contexts with expected outcomes. We get this general idea of music as the organization of sound from the composer Edgar Varèse (Goldman 1961). But we know that music varies greatly crossculturally. And some languages have no word for music at all. What was intended to make one dance might simply put a smile on another's face, or even force one out of the room: "it's just noise!" As we understand it, music is a uniquely human creation and endeavor - it is anthrophonous sound. Elephants trumpet and mourn over the loss of a family member. Though it is communal, emotive, personal, and meaningful, their sounds of grief form a soundscape, a collection of sounds, rather than music. Bird songs most often than not are direct, message-like signals, more like a mandative tense in English; "Watch out!" or "Get over here!" are certainly persuasive in crow caw form, 
to other crows, but they are, seemingly, singular in their intended meaning. ${ }^{3}$ Music, on the other hand, is rich and slippery in its multilayered and complex arrangements. Music carries multiple meanings through its sonic qualities and character, its dynamic crescendos, its various movements and sections, its appropriation of language in lyrical form, and in its particular ability for us to memorize its passages.

The relationship between rhetoric and music has been opened up, cast aside, disregarded, and altogether tossed around since its early works set out the tradition of musica poetica. Of the first to publish on the connection between rhetoric and music was Nikolaus Listenius in his Rudimenta Musicae Planae from 1533. This has left a trail of ambiguous associations between the classical study of rhetoric and the theory of music. It may have even been more of social reality. Rhetoric was, perhaps, more widely taught then, and thus its influence may have crossed into musical composition, demonstrating an interesting fluidity between the studies. Musical theories with rhetorical characteristics - discussions of pathos, predominantly, and emotional affect for the audience-predominated in the $16^{\text {th }}$ and $17^{\text {th }}$ century German thought—and praxis - though this connection did not continue. Indeed, contemporary musical theory is decidedly unconcerned with rhetorical considerations. Yet, new interest in this tenuous tie between rhetoric and music surfaced again in the work of American scholar George J. Buelow beginning in the 1970s as he sought to investigate the rhetorical groundwork set out by the German baroque composers: Burmeister, Dressler, Mattheson. It may have been the near-concurrent explosion of cultural studies and its

\footnotetext{
${ }^{3}$ The Cornell Lab of Ornithology has a research group dedicated to this study of the American crow and its call.
} 
engulfment of music — and so much else_- that drew attention away from this new research. Or, perhaps, like those German composers, the time had simply not yet come for a meaningful assessment of music as argument.

It is plausible, too, that rhetorical theories of music have been overlooked because of their historical situatedness of what is known widely to the West as classical music, an umbrella term that is used to encompass periods that are distinguished usually as Baroque, Classical, and Romantic. Classical music can also refer to any art music that derives from these European traditions or precedes them, making it dangerous in the ease with which it can misguidedly group unrelated material together. On another side of the matter, it is also plausible that the area of scholarship that promenades with both the study of rhetoric and the study of music has been dismissed because of its extraordinary ambivalence. Early baroque theories that developed from the tradition of musica poetica, such as the doctrine of the affections, sought to apply the rhetoric of oratory to musical composition with the pepper of emotive binaries (joy/sorrow). Yet no direct correlation between rhetorical tropes and those of music were cemented — though numerous rhetorical-musical figures were suggested-nor was a serious attempt made to formulate a new conclusive and applicable theory of the rhetoric of music. Looking back with our vantage point, it seems that a rather confused commingling occurred considering the passionate fire of rhetoric and bubbling ebullience of that time's talented songsmiths. It's often the conditions under which ideas meet that are more important than what some call chemistry.

Joachim Burmeister described in the opening to his 1606 treatise Musica Poetica what a musical poetics would entail: 
...how to put together a musical piece by combining melodic lines into a harmony adored with various affections of periods, in order to incline men's minds and hearts to various emotions. (1993)

Burmeister was restricted in his analysis by relegating the rhetorical potential of music to only have affective properties. He drew from Plato and Aristotle, who, although they were advocates of musical education for the youth, wrote with a preconception of music as chiefly a method to stir the passions, though noted its manifold powers. Burmeister wrote, too, that to experience these emotional powers of music, one must be "not altogether unmusical" (1993). This privileges those with a formal musical education and background, something not widely available to many at the time of Burmeister's writing, and still not universally available. Music in contemporary $21^{\text {st }}$ century digital society is still not a sort of lingua franca. Though instruments are mass produced and, for certain peoples, relatively inexpensive, and digital composition and recording tools present themselves as freeware for public proliferation, we must be very careful here: we do not all have access to these tools. It is very much because of the prevalence of music in the digital age-in advertising, in politics, in education, in games - that we must understand how music does more than merely move our moods. Commentary on music is evident throughout the work of both Plato and Aristotle, as aforementioned, in Laws, Politics, and Republic, where music is often regarded with much seriousness, due to its incredible ability to move the mind and soul. It is unusual to me, then, that a theory of musical composition which took into consideration a rhetorical grounding did not seem to develop until the $16^{\text {th }}$ century in European musical composition in the form of musica poetica (Listenius 1533). The 
ancient Greeks developed a loose body of works that here can act as a starting point for the foundation of a rhetoric of music: though I do not intend to be so presumptuous as to re-write history, I suggest that because of the prevalence of rhetorical considerations in the lives of so many educated ancient Greeks, it's likely that a composer of music may have considered such elements as audience or the appeals of ethos or logos in performance, and certainly beyond narrow heuristical understandings of rhetoric, as an education in rhetoric extended centuries beyond ancient Greece, and seems to have dwindled only in the 1800 s following practices of standardization in education which began to slowly occlude rhetoric from the curriculum.

Music is a human system, one that is heavy with meanings. The perception of music by animals is unfounded and, unfortunately for our domestic pets, the linking together of sonic phrases into arrangements doesn't seem to register to them. But this is surely an important understanding: when encountering a protective, aggressive black bear in the woods, better to yell at the fellow than to start singing a lullaby. Though we often hear an anecdote along the lines of "Music soothes the savage beast," this is a misappropriation of the opening lines of William Congreve's The Mourning Bride. Congreve's text goes as follows:

Almeria: Musick has charms to soothe a savage breast, To soften rocks, or bend a knotted oak. I've read that things inanimate have moved, And, as with living souls, have been inform'd, By magic numbers and persuasive sound.

What then am I? Am I more senseless grown 
Than trees, or flint? O force of constant woe!

'Tis not in Harmony to calm my griefs.

Anselmo sleeps, and is at peace; last night

The silent tomb received the good old king;

He and his sorrows now are safely lodged

Within its cold, but hospitable bosom.

Why am not I at peace? (Congreve 1855, p. 237)

My argument in this work is that music is persuasive, not merely in terms of emotion, of pathos. I suggest an investment of rhetorical studies into interdisciplinary work that will seek to understand the complex ways that music effects us, beyond affect. And it is not in the "magic numbers" of music - in purely technical music theory-in which we must identify the arguments that are made by music, and by the performers and composers of music. While music may not soothe the savage beast, it soothes the savage breast so very often. Yet, its lyrical contents and musical structures can also enrage. Motivate. Inspire. Incite introspection. It can carry heavy ideological weight and bring forth patriotic thoughts in view of a national flag. Thus, in defining music, we must look beyond this notion of music as an arrangement of organized sounds, and understand that music is experiential, that it conveys meaning, and carries particular persuasive structures.

It would be too much to say that through the philosophies and writings of Plato and Aristotle that a directly stated "rhetoric of music" or a comprehensive rhetorical theory of musical composition was established. There is no mention of this in any surviving texts. However, the parallels and points I have above offered 
demonstrate that for ancient Greek thought, both musical and rhetorical performances rely on careful consideration of intent, situation, and audience, and wee see that the end goals of both the pursuit of oratory and of musical training, done in the right way, lead the individual to the cultivation of virtue, and lead listeners to truth. In Phaedrus, good rhetoric is lead along by philosophy — in this very pursuit of truth. And the best of music to be found in the polis is that which not only moves the emotions but searches for "truth" and so guides its players, performers, and listeners. ${ }^{4}$ Rhetoric, a scholarly tradition on the methods and theory of persuasion, has come to us with plentiful connotations. What was once the art of oral delivery in the Athenian courtroom now means something more. Aristotle's famous definition, from Rhetoric, regarding the use of all the available means of persuasion, has a sort of addendum in another work, Topics: the rhetorician must be able to see what is persuasive [VI.12, 149b25] (W. Rhys Roberts 1994). That is, the rhetorician must be able to not only apply but also identify the set of skills available for persuasion. Contemporary scholarship, such as that by Joddy Murray, in his Non-Discursive Rhetoric: Image and Affect in Multimodal Composition, tells us that "By considering non-discursive texts, all possibilities of symbolization become tools for the rhetor: the symbols of math, music, textiles, food, poetry, commerce, violence, inaction, and even silence"

\footnotetext{
${ }^{4}$ Now, we must understand that Aristotle and Plato mean seemingly different things by the same word of "truth." Plato's "truth" is derived from what we commonly call the Theory of the Forms. It seems that when Plato tells us that music can direct us toward truth, he means that particular musical arrangements point to the universal principles which have informed its structure and composition. Aristotle, on the other hand, might have argued that music which leads us to truth does so by means of offering a particular replication of an emotion. From both meanings of "truth" in music, we can see how singular musical pieces takes particular stances.
} 
(2009, p. 12). Aristotle conceived of rhetoric in a sort of neutral fashion. That is: it can be put to use for the good or bad, for just or unjust purposes. ${ }^{5}$ Through Plato's Phaedrus we can understand the rhetorician as being one who identifies the type of soul that is being addressed, and moves that soul.

We can begin to understand a relationship between rhetoric and music in ancient Greek thought, as it was situated in particular contexts: the ways theorized regarding how music should be taught to the Athenian youth, where it fit into the polis, and its contingent pedagogy through work by Mary B. Schoen-Nazzaro and Thomas J. Mathiesen (1978, 1984). Plato and Aristotle wrote extensively on music, and disagreed at times, as well: especially regarding which modes were best suited for which occasions or audiences. These sorts of considerations by the ancient Greek philosophers demonstrates what I think to be a very early consideration for the persuasive power of music. Both speech and music in ancient Greek thought were seen as modes to move: to move the soul, the mind, or the emotions. I thus stake the claim that Aristotle and Plato found agreement in the power of music to effect its listener, that certain forms of music and modalities are best fit for certain audiences, and that the pursuit of music in education and the performance of music in public in its best form was a sort of guiding light toward "truth." Here, then, we can argue that a series of similar structures arise between ancient Greek theories of music and rhetoric, and that musical performance for the ancient Greeks was an inherently rhetorical activity, from the Athenian classroom to the festival.

\footnotetext{
${ }^{5}$ Chapter 4, I discuss the rhetoric of music in its subjective and objective appearances through violence.
} 
Plato has Socrates tell us in Phaedrus that the true rhetorician must define the soul, categorize every type of it that might be, and what sorts of speeches will direct these soul types, as "the nature of speech is in fact to direct the soul" (Nehamas \& Woodruff 1995, p. 548). The speakers in Phaedrus realize, of course, this is a daunting task. Similarly, Mary B. Schoen-Nazzaro tells us that Plato understood that music is useful for education "because more than anything else rhythm and harmony find their way into the inmost soul and take strongest hold upon it" (1978, p. 262). Let us first explore Socrates' understanding of rhetoric as relayed by Plato in Phaedrus. Socrates tells us:

Well, then, isn't the rhetorical art, taken as a whole, a way of directing the soul by means of speech, not only in the lawcourts and on other public occasions but also in private? Isn't it one and the same art whether its subject is great or small, and no more to be held in esteem-if it is followed correctly-when its questions are serious than when they are trivial? Or what have you heard about all this? Nehamas \& Woodruff 1995, p. 537)

What should be of interest, here, is that Socrates is willing to place his understanding of the art of rhetoric — "a way of directing the soul by means of speech"—outside of the Athenian lawcourts (Nehamas \& Woodruff 1995, p. 537). It is fitting, then, that in this dialogue, Phaedrus and Socrates have wandered outside the walls of the city, and have found themselves in private. Here, by the shade of a tree and in view of the Ilissus river, the two share speeches and offer critiques. We might backtrack to understand what Socrates means by the soul-though it is a complex notion, he tells us that the 
soul is always in motion, and that it is a "self-mover" with no "source" or "beginning," and thus it is immortal, as we read near Stephanus number 245c (Nehamas \& Woodruff 1995, p. 524). In this revision of Phaedrus' speech that Socrates offers, he goes on to liken the soul to a chariot, which he imagines is pulled by good horses and bad. The bad horses weigh down the chariot and bring it closer to earth. The good horses can steer the soul to the "high ridge of heaven," where the soul may "gaze upon what is outside heaven" at 246a-247e (Nehamas \& Woodruff 1995, p. 524-525). Here we have a bit of a theoretical conundrum-if the soul is self-moving and self-steered, what do we make of rhetoric and all that which moves the soul?

Socrates' explication of eros in the Phaedrus can help us, here. Eros threatens the selfness of the soul, and it seems the soul has inherent tensions, as evidenced by the white and black, good and bad horses in the example of the chariot. For Plato's Socrates, learning is a sort of remembering - a tapping into the eternal. The mad, divine love that Socrates speaks about shows that beauty can awaken us to these truths, but beauty also leads to a sort of drugged state: the trope of the pharmakon. But there are many different "kinds of souls," for Socrates, and "whoever intends to be a rhetorician must know how many kinds of soul there are..." as "some people have such-and-such a character and others have such-and-such" [271d] (Nehamas \& Woodruff 1995, p. 548). There is no singular soul, then, and there is thus no perfect speech fit for every person and every occasion. While we might not be able to directly reconcile this apparent conflict between the self-movement of the soul and external influences on its movement, it is for Socrates that a rhetorical speech should be of 
good intent - that is, to aid the soul in its movement toward the Good and to the limitless and that which is beyond the ridges of heaven: a sort of return to the eternal.

Gorgias, in his Encomium of Helen, is also fascinated with the trope of the pharmakon, of the drug, of the "potion" that we see at 230c in Phaedrus (Bizzell \& Herzberg, 2001). Phaedrus tells Socrates that he had to charm or seduce him to get him outside the city. Socrates later uses the trope of the pharmakon to discuss writing and memory. Gorgias more directly applies this to his theory of how speech effects the soul:

The effect of speech upon the condition of the soul is comparable to the power of drugs over the nature of bodies. For just as different drugs dispel different secretions from the body, and some bring an end to disease and others to life, so also in the case of speeches, some distress, others delight, some cause fear, others make the hearers bold, and some drug and bewitch the soul with a kind of evil persuasion. (Bizzell \& Herzberg 2001, p. 46)

Plato and Gorgias are not completely at loggerheads, here, as both put forth a theory of speech as that which effects the soul. Aristotle writes in his Politics-to which I will return—that certain "mystic melodies" can even bring "healing and purgation to the soul" (1342a). Rhetoric, then, in what I have examined, is a way of moving the soul, of directing the soul through Plato, and for Aristotle the identification and use of the available means of persuasion. The good rhetorician is also a good philosopher for Socrates in the Phaedrus, for the speaker must know the "truth" of what he is saying before he then goes on to assess the souls of those to whom he is speaking [277b] 
(Nehamas \& Woodruff 1995, p. 554). As music is that which moves the listener, and the ends of music, the goals of music, for the best sort of music, as explained by Aristotle in his Laws is to approximate, locate, or identify that which is true. Such an importance granted to music by the ancient Greek philosophers is undoubtedly what led them to write of the proper education of music for the Athenian youth.

\section{The Pedagogy of Music in Ancient Greece}

In Plato's Laws, the latest of his dialogues to have been written, an Athenian Stranger speaks of the education of the youth:

Education has two branches_-one of gymnastics, which is concerned with the body, and the other of music, which is designed for the improvement of the soul. (Jowett 2001, p. 223)

Yet, these distinct associations fall apart within the dialogue to reveal a more organic and embodied approach to musical pedagogy. Music, for Plato's Athenian Stranger, is characterized by its ability to incite pleasure in the listener (Jowett 2001, p. 233). Yet, it' is proposed in a utopian state that there should be three years of musical education following three years of intensive study in what were seen as fundamental literacy skills, roughly reading and writing. We know, too, that the mathematics of music found its origins in Ancient Greece. Pythagoras first wrote of simple ratios between notes from which we derived such musical mainstays as the major third and perfect fifth. There is a two to one ratio for the octave, for example, and three to two for a perfect fifth, in terms of frequency — Pythagoras wasn't measuring wavelengths, though, but the 
lengths of vibrating strings. Here we can argue: is there something universally appealing about the perfect fifth both in the ratio of the frequencies between the notes and its aesthetic quality, or are we left with this fifth that still haunts our popular music today because a mathematician was enamored with the apparent perfection of these ratios? Pythagorean scales, it should be noted, dominated Western music until Bach began experimenting with his "well-tempered scale," seeing that composers wanted more notes with which to play. The resulting well-tempered, and later even-tempered scales deviate from Pythagorean models, and, it seems, the ratios of the frequencies of the modern piano are not quite Pythagorean-perfect.

Rather than focusing on the mathematics of music in education, Aristotle moves beyond, to the moralistic. Aristotle uses Book VIII of his Politics to describe a liberal education for the youth, the place of music and gymnastics therein, and to discuss the role of the professional musician in his ideal polis. He then goes on to clarify three purposes for the study of music: "education," "purgation," and for "intellectual enjoyment" or "relaxation after exertion" [1341b] (Ellis 2009, p. 314). The educational dimension has less to do with the eternal soul and more to do with the mortal being and his morality. For Aristotle, the right sorts of music—that is, learning to play the right sort of music — can aid the youth in developing a proper temperament and facilitate a coming-into awareness of what is virtuous. Aristotle sees music, here, as an imitation of the emotions. As Schoen-Nazzaro tells us, regarding Aristotle: “...the power of music is to move the listener in harmony with itself, it follows that the skillful musician will be able to reproduce almost any emotion so that it can be felt and recognized by the listener... This is what imitating emotions entails" (1978, p. 268). 
This theme of imitation is evident throughout ancient Greek theories of music, and not only in application to the emotional states of humans, but also the intellectual and the philosophical. As Thomas J. Mathiesen tells us in his "Harmonia and Ethos in Ancient Greek Music," Aristoxenus, a pupil of Aristotle, understood music “as an analogue for higher philosophical truths” (1984, p. 265). Though Aristotle and Plato were very careful in their rendering of music, it is ascribed much more power and wider depth in subsequent ancient Greek scholarship following from their traditions.

Despite the evident phonetic and linguistic etymological link between our present day "music" and the ancient Greek mousikê, we should not be so quick to equate the two terms. Indeed, much has changed over some 2500 years in understanding the role and purpose of music, as well as its place in education and society. Babette Babich, in "Mousike techne: The Philosophical Practice of Music in Plato, Nietzsche, and Heidegger," writes that:

As mousikê is only partly equivalent to the contemporary conception of music, our tendency to reduce music to the "organized" art of sound obscures the equiprimordial sense in which Musik is the quintessence or enabling element of intellectual or spiritual education and in which Musik figures as the determining force of both individual and societal character or ethos. (Babich 2005, p. 172)

Much has changed in the pedagogy of music. My personal experience in public education music classes - once a week from kindergarten to $5^{\text {th }}$ grade, and then a daily middle school band class from $6^{\text {th }}$ to $8^{\text {th }}$ - showed an extreme favoritism to the reading of notation and the recitation and mechanical reproduction of music rather than the 
creation of music, or even the understanding of music theory. Certainly, never were we asked to compose music, or to think about the structures of music, or to analyze the figures of the music we were performing. It is easy to harken to a "Golden Age" and think that the ancient Greeks might have had it all right. But, it is clear that ancient Greek musical pedagogy for the youth was more concerned with music as a passageway to a liberated mind, a virtuous soul, and ultimately as a way to seek truth. We come across the Athenian stranger make this claim in Plato's Laws: “And those who seek for the best kind of song and music ought not to seek for that which is pleasant, but for that which is true..." [668a-668b] (Jowett 2009). Schoen-Nazzaro clarifies this for us in terms of Plato's work on music:

...in some way, although not in exactly the same way as Aristotle, Plato sees the type of music chosen in a particular instance as dependent upon the nature of the one performing or benefitting from it (1978, p. 273).

Here, we begin to see the connection between the oratorical choices of the rhetor and the contextual choices of the musician. The musician attempt to identify his audience and their nature-much like the orator attempts to identify the souls of his listenersand makes particular choices about how to direct them with music. Granted, we should again stray away from thinking about music as simply that which moves the emotions. For, both Aristotle and Plato recognized the music can bring about order and carry more profound moral meaning in its structures: this rhetorical link, or rhetorical parallel, between defining the right structure/arrangement for the right moment for the 
given audience is present in both Plato's rendering of rhetoric in Phaedrus and in the theories of music and musical education put forth by Plato and Aristotle.

Because of this power of music, musical education for the youth is necessary in the thinking of both Plato and Aristotle, as this education leads to the cultivation of virtue-we might even say, in a sense, that for these philosophers a musical education precedes and facilitates the development of higher, critical thought, and it is thus considered an integral part of pedagogy. This is not a merely technical training that the philosophers are concerned with: not the skilled use of an instrument, which can with leisure be learned in adulthood, but a sort of ear for music, and the connectivity between being and sound. Schoen-Nazzaro tells us more:

A musical education neither trains a child to be a skillful musician nor teaches him a science. What Plato says about the fine arts as fostering learning can be applied to music in particular. He speaks of these arts as preparing the mind for understanding by providing a cultural formation. They do this first by arousing and feeding man's love of knowledge and secondly by purifying and sharpening his perceptions. (1978, p. 265)

This is a vastly different form of musical pedagogy than we know of in today's American public schools. From early note-reading and the playing of the plastic recorder, to the high school marching and pep band, musical composition is not stressed, but rather the reification of musical notation: the translation from text to sound. For, we know that the ancient Greeks had only a rudimentary system of relative notation, of which few remnants survive in Pohlmann and West's Documents of Ancient 
Greek Music: The Extant Fragments (2001). This relative notation seems to have acted as guiding marks rather than universally recognizable symbols which identify a common tone at a particular frequency, such as today's "A440" which is used as a tuning standard, setting the musical note $\mathrm{A}$ above middle $\mathrm{C}$ at $440 \mathrm{~Hz}$. We might wonder, too, what the implications of such an unregimented musical notation system would have had on musical composition, improvisation, and invention. Musicologist Susan McClary comments on this tension which still holds true in Western society regarding musical pedagogy:

Now it is quite clear to most listeners that music moves them, that they respond deeply to music in a variety of ways, even though in our society they are told that they cannot know anything about music without having absorbed the whole theoretical apparatus necessary for music specialization. But to learn this apparatus is to learn to renounce one's responses, to discover that the musical phenomenon is to be understood mechanistically, mathematically. Thus non-trained listeners are prevented from talking about social and expressive dimensions of music (for they lack the vocabulary to refer to its parts) and so are trained musicians (for they have been taught, in learning the proper vocabulary, that music is strictly self-contained structure). Silence in the midst of sound. (2009, p. 150-151)

We might even assume a link between the lack of stagnant, concrete notation for the ancient Greeks and their insistence on a musical pedagogy with such high aims beyond the reading and playing of notation. Emily Howell, the computer program created by 
Dr. David Cope, then professor of music at the University of California, Santa Cruz, is said to compose music. I would argue that, rather, it is improvising within certain structures and within established keys and modalities, that it relies on particular patterns, and that it is not creating anew. Another thought problem that is often posed: "Will we ever run out of music?” Using Dirichlet's box principle, I readily say "no": there is an infinite number of musical possibilities, considering distinct timbres, and with unlimited multi-track digital recording a theoretically infinite number of possible arrangements, among other considerations. But, we must understand: it's not all like to be rich with meaning. These meanings of music are, as previously discussed, often rooted in cultural histories and trajectories of musical tradition, as well as seemingly "natural" psychological reactions to particular musical moves and motifs.

More concrete examples of the interweaving of rhetoric and music in Athenian society can be identified. Debra Hawhee makes a bold claim regarding the presence of the aulos in Athenian schoolyards, and how the rhythm of music may have influenced the making of speeches, and thus their rhetorical design: "Given the proximity of athletic and rhetorical training, as well as the noisiness of auloi... it is also likely that music flowed into recitations and sophistic lectures, producing an awareness ofindeed, facilitating - the rhythmic, tonic quality of speeches.” (2002, p. 146) Though we cannot readily place origins, we might wonder if such early musical compositions were influenced by the patterns of speeches, or at least of conversational language, and thus a reciprocal relationship was established between music and speech of the time: in terms of phrasing, rhythm, and pacing. This claim by Hawhee demonstrates the everpresent reality of music in the educational environment and even a direct link between 
the composition and practice of speeches and the performance of music. We know, at least, that various genres existed in musical composition for the ancient Greeks, such as the Doric Hymn, which had structure that could be compared in part to rhetorical, oratorical speech, where introductory phrases might lead into distinct melodies which are repeated for emphasis, and certain conclusive or closing figures were used to end pieces. Thus, we see parallels in the classical structure of the canons and their early application to music: Invention, Arrangement, Style, Memory, and Delivery. As oratorical speeches were thought to have certain necessary arrangements, so too were certain compositional styles in music thought to have necessary arrangements. Quintilian, in his Institutio oratoria, explains a hypothetical legal case where, during a sacrifice, the flute-player performs in the Phrygian mode, a mode thought to be unsuited by Plato; the priest jumps off of a nearby cliff in madness [1.10.33] (Watson 2006). Here we see music acting beyond what Cicero called mesos, the rhetorical partition of style with the intention to please the listener. Quite literally, and physically, in this anecdote, music is functioning in the partition of style of adros: to move the listener.

\section{Music Beyond its Affective Dimension}

A resurgence of scholarly interest in looking at the music of ancient Greece has again blossomed. Egert Pohlmann's Documents of Ancient Greek Music, first published in 1970, is a collection of the remaining 61 fragments of ancient Greek musical notation. While the Greeks, in general, rejected the idea of a musical notation system-much like 
Plato rejected the concept of the written word and condemned it- the 61 surviving fragments are of much curiosity and excitement to scholars interested in ancient Greek music. Unfortunately, these fragments have come to us more by chance than by purposeful, selective preservation, so we must be careful in considering their value and we must wonder if they are, in any sense, representative of the music upon which our ancient philosophers theorized so often and with such conviction (Pohlmann 1970, p. 5). In summary: we know very little of what the music of our Western intellectual ancestors would have sounded like, nor can we perfectly imagine what the subjective experience of music would have entailed, or how listeners would react: might they dance carelessly and freely to this particular tune, might they dance spiritually and ritualistically, or might they rally in political fervor? Some interesting digital projects are being done to recreate virtual amphitheaters based on archeological work at Pompeii (Hawkins 2011, p. 1-6) as well as to recreate both physical and digital instruments of ancient Greece (Georgaki 2009, p. 58-59). Yet, these are still distant echoes, haunting howls of what would have been.

We remain curious, and much contemporary scholarship continues to investigate theories of ancient Greek music. Mary B. Schoen-Nazzaro, again, writes of the musical approaches of Aristotle and Plato in "Plato and Aristotle on the Ends of Music” (1978, p. 261-273). She quotes from Plato's Laws: ‘All young creates are naturally full of fire, and can keep neither their limbs nor their voices quiet.' (via Plato, Schoen-Nazzaro 1978, p. 261). Motion, energy, and sound are a natural inclination for the young according to the thoughts of Plato. And as I have mentioned above, Debra Hawhee writes how gymnastics and music were intertwined in Athenian schools, as 
students would have heard the steady sounds of the aulos bleeding through the air to set the pace of their movements, and speculates that those practicing rhetoric in the form of oratory may have used sound to set the rhythm of their speeches (Hawhee 2002, p. 142-149). A musical education, then, for Plato, is meant to help the youth control their bodies and minds in harmonious ways that will move them toward virtue. Here we begin to see the potential dangers of unassessed music, and why rhetorical concerns for the study of music are necessary — though perhaps not as conceived and dreamed by our ancient philosophers. Music is incredibly persuasive, and can carry deep ideological structures that often go unanalyzed but are nonetheless promulgated to listeners. It is interesting now that we often perceive music as a way to engage our passions, our emotions, rather than to control them, as our ancient Greek philosophers suggested. Yet this contradiction of sorts is apparent, too, in both the works of Plato and Aristotle; music can both calm and rally, quell and entice. It depends on the sort of music, and the nature of the audience.

The multiplicity of effect and affect that could be derived from and through music was well known to the Greeks, though they seemed to distance themselves from the practice of it. This is evidenced especially by fleeting, seemingly strange comments by Plato that adult men should not take up the learning of an instrument, that it should be reserved for the youth. Still, though, Aristotle recognizes the "natural sweetness" in music that moves us, and seems to appeal universally to humans (Schoen-Nazzaro 1978, p. 267). Schoen-Nazzaro writes that the Greeks understood that "music is a movement which moves us" (1978, p. 267). Yet, both Aristotle and Plato are reductive in their assessment of music as that which imitates human emotions. Indeed, it is 
reductive to think that music functions only at the level of human emotion, and does not influence other aspects of both body and mind and life. Aristotle, in Chapter VII of his Politics, recognizes that there are certain situations in which particular modes (Phrygian, Dorian, Lydian) are fit to particular situations (Ellis 2009). And, in Aristotle's Minor Works, a piece "On Things Heard," most likely wrongfully attributed to Aristotle but written in the Aristotelian tradition, features a discussion of the importance of the body in creating sound:

All voices and in fact all sounds arise either from bodies falling on bodies, or from air falling on bodies; it is not due to the air taking on a shape as some think, but to it being moved in the same way as bodies, by contraction, expansion and compression, and also by knocking together owing to the striking of the breath and by musical strings. (1955, p. 51)

Sound, here, is a very physical, even violent phenomenon. It has less to due with form — 'it is not due to the air taking shape'—-but more to do with collision, materiality, vibration and resonance. This is indeed interesting to our early understanding of the physics of sound, but it is also rather important in understanding the historical trajectory of our relationship with sound and music. For, contemporary physical theories of sound tell us that much is due to compressions and rarefactions in the air. For the ancient Greeks, song and dance, and thus song and body, were closely coupled. Music could also be used for relaxation rather than excitement: to remedy uneasiness in the mind, in what Aristotle saw as this 'natural sweetness' of music, all with the eventual end of moving the soul to virtue, for helping us find the 'good' emotional 
dispositions (Schoen-Nazzaro 1978, p. 267). It should be noted that, contrary to Plato, who admonished the learning of musical instruments by the adult, Aristotle saw music as an important part of the education of a man, and thought children were unsuited to take it up as a discipline; children could be pleased by music but not see the 'good' in it (Schoen-Nazzaro 1978, p. 269). Music was an integral element of festival, ritual, funeral. Of theatre and of wars. Yet, mere mechanical recitation was less important in the pedagogy of music for the youth. Invention and original composition were stressed over the simple 'mastery' of an instrument: the 'musical' over the 'mathematical' elements were emphasized, and while it may be difficult to retrospectively decipher what was meant by this, it seems fairly evident that an involved, embodied, creative, and improvisational approach to music would have been stressed over regimented performance (Schoen-Nazarro 1978, p. 272-273). Thus, as mentioned, though it is dangerously reductive to view music only in terms of its potential to stir us emotionally, Aristotle no doubt understood the incredible rhetorical power of music not only through pathos. Music, as described by Aristotle, must play to its audience, and the listener, similarly, must be actively involved in the process of listening, of understanding, of immersion. It was, perhaps, a sort of rudimentary and early theory of interactivity and interplay between listener and audience that was no less participatory and dialogic than the work of rhetorical political orators.

Where do these theories then lay today? While some music is openly political in nature-something like the protest songs of Phil Ochs, as in 'I Ain't Marching 
Anymore"-music is also appropriated into the political realm ${ }^{6}$. Slavoj Žižek examines this phenomenon in his The Pervert's Guide to Ideology, directed by Sophie Fiennes, in which Žižek brings us an analysis of Beethoven's famous “Ode to Joy" from his $9^{\text {th }}$ Symphony :

What does this famous "Ode to Joy" stand for? It is usually perceived as a kind of ode to humanity as such, to the brotherhood and freedom of all people. And what strikes the eye here is the universal adaptability of this well-known melody. It can be used by political movements which are totally opposed to each other. In Nazi Germany, it was widely used to celebrate great public events. In Soviet Union, Beethoven was lionized and the "Ode to Joy" was performed, almost, as a kind of a communist song. In China, during the time of the Great Cultural Revolution, when almost all Western music was prohibited, the $9^{\text {th }}$ Symphony was accepted. It was allowed, to play it, as a piece of progressive bourgeois music. At the extreme right, in South Rhodesia, before it became Zimbabwe, it proclaimed independence to be able to postpone the abolishment of Apartheid. There, for those couple of years of independence, South Rhodesia, again, the melody of the "Ode to Joy", with changed lyrics of course, was the anthem of the country. ...When Germany was still divided, and their team was appearing at Olympics, when, one of the Germans won golden medal, again, "Ode

\footnotetext{
${ }^{6}$ Chapter 4 deals more specifically with the violence of sound, ideology in music, and the politics of music.
} 
to Joy" was played instead of either East or West German national anthem. And even now today, Ode to Joy is the unofficial anthem of European Union. (Fiennes 2012).

Thus, across global geographic, cultural, and political divides, we come to understand how a single piece of music can be appropriated in the support of seemingly limitless political ideologies - though the strength of the argument of this particular piece of music, the "Ode to Joy," is in its apparent ability to grant its listeners a sense of solidarity, of unity. Whether in its use in "Nazi Germany" or in its present use as the "unofficial anthem" in the European Union, the power of this swelling movement is in its ability to persuade its listeners to rally. Herein we begin to see the political significance of aleatoric music_-from the Latin alea, meaning dice-or music that is unpredictable in nature, music that disrupts the expectations of its listener. Those musical structures to which we have become so accustomed can be so easily reappropriated to divisive ends, violent ends.

We see another such example in "My Country, 'Tis of Thee," wherein Samuel Francis Smith adapted the melody from what is now the United Kingdom's national anthem, "God Save the Queen," and rewrote the lyrical content to fashion a hearty, patriotic, American song. "My Country, "Tis of Thee," also called, simply, "America," was used often as an unofficial national anthem before "The Star-Spangled Banner" was given official anthemic status in 1931. Though it should be noted, too, that "The Star-Spangled Banner" originates from a composition called "The Anacreontic Song," or "To Anacreon in Heaven," attributed to the British composer John Stafford Smith. We must move to critique this apparently open and ideological nature of music- - for, it 
is not that any piece of music is reappropriated with varied lyrical content. There is already, in the music itself, a persuasive structure which so enraptures its audience. There is already a musical signification — that is, the music is already pointing toward a particular symbolic meaning-before it is lyrically adorned. And, following the mass distribution and reproduction of a song, it becomes culturally significant, and so we modify our national anthem for further meanings still, such as Jimi Hendrix's lone, lead electric guitar interpretation at Woodstock in 1969, or something genre-specific and trivial as the pre-game performance of Steve Vai in 2010 at Madison Square Garden, whose contribution was to add technicality and speed as a sort of run-off from metal guitar virtuosity. A point in case-it took only some forty years and political contextual shifting for distortion as a sonic characteristic in the signal processing of an instrument to fall from a violent, human, protestive wail in Hendrix to a normalized attribute of a particular genre in Vai.

\section{The Exigency for Such a Work}

A significant decline in scholarship has occurred between these two fields of rhetoric and musicology—nearly a complete forgetting, leaving little for scholars to draw from in analyzing music rhetorically. In Brian Vickers's "Figures of rhetoric/Figures of music?" the state of this relationship between rhetoric and music is presented as having changed very little since the first of the treatises on the subject, Joachim Burmeister's work in 1599, and subsequent work by Unger, wherein the basework for this rhetoric of music is presented as lists of figures of rhetoric and 
figures of music (Vickers 1984). This mostly consists of the application of rhetorical figures to musical tropes_ such as seeing a certain similarity in the written and oral figure of anaphora to a musical composition which has a repetition of a set of similar notes at the beginning of parallel phrases. It is a simple equating or conflagrating of terms across rhetorical language and rhetorical music, and may even lead to misunderstanding in the nuances of both written, oratorical, and musical composition. A framework for understanding the persuasive nature of music must look beyond creating these simple parallels between figures. Rather, we must address the situations out of which music is composed, the networks in which it is distributed, and the contexts in which it is played back. And further still, we must look beyond music as that which moves the emotions, that which plays with pathos. To restrict the power of music to the realm of affect is to disregard the intricate relationship between humans and the music they make. From ancient theories of music through Aristotle and Plato, to the treatises of German Baroque composers from the 1500 and 1600s, we see that rhetorical theory has had a significant role in the composition, analysis, and understanding of music. Music is persuasive in nature, and not only in such a way as it imitates the emotions or stirs in us particular feelings. I hope to bring the history of rhetoric and music to a table on which also sits our latest digital recording technologies, so as to better understand the topography of contemporary music: how it is made, shared, played, and how it moves us. I ask, too: how does the independent, domestic production of music influence its composition, let alone its distribution? Through changes in the means of production of music — specifically the turn to domestic, independent, digital production—we see changes in the aesthetics, meanings, and 
rhetorical characteristics of independent music, and thus new offerings for the directions of social movement.

Ancient Greek theories of music help us to understand the foundations for historical theories of music. While Plato and Aristotle seem most concerned with the ability of music to help men move toward virtue, we also see the hint that music can be disruptive, that it can heal the mind and body, that it has almost mystical properties. A rhetorical reconsideration of musical invention, composition, production, and distribution is needed to grasp the gravity of music beyond the emotional dimensions of musical argumentation - to begin to consider seriously why we have clearly understood the ability of music to move us over the millennia and yet have disregarded how it does so, relegating it either to the dimension of ex nibilo or ex deus inspiration, or to the mathematical dimension of discrete frequencies and ratios. Herein, I hope to expand the field of sonic studies through demonstrating that through a revised harmonization of rhetorical theory and music we may reveal the argumentative nature of music, not only through its structures, arrangement, tonal qualities, lyrical content, and in the methods of its production and distribution—-but also in the social, cultural, and political scapes from which it is composed and on which it works.

The theory of the soundscape is, at times, limiting in its passivity: allowing us to hear the world only as a collection of disparate parts which are by the nature of their locality brought together. Thus, in this dissertation I seek to evaluate contemporary issues in the digital-political economy of music and independent music production through its material and immaterial properties, to examine how music is distributed, stored, and remembered, and to see how music carries with it worlds and ideologies 
through sonic figures. We can, in this way, move beyond thinking about music in the affective dimension and assess its political gravity, its agency. Through the example I provide from the localized musical community of Marquette, MI, and through the theoretical steps I take through issues in the non-presence of presence, the (im)materiality of music, and digital music in virtual worlds, I suggest a rhetorical framework for examining the arguments in music as that which is beyond affect. A theoretical framework that builds on and passes over those theories of rhetorical figures in music from the Baroque period of German musical composition will inform these analyses; from work by Vickers (1984) and Farnsworth (1990), we can understand why scholarship on the role of rhetoric in music has largely been left alone: there is little insight to be gained from applying figures of rhetoric to figures of music by, for example, labeling a series of repeated notes at the beginning of parallel musical phrases as the rhetorical figure of anaphora. Neither field gains from this cross-pollination of terminology. What I investigate instead is the situations in which the exigency for composition arise, and the relationship between rhetorical invention and musical invention. I turn to Lloyd Bitzer's "rhetorical situation" and adapt his framework of exigence, audience, and constraints to think about where music comes from, why we make it, and who listens to it. I add to this framework the antithesis to constraints: openings. We see in theories of music the suggestion the music is prophetic, that it points toward future social, cultural, and political realities (Attali 2009). How does this happen? I suggest that the aleatoric moment in musical composition and performance signals the musician's ability to not simply improvise, but cause a rupture in the form being followed. These aleatoric moments, I believe, are crucial to persuasion. They are 
kairotic moments that change our perceptions of the possibilities of a medium or a mode.

Theories derived from the science of music from key contributors in $19^{\text {th }}$ and early $20^{\text {th }}$ century-Helmholtz (1885), Rayleigh (1896), and Jeans (1937)—will further inform the exploration of digital music as a material and immaterial commodity. While scholarly work has been written on the history of the relationship between rhetoric and music, little contemporary work on rhetoric and music, especially digital music, exists. I seek through this work to contribute to the field of rhetorical studies by opening an avenue of concerns in the creation, production, and distribution of audio, while expanding the field of sonic studies by providing a theoretical bridge for rhetorical scholars. We must address both the materiality and immateriality of the digital music commodity and its distribution networks to understand the musical commodity as it currently functions. And here is where music as a commodity also concerns us: there is an apparent dissonance between public desire and what is actually produced through the music-industrial-complex. There have been interesting cultural backlashes, such as postmodern joke music: Rebecca Black’s “Friday," which only came into popular attention through its online distribution and rapid Internet sharing. For, a completely fulfilled desire is the death of the desire itself, and musicians often write very different music than that which they take pleasure in listening. A politics of music matters most, here, in the intersection of public and private life, in the intersections of our desires and the realities of production and distribution, and in the peculiar role of the musiciancitizen as something of a subversive character. Yet, we all are continually, endlessly 
shaping the sonic realities around us by the very necessity of living. As long as we are alive, we are always sounding. Music is inherently political in our world.

What does it mean, then, when the popular music of a culture does not satisfy its listeners? We are always surrounded by vibrations, and are often unmindfully influenced by song and music. We dismiss much of it to the "background," as a way to pass time, and as a method of changing our immediate subjective realities. As Robert Bruce Lindsay writes, "Life is full of sounds... pleasant and vital ones... [and] the unpleasant and dangerous variety" (1945). Jacques Attali writes that music is the order of sound — as opposed to noise — and Plato insists that music must move us to "Good," while Adorno laments the loss of a "serious music." In this work, I expand on theories by Jacques Attali in his Noise: The Political Economy of Music and seek to identify how the digital music commodity functions, moves, replicates, and exists in the world. What are the political ramifications of widespread digital recording technologies and the recent outburst of independent music production? What does the changing relationship between major industry label music production and independent production tell us about the political stakes of music? What is the theoretical relationship between the apparent materiality and simultaneous virtuality of digital music, and the presence and non-presence of the stage performer? From this point, I look at movements and the resurgence of independent music in American popular culture. Why, for example, have we seen increased sales of "outdated" media such as the LP vinyl record? Why have artists such as Sufjan Stevens moved almost entirely to online based sales through websites such as BandCamp? What are the implications of file-sharing and intellectual copyright law on the musician-artist-producer, and what are 
the implications for the citizen who happily "pirates" such content? Playing off of Marx's work on commodity fetishism and Derrida's explication of archivization in Archive Fever, I look at how digital recording and distribution technologies have influenced the digital music commodity as well as the musician, who has become selfpublisher. How has independent music been appropriated into popular music, how has the "folk" aesthetic been commodified, and most recently in American musical culture, how has it been appropriated into popular music? How might we reconcile the material reality of sound as vibration with such phenomenological tropes as the Derridean idea of the specter, or the non-presence of presence? How can we revitalize the role of the musician-citizen, who has been so often cast as a delinquent madman since Plato's Republic?

Yet, beyond ancient theories of music, this project deals with both concrete and theoretical issues of musical composition in the digital age: a call for independent musicians to reclaim autonomy from the music-industrial-complex. I assess the ideological and political gravity of music_-from musical torture at Guantanamo, to the corporate use of Muzak, to the persuasive power of music in the shaping of our political realities. Our sounds are both virtual and immediate. Here and not here. No longer is the musician solely a writer and performer. Reception and listening are becoming at once increasingly private- through headphones, earbuds, personal computers, mobile devices-yet also widespread through their digital distribution. The author envisions this work as being an important contribution on a theoretical level as well as a practical guide for contemporary independent musicians and scholars concerned with music and sound across the humanities. Further, this dissertation also 
serves as a manifesto for scholars to reconsider the significance of applied rhetorical theory to sonic studies.

\section{Overview of Chapters}

The trajectories of this work appear as such. Chapter 1, "Rhetoric and Music: An Introduction," serves here as a review of literature on ancient Greek theories of music, pedagogical approaches to music, and to offer the suggestation that we must move beyond examining music in its ability to move us emotionally. Though there seems to us to exist several historical bursts of interest between rhetorical studies and musical composition from extant writings, we can see that a long human understanding exists of the persuasive power of music. But should we trust Vargese when he tells us that music is just an "ordering" of sound? No, we must expand this notion beyond mere "ordering" and delve into the intricacies of non-linear processes and phenomenological inquiries into invention. It is from the Athenian Stranger in Laws that we see a glimmer of the extraordinary gravity attributed to music by the ancient Greeks: here, we see the possibility of music to help men find truth. Yet, while music for the ancient Greeks in its best forms would move men to virtue, we see that even in antiquity the power of music to do much more than this was understood: to move men to violence, to move us to madness.

Here, we move to Chapter 2, "Rhetorical-Musical Invention Through the Material and Immaterial Properties of Music," in which I set up a theoretical framework for musical inspiration and composition in terms of rhetoric through a 
close analysis of Phaedrus and Derrida's figure of the ghost and the non-presence of presence. In this space between the apparent mystery of musica ex nibilo and the source of musical inspiration and musica ex materia, or music which arises out of something, out of our interactions with the immediate, physical vibrations of sound and of the interfaces of instruments, it is in this space between that we find the figure of the ghost and can examine the functioning of rhetorical-musical invention and composition. Herein, I ask: where does musical inspiration come from, through what properties, and how is musical invention a rhetorical act? The voice presents itself to itself. In Derrida's critique_or response_- to Husserl, we find a better understanding; Derrida explains that Husserl imagined a pre-expressive element to "lived-experience" (2011, p. 13). It is through the difficulty in discerning between the "element of language" and the "element of consciousness" that a certain "indiscernibility" arises: this interdiscernability brings "non-presence and difference" forward, "right into the heart of self-presence" (Derrida 2011, p. 13). Thus, through the voice, there is a sort of mediation that occurs. The non-presence arises through the dismissal of the Mind, of the Ideas, of "ideal objects," which are not ideal objects at all but "historical products" (Derrida 2011, p. 13). Derrida continues, from Ghost Dance:

Therefore, if I'm a ghost, but believe I'm speaking with my own voice, it's precisely because I believe it's my own voice, that I allow it to be taken over by another's voice. Not just any other voice but that of my own ghosts. So ghosts do exist... and it's the ghosts who will answer you. Perhaps they already have. (McMullen 1983) 
From Derrida we have the theoretical front porch to address this key duality of the material/immaterial properties of music, and of the musician being both here and not here.

I move, then to the recording, distribution, and storage of music in digital spaces through Chapter 3, "The Digital-Political Economy of Music: Memory, Notation, and Reproduction." I ask, here: how has the political economy of music changed with the introduction of relatively inexpensive, domestic recording technologies and digital file sharing and selling? Chapter 3 looks at archivization first in terms of ancient Greek musical notation, the problems surrounding the archivization of digital music, the moveable substrates of digital archives, and further issues on the (im)material nature of digital music. I introduce Marx and commodity fetishism, the fetishism of the virtual, and ideology and the interface: I call on Nusselder's Interface Fantasy and Pohlmann and West's Documents of Ancient Greek. Music: The Extant Fragments for these analyses (1970). I introduce the digital-political economy of music as a way of understanding how rhetorical choices are made not only by composers but by individuals who are enveloped in a vast and connected network of composition, performance, and listening.

In Chapter 4 I address the larger, socio-political implications of the persuasive power of music and examine instances of musical torture and applications of audio by military means. I ask, in this chapter: who orchestrates musical torture? I then call upon anecdotes about the role of music in contemporary protests by sharing some personal experiences from my participation in the Six Month Anniversary March on the Brooklyn Bridge with the Occupy Wall Street movement, while drawing from work by 
Jonathan Sterne and others on Muzak while using a framework from Slavoj Žižek regarding subjective and objective violence. Music has extraordinary political stakes, and the independent production of music — and indeed, as it is sometimes silencedplays into the organization of protest and revolution.

In Chapter 5 I present what I call the significant function of music as a conclusion from these approaches to understanding music beyond its affective dimension: through parallels in ancient Greek theories of rhetoric and music, through the notion of invention and in Derrida's non-presence of presence, through our digitization, archivization, and storage of the digital music commodity, through the relationship of game music to virtual worlds, and through the political violence of music. I adapt the term significant function from Huizinga to explain how music works not only pathetically, but with a significant function, especially as music arises in its new, digital form: arising from domestic recording technologies, independent production. Herein, we must ask, then: what is "independent music"? I define independent music as music performed, recorded, and shared by the members of a localized community, composed or produced independently of the music-industrial complex. This might seem easily complicatable: what happens when traditional music of a culture is recorded in a studio funded by a major label? The music was nonetheless composed outside of the musicindustrial complex. We can ask: what about the musical influences that carry through from our interconnected, telecommunicative world? Independent music, as I understand it, is also that music which is produced by members of a community outside of the music-industrial complex. This encompasses home-recording, local shows and performances, and homemade media for the distribution of music. I come by this 
definition through work by Alan Lomax in his cantometric system of musical analysis in his comments on the significance of the timbre of the voice and Roland Barthes's notion of the "grain of the voice": rhetorical analyses can especially help us, here, for other methods of music analysis often disregard timbre as that "unique" or "special" quality on which we cannot put our fingers. Yet, a rhetorical-musical analysis can be directed at these particularities which are reified somewhere in between the apparent subjective and objective qualities of musicality.

\section{Methodology}

I use what approximates a postdisciplinary approach to the problems I have presented to suggest an interdisciplinary cooperation in scholarship between rhetorical studies, sonic studies, and musicology. ${ }^{7}$ It is necessary to work outside of the particular limitations of certain fields of study because of the broad scope and multiple interterpretative models that have been suggested for understanding music, from ancient philosophy to the physical sciences, behavior therapy to digital media studies. I must qualify my claim, here, though, for it is simple to say that "this problem is too complex to be limited to a single field" or "conventional approaches simply won't work, here.” While I draw on scholarship from diverse academic fields to represent important findings and research on music and audio-its creation, reception, distribution, and our experiencing of it — to constitute a theoretical space of work, it is very much unlike a knot—such as the trefoil, or the Lacanian Borromean knot. Rather,

\footnotetext{
${ }^{7}$ See Petrisor 2013 for work outside of the humanities on inter-, cross-, multi-, and trans-disciplinary approaches, and Salmons and Wilson 2007 for a general layout.
} 
I am suggesting a denouement, an untying, and an untangling of tensions. We must first understand the strings with which we are working before we start to loop them together again. And thus, this dissertation might be seen as such: a card table brought outside to sit by the fire on an August evening, placed on it a worn and weary coil of rope, another tied into it, another still, and another. Together, with no beginning nor an apparent end, is the complex mass we have made of our theories of music: the crack of the logs and the light of the flame are that enchanting mystery of music always in our minds, our ears, all around us. I hope to begin the work of the hands that helps to see how these overlaying theories, philosophies, ideas, and writings about sound and music have come together, and to attempt to make sense of the present moment where we find ourselves - to trace the coils and to tug on the discordances, to see how we've folded together this story about music that we have made together.

Musical composition, itself, is a non-linear process. It is not so simple as: I imagine a song spontaneously while I am walking down the street to Monticello's grocery store on the corner, I come home and pick up my instrument, reify the song from start to finish, and pen it down to remember it for later. Rather, a snippet might erupt that is half a melody. But is it a call or response, and to what? Just some inkling. Perhaps it grew out of a song that just happened onto my Pandora Internet radio station by Bill Bragg that I was only partially attentive to while washing dishes, or a musical number from an old Disney movie I haven't heard in fifteen years. I might run right to my computer to hum the little thing, to save it; because ideas, verbal and musical and visual, disappear quickly! We all know the disappointment of an idea lost. Then, I might return later and find that I simply don't like it, or find that in the 
adaptation from hum to the plastic keys of my MIDI controller there is a more exciting variation, and something altogether new takes shape. So, too, with writing: some idea is not transferred to the page, but ideas pull and tug on the words we know and the cursor might curse us with a little block. So we walk outside and forget the song, the idea, again. Is it even a song, yet? Maybe in this time, a few lyrical lines pop up, or maybe they're borrowed from a song I wrote three years ago that didn't quite work out in a way that I found fulfilling. Or I might find that it sounds suspiciously like a tonedowned adaptation of a Tony Iommi lead guitar lick from Black Sabbath's "Fairies Wear Boots." In which case I can decide to tease out something new from it, or throw it away as an empty recitation of an old theme. David Plans Casal, in "Crowdsourcing the Corpus: Using Collective Intelligence as a Method for Composition," shows how non-linear musical compositions are becoming more common with digital technologies. Eric Whitacre, an American composer, has used such methods to create a “virtual choir" by sending out sheet music to 250 participants (Casal 2011, p. 26). Vocalists then recorded their parts and uploaded a YouTube video. The finished production, Lux Arumque, is an edited and spliced version of these voices, from across the world, recorded at different times, woven together into a media object that has a linear form. So, too, has this dissertation been composed from diverse inspirations, smaller projects, ideas too grand and ridiculous to publish, manic latenight writing, sleepy January afternoons in my office. I sing along with other voices—here Derrida, there Listenius — and allow an arrangement to develop.

Thinkers and philosophers from all disciplines have been fascinated with music for millennia, and I do not mean to offer some universal theory of musical analysis 
which de-mystifies music. Rather, the rhetorical study of music should better help composers to understand their decisions in the composition process, to allow spontaneous inspiration and derivations from form through the aleatoric moment and non-linear composition, and to aid rhetorical scholars and teachers of multimodal composition a set of tools for addressing music in the classroom, even where a background in technical, traditional musical theory is not necessarily held.

\section{Summary}

To review the trajectories plotted here, we may first turn to the title of the work. This dissertation examines what we shall call the digital-political topography of music, or the places and spaces that are occupied by music in its digital and political positioning. So, too, does this work examine the ways in which music moves in distribution networks, from invention to performance to playback, as well as how music moves us: ideologically, socially, with promise for new political potentialities and with the violence of the suppression of these dreamings. In Chapter 1, I have begun by examining the argumentative nature of music through ancient Greek theories of music, and set up the groundwork for this project. In Chapter 2, I look to the moment of musical invention and the role of the audience in the musical composition process through the figure of the ghost. Chapter 3 examines the digital music commodity in light of the phantasm: how sound is stored, transmitted, and archived in the liminal spaces of digitality, as sound is composed in the liminal spaces of being. Chapter 4 introduces the violence of music in its subjective and objective properties to further 
demonstrate how music moves us: not merely in the emotional dimensions, but also in protest, in silencing, in the potentiality for the musician-citizen to stake a claim against the music-industrial complex. Chapter 5 returns to our theoretical beginning by calling on work by Brian Vickers who criticized the long-standing tradition of the application of figures of rhetoric to figures of music; I propose a new way of understanding the relationship of rhetoric and music through what I call the significant function of music, the culmination of the elements herein discussed as the persuasive power of music (1984). To inquire about the topography of music — that is, the place of music, the space of music - is to inquire about not only how music moves us emotionally, socially, culturally, politically, but also to ask how music itself moves. How does music circulate, and how is it distributed in digital networks? The persuasive power of music is now mediated by and situated in and around the liminal spaces of digitality. To think about how music functions, how it argues across media, we must examine its material and immaterial realities as they float and form around us, and as we float and form them around ourselves. This dissertation thus seeks to identify the changing scope of the digital music commodity, and the changing role of music in society and in the shaping of new political realities.

If, as Jacques Attali tells us, music is prophetic, that the superstructure is not determined indefinitely by the base of society, that indeed our musical culture can play reciprocally back into the base, then we might think that in the digital-political economy of music, we have the same opportunity — and at once, the same dangers ahead of us. Yet what is certain is that it is our responsibility to listen to ourselves and to each other, to understand the persuasive power of music across all its forms and in 
all its figures, not merely in the application of immediate, apparent figures of rhetoric to discrete tropes in musical composition. Here we expand our understanding of the power of music in society, and the power of the citizen to use music to contribute to the human future, not merely as an aesthetic contribution but as a pertinent political, rhetorical device. Within the figure of the ghost we know ourselves-we are at once here, and not here, in a world that is not our own but has been handed to us, but nonetheless a world in which we set our feet, let rattle our voices, and compose. Through our technologies we have built instruments that can be amplified, songs that can be transmitted on electromagnetic waves, trans-oceanic cables that permit the passage of digital file formats across the world. And so, too, have we engineered devices of torture, let our songs be cyclically recycled for profit, and forgotten that incredible power of music. And so bringing together that study of persuasionrhetoric - with the study of music, we can begin to attempt to, as Jacques Attali phrased it, dream up our own "criteria," and better still to understand to which criteria we presently "conform" (2009). 


\title{
Chapter 2
}

\section{Rhetorical-Musical Invention Through the Material and Immaterial Properties of Music}

\author{
The unlike is joined together, \\ and from differences result the most beautiful harmony. \\ -Heraclitus, Fragments
}

\section{Invention}

Rhetorical invention —we have, from the Latin invenire, "to find"-was thought to be, by Aristotle, the most important of the canons of rhetoric and the seat of the development of argument (Crowley 2010, p. 3-4). And, for Crowley, in our modern understanding, "invention" encompasses "the study of all the possible means by which arguments or proofs can be discovered and developed" (Crowley 2010, p. 2).

Quintilian, in Volume 5 of his Institutes of Oratory, first published around CE 95, likens topoi to what Crowley describes as "haunts," or, "'the secret places where arguments reside, and from which they must be drawn forth' (5.10.21)" (Crowley 2010, p. 3). The translation I have referenced, by John Selby Watson, renders this line slightly differently: " ...the seats of arguments in which they lie concealed and from which they must be drawn forth.” [5.10.21] (Watson 2006). Yet, whether we understand this as some secret place or some concealed content waiting to be discovered, scholars have 
long disagreed about the origins of these wells from which we draw up our pails.

Quintilian tells us:

21. For as all kinds of fruits are not produced in all countries, and as you will be unable to find a bird or a beast if you are ignorant where it is usually produced or makes its abode, and as among the several kinds of fishes, some delight in a smooth and others in a rocky bottom of the water, while particular sorts are confined to particular regions or coasts, and you could not attract the ellops or the scarus to our shores, so every kind of argument is not to be got from every place and is consequently not everywhere to be sought. (Watson 2006)

In this chapter, I present the figure of the ghost as a mediator to explain the process of musical invention. How does the song materialize amongst us, and in through which media? Having examined parallels in the theories of music and rhetoric in Plato and Aristotle, and the pedagogy of music in Athens, we are faced with the question: where do songs come from? ${ }^{8}$ Further, if it is not a technical training in music that allows the composer a sense of musicality —as is suggested by Aristotle — what is the origin of musicality, of the tools for musical composition? Through a close reading of Plato's Phaedrus, I expand on the notion of audience to include the venue, the environment, as a contribution to the rhetoric of music, and its role in the subjective experience of

\footnotetext{
${ }^{8}$ Parts of this chapter are adapted from an article first published in the Rupkatha Journal on Interdisciplinary Studies in Humanities, in a special issue on Performance Studies, under the title "Singing Specters: Phenomenology in the Performance of Music," October 2013. With thanks to and permission from Dr. Tarun Tapas Mukherjee, editor of Rupkatha.
} 
musical inspiration. Through Derrida's rendering of the non-presence of presence and in the figure of the ghost, and the madness of inspiration, we can begin to see the rhetorical invention of music as a process that both calls upon history and simultaneously seeks to annex the musical roots from which it emerges. ${ }^{9}$ First, through a phenomenological inquiry, we address the mind and musical inspiration: how, from the theoretical figure of the ghost, we can understand how compositional and performative responsivity functions in musical creation. That is, by looking to problems in rhetorical-musical invention, we can ask: where do songs come from? This chapter looks at the Derridean figure of the ghost and the duality of being here and not here as a sort of liminal space where material and immaterial properties of music are brought together by the composer. We transition, in Chapter 2, from the explication of early theories of music by the ancient Greek philosophers in Chapter 1 as that which moves men to virtue and that which can move the soul, but also that which moves us toward truth, to the extension of our understanding of the role of rhetoric in music by addressing issues in invention and audience.

It is through the figure of the ghost that we can begin to reconcile the apparent problem of musica ex nibilo - that is, music out of nothing, or the apparent mystery of why a melody seems to form from nothing in the mind of the composer-and those old Ancient Greek notions of inspiration which are not entirely helpful for the

\footnotetext{
${ }^{9}$ Later in this chapter, the topic of historical trajectories of sonic figures emerges through work by Theodore Adorno on "popular" and "serious" music and their distinctions, where Adorno laments "popular" music as being highly derivative, and formulaic. Despite my earlier assumptions, perhaps we should be worried: might we someday "run out of music?" No, but we must look to potentialities in the breaking of form to invent new possibilities for our music that is replicated and reproduced.
} 
composer, to say that music comes to us ex dens—from the gods—with the idea of musica ex materia—or music from something, from the composer's and performer's interaction with the world. Through the figure of the ghost, we come to understand that musical invention occurs in the composer's interaction with the immediate world as well as with the liminal, with the technological interfaces of instruments, with the physical reality of sound and with the elusive dimension of time. Thus, in this chapter I turn to assess materiality of sound, its immediate physical properties and the instrument as a technology with which we interact to mold our sonic creations, as well as the figure of the ghost who brings us this reconciliation of musica ex nibilo and musica ex materia. To begin I write along with key $20^{\text {th }}$ century thinkers-Maurice MerleauPonty and Jacques Derrida—to understand how a phenomenological examination of the performance of music can contribute to a meaningful exploration of the roles of consciousness and presence in the process of rhetorical-musical invention. I begin by looking at Plato's Phaedrus and assess the notion of "fit" as it relates to rhetoric and performance as well as the mythical trope of the cicadas (Nehamas \& Woodruff 1995). I will then explore how Plato's rendering of madness in this piece might help us understand Derrida's almost paradoxical construction of the voice in Voice and Phenomenon (2011). From here, I move to analyze the figure of the ghost as presented by Derrida and relate this to the non-presence of presence while asking: how might this notion better help us understand how rhetorical decisions are made by musicians?

I both criticize and applaud the recent American revival of "folk" music. The Swedish folk musician Kristian Mattson, popularized in the United States, said in an interview: "I don't consider my work to be a part of any tradition. This is how I play. 
This is how I write songs," despite stylistically similar songwriting to American folksters such as Bob Dylan, who drew heavily from Woody Guthrie, who channeled ghosts of Appalachian ballads strung from Old English ballads, and so on. To discredit history and suppose some sort of ex nibilo composition as potential for social change is to attempt to uproot a hundred-year oak with bare hands. Rupture must come from roots, and so the ghost is as new as it is old. A phenomenological framework to assess musical invention in a rhetorical assessment of music should hope to welcome the ghost with open arms — though it will never quite touch it, we can watch and listen, still:

GLENDOWER Do so, and those musicians that shall play to you

Hang in the air a thousand leagues from hence, And straight they shall be here. Sit and attend.

[3.1.220-22] (Shakespeare 1997)

And as we sit and attend, we now turn from our philosophical inquiry to the physical properties of sound to further our understanding of rhetorical-musical invention. From this investigation into the (im)materiality of the self, we turn to the materiality and physicality of sound itself: as it appears to us, as we understand it, and the ramifications of such.

\section{Audience, Invention, Rhetorician}

I begin, here, with a rough etymological inquiry. The notion of the Platonic Idea stems from the Greek "to see," from iden. Audience has an interesting 
relationship, here, from the Greek root au which is "to perceive," to feel or grasp, even, aisthanesthai, and through time audience has come to mean both an assembly of listeners and then later, through French it seems, to mean the reader of a text. This notion of the audience as those who encounter the text directly correlates most with our contemporary understanding in rhetoric and composition studies, but might we expand this notion? Plato distinguished that the work of the mind is separate-we abandon the senses to think theoretically, as in the Pythagorean theorem, where we think of the law behind the triangle and not the triangle itself — and it is from Plato that we have this understanding of the idea. This idea is the distinct knowledge of something, the mind's eye, and is distinct from what was perceived as an empirical reality.

What of audience, then? G.R.F. Ferrari, in his "Listening to the Cicadas: A Study of Plato's Phaedrus," provides an interesting analysis of the notion of being "fit" that I would like to here incorporate (1990). Phaedrus is unique among the Platonic dialogues in its descriptions of environment and for setting up a narrative which

${ }^{10}$ Ferrari's figuring of "fit," or what we might call fit-ness, is an exciting contribution to rhetorical theory. In my following analysis, I describe the influence of the speakers' environment in Phaedrus. But we can easily transfer these ideas beyond our old Platonic dialogues. In terms of the musical performance, much thought and preparation is put into a set, based on the specificities of the venue-that is, not only the members of the audience, but of the environment. I once arrived at a small coffee shop gig to realize that there was no amplification system! Beyond that, I was to play outside of the store, in cold, late-Autumnal Calumet, MI, standing by a small portable heater. Being accustomed to performing with a microphone and DI (direct input) box for my acoustic guitar on stage, rather than unamplified and on the street-corner, I had to adjust my entire set-list and approach accordingly. Further, these decisions are not all made in preparation. As I was playing, I found that my voice, in certain registers, reverberated off of the buildings across the street and helped carry the sound down a ways - there aren't many vehicles driving through Calumet in the evening — and I thus selected songs from my memory that allowed me to sing in this range, and invented new verses for these songs, and repeated some. 
corresponds to the themes of the dialogue itself. Socrates was known for having seldom left the city — so it is significant that we find Phaedrus and Socrates outside of Athens in this dialogue. Ferrari explains:

He [Socrates] takes pains to select a suitable place for reading. A tall plane-tree nearby marks a zone of shelter from the sun, he judges, 'just the right breeze' (pneuma metrion), and soft grass to accommodate whichever posture they prefer, whether sitting or lying down (229a8b2). On the way to this bower he speculates that they are passing the very spot where according to story Boreas the wind-god snatched off the princess Oreithyia. What fuels his conjecture is, again, the recognition of fit: that the alluring purity of the water at this point makes it suitable (epitedeia) for girls to play in (229b4-9). Furthermore, had Phaedrus not been struck at the outset of the dialogue by how especially 'appropriate' (prosekousa) Lysias' speech on love would be for the notoriously 'erotic' Socrates to hear (227c3-5) he would not now be applying to the environment this ability to recognise fit. (Ferrari 1990, p. 8)

How can we understand this characterization of nature and environment? Do we simply impose, anachronistically, the nature/culture divide or the divide between nature and city? No, for it seems that, while Socrates is not accustomed to the land outside the walls of Athens, he seeks to use his environment in his speech. He finds himself in the country and so incorporates it. This is now his venue. Similarly, Plato has Socrates speak throughout Phaedrus about the relationship between the body and 
rhetorical composition: "Every speech must be put together like a living creature, with a body of its own; it must be neither without head nor without legs; and it must have a middle and extremities that are fitting both one another and to the whole work (Nehamas \& Woodruff 1995, p. 541).” Despite this concentration on the physical body, it is still Socrates' assertion that "the nature of speech is in fact to direct the soul" (Nehamas \& Woodruff 1995, p. 548). Mary B. Schoen-Nazzaro writes in "Plato and Aristotle on the Ends of Music" that Plato understood music to be an essential part of the education of young Athenian boys because of its ability to shape "proper order in man's nature": gymnastics worked toward the ordering of the body, while music worked "principally toward his soul” (Schoen-Nazzaro 1978, p. 261).

Further, Schoen-Nazzaro reads Plato to tell us that musical education should not just give "dexterity to the fingers or strength to the voice" — that is, a sort of technical training that is most common in today's Western musical pedagogy—but rather that "musical education should measure and order the movements of the soul" so that the child can learn to "feel pleasure and pain the right way" (1978, p. 262). And in many ancient theories of music, we see this theme of "ordering." Ptolemy wrote extensively on the harmony of the universe and its various spheres in his Harmonics: a sort of music of the heavens (Solomon 1999). We now know much more concerning astronomical objects and their movements, but the religious and cultural influence on the logic of music theory is still evident. There are certain obvious relationships between what we often identify as "pleasant" sounds in music: a note one octave above another has twice the frequency in $\mathrm{Hz}$, for example. 
We can return to Debra Hawhee to help us further understand the role of rhetoric, here, by linking oratory, the body, and music in educational environments in her "Bodily Pedagogies: Rhetoric, Athletics, and the Sophists' Three Rs":

Given the proximity of athletic and rhetorical training, as well as the noisiness of auloi — their shrill sounds approximate those produced by modern-day bagpipes - it is also likely that music flowed into recitations and sophistic lectures, producing an awareness of-indeed, facilitating - the rhythmic, tonic quality of speeches. As Kenneth J. Freeman points out, the aulos did not merely provide background noise, but rather played an integral role in training, as the instrument was used "in order that good time might be preserved in the various movements" (128). Music's role in the gymnasium, then, was to introduce a rhythm, to provide a tempo for the practice and production of bodily movements. In short, music established a rhythm through the cyclical repetition of patterns, and this rhythm was replicated in the bodily movements of those in training. (Hawhee 2002, p. 146)

It seems that the practical use of music in Athenian society may have differed from Plato's hopes, then. Here, music is being used to keep time for gymnastic exercises, and is leaking out into the study halls, into the classrooms. Of course, we have many types of music, now, and certainly so did our ancient friends. Yet, this trope of repetition remains in contemporary rhetorical composition practices in both musical composition and in the writing classroom. But here, we see the significance of the sounds of an environment. Might we better think about how we design the acoustic spaces of our 
classrooms and our universities? Not in architecture, as an end, but in thinking of how sound works rhetorically on us. Yet here too we must be reminded as to why we should pay attention to the sounds around us and to listen: the rhythms at play effect our experience, or even constitute our experience. We are the sound, and in the sound, as much as it has an effect on us. As in the example of the Athenian orators above, we find a rhythm to our oratory from sounds that come from our environment. Walter Ong in his Orality and Literacy describes how, while vision "dissects," sound is a means of centering (2002, p. 72). Through our hearing, we are the experiential centers of not the world of sound but our world of sound. But can we say so easily that the experience of hearing is not one of dissection? The very biological reality of binaural hearing —of having two ears-we locate sound sources, a sort of automatic calculation that is conducted through the difference between our ears: this is why we see a dog tilt its head in "confusion": it is trying to listen "better," to get a sense of the source of the sound. We are thus always looking for origins, for causes to the experiences which we come by, whether sound or sight. We should be careful with Ong, who argues that "The spoken word is always an event, a movement in time, completely lacking in the thing-like repose of the written or printed word" (Ong 2002, p. 75). For, our written texts are ephemeral, too, and only seem to have permanence.

We can transition back, then, and bring forth the cicadas in Phaedrus. What role do they play for the dialogue? The backdrop of the pastoral countryside provides many discussion points for Socrates and Phaedrus, and the cicadas are noted throughout the text. Socrates spins a myth to explain their existence and their presence: 
When the Muses were born and song was created for the first time, some of the people of that time were so overwhelmed with the pleasure of singing that they forgot to eat or drink; so they died without even realizing it. It is from them that the race of the cicadas came into being; and, as a gift from the Muses, they have no need of nourishment once they are born. Instead, they immediately burst into song, without food or drink, until it is time for them to die. After they die, they go to the Muses and tell each one of them which mortals have honored her. (Nehamas \& Woodruff, 2005) There is a close relationship here between the role of song and the role of madness. The people were "so overwhelmed with the pleasure of singing" that they died without "even realizing it" and were given a gift from the Muses: they would no longer need to eat. Now, these creatures can "immediately burst into song" from birth, and continue singing until they die. There is a sort of strangeness, here, however. The mythological people who were converted to the race of cicadas died without knowing, so we can assume they felt no pain, so powerful was their love of song, so great was their pleasure. What need was there to change their form, if already present in the human is the capacity to be "so overwhelmed"? I'll leave this point for another time. But we might take this rendering of the cicadas as an indication of the celebratory power of music for Plato. Or is this too far? There is, too, a more morose mythology here being crafted: that the allure of song, of sound can be so great that it leads to death, a complete loss of the self and a stripping of life to bare performance. But is this not experience itself, a coming together of desire and action? Perhaps in the myth of the 
cicadas we see a notion of the embodied rhetoric of music: the cicada is not-present and beyond its own "self-control": it leads itself unwillingly to death. An early critique of phonocentricism? Most likely no, considering Plato's distrust of the written word, but we'll approach this notion of writing and the voice later in the paper. And of course it would be anachronistic to think of Freud in the venue of the Phaedrus, but the death drive here seems to call strongly through the song, through the cicadas.

Let us think again about what role the cicadas have in the framing of the dialogue we read in Phaedrus. The always present sound of the cicadas makes for an ensounded environment. The dialogue occurs in the sound, with the cicadas. Ferrari can perhaps help us again with his notion of the "impresario": "Phaedrus' careful matching of audience to performance and performance to environment shows him turning from the mere consumption of others' art to the exercise of the art to which he is peculiarly devoted" (Ferrari 1990, p. 8-9). Here I have come back to my original etymological inquiry. What is the significance of audience in the Phaedrus, and for the rhetor? This is part of Socrates' critique of writing, that with oratory, one can know the souls of his audience: the rhetor can see to whom he is speaking. But with writing, it is not known. The performing musician, similarly, can see and hear his audience, be in a sort of dialogic responsive atmosphere with them, but with recorded music, there is the possibility of being heard through tinny speakers or being remixed, edited, spliced up through a digital audio workstation.

Ferrari sees that Phaedrus is acting as a sort of impresario, here, as Ferrari argues - traditionally and interestingly, an impresario is a manger of a concert hall or venue- that Phaedrus is trying to manage the conversation through "fussing" over 
"fit" in assessing the "landscape" and the "environment" (4). Yet, Plato seems to engage with wherever they find themselves, though he does deliberately choose a shaded area. Perhaps this is why Ferrari is critical of the role of Phaedrus as impresario, deeming it something less than philosophy. Ferrari interprets that Phaedrus attempts to pass off his "art" of acting as an "impresario" as the "good" where really it is just the "fitting" (1990, p. 12-14). And, as aforementioned, Phaedrus attempts to pass this off as "philosophy" (1990, p. 14). Yet, Phaedrus, in his oratory, knows that "If the physical arrangements for the performance become the focus of audience attention, those arrangements have failed their purpose" and that "Phaedrus understands that his arrangements will give pleasure to the extent that they are appropriate, but must not be declared appropriate merely because they give pleasure. In this he has a fair grasp of his art as impresario" (Ferrari 1990, p. 12). The impresario cannot quell the fervor of the audience, though. The environment becomes part of the performance. And the cicadas are a key contributor to this soundscape that surrounds Phaedrus and Socrates in their dialogue.

For, we know, all along, that there is the incessant singing of the cicadas. Can we call it singing? The cicada produces what some call a deafening noise- the loudest insect, over 100 decibels_-yet it is a hallmark of a bucolic sun-lit summer afternoon. Should we assume the cicada songs are distant, and thus non-interruptive of the speech that occurs between Phaedrus and Socrates? How does this sort of feedback from the environment influence their conversation? We can only speculate-and it is a fictional account, most likely, of the two speakers-but perhaps the exploration of the concept of madness in Phaedrus can further direct this exploration. 
Socrates describes four types of divine madness. The third describes the very sort of state of being "overwhelmed" which gave rise to the death and birth of the race of cicadas:

Third comes the kind of madness that is possession by the Muses, which takes a tender virgin soul and awakens it to a Bacchic frenzy of songs and poetry that glorifies the achievements of the past and teaches them to future generations. If anyone comes to the gates of poetry and expects to become an adequate poet by acquiring expert knowledge of the subject without the Muses' madness, he will fail, and his selfcontrolled verses will be eclipsed by the poetry of men who have been driven out of their minds. (Nehamas \& Woodruff 1995, p. 523)

I find here a fascinating relationship between this state of divine madness and its contribution to the creation of art, to "poetry." Is this not also the transcendent state of the musician in times of creation, of inspiration, of aleatoric moments? It seems that these cicada people were indeed mad, that is, they were lost in the "frenzy of songs" that overtook them and thus, in a sense, non-present. Yet, it is also in these extraordinary moments of divine madness that the artist is most present. Can we relate this to the Derridean notion of the voice and the non-presence of presence? Is the mad artist not also a ghost, both here and not here, both alive and dead?

${ }^{11}$ Still today we carry notions in some cultures of the mad artist, and so on. Work by Dr. James MacCabe in the American Journal of Psychiatry showed a link between good grades creativity and bipolar disorder in students, a fourfold effect compared to socalled average students (2010). This appeared to be especially true for those studying languages, literature, and music. I'm unsure as of yet what to make of this, though it is noteworthy. 


\section{Madness and the Ghost: The Non-Presence of Self in Invention}

Madness is a recurring topic in the Phaedrus, and its characterization differs greatly from notions of mental disease or disability. Madness is a sort of gift. A source of inspiration, a reaching out of the fingers of the divine into the mind of the mortal. Socrates tells us that: "The people who designed our language in the old days never thought of madness as something to be ashamed of or worthy of blame; otherwise they would not have used the word 'manic' for the finest experts of all... thereby weaving insanity into prophecy" (Nehamas \& Woodruff 1995, p. 522-523). The academic and the philosopher often carry the stigma of madness: of working against expectations and norms. So, too, we think of today's musician as the Bohemian. The ancient Greeks, however, found solace in the madness of Homer: the figure of the blind prophet. The bard, the eccentric, the performer acted as a cultural touchstone to unite pre-Socratic Grecian culture and thought. We can of course criticize this unity-perhaps this is the first heralding of nationalism in the lines of epic poetry inscribed, so long ago, then. But the trust in the blind and the mad as a prophet, as he who has access to another realm — a metaphysical realm, the realm of Ideas, of gods — might first be located here. The mad man is both of this world and of another. He is a living ghost, a spectral figure.

Who now is a ghost? Derrida appears in Ken McMullen's improvisational film Ghost Dance (1983). He is asked, "Do you believe in ghosts?" and responds:

That's a difficult question. Firstly, you're asking a ghost where he believes in ghosts. Here, the ghost is me. Since I've been asked to play 
myself in a film which is more or less improvised, I feel as if I'm letting a ghost speak for me. Curiously, instead of playing myself, without knowing it... I let a ghost ventriloquize my words, or play my role, which is even more amusing... (McMullen 1983)

We might think of this in terms of Derrida's Voice and Phenomenon: Introduction to the Problem of the Sign in Husserl's Phenomenology. Derrida writes: "When I speak, it belongs to the phenomenological essence of this operation that I hear myself during the time that I speak" (Derrida 2011, p. 66). Time and the voice. The immediate past, the present, and the immediate future are strung together by the voice. The syntax of our Western conversation is comprised by a logos of repetition. We speak sentences, like melodies. Strings made of units. Further, “...the soul of language, seems not to separate itself from itself, from its presence to itself. The soul of language does not risk death in the body of a signifier abandoned to the world and to the visibility of space" (Derrida 2011, p. 67). The voice presents itself to itself. In Derrida's critique—or response—-to Husserl, we might find a better understanding; Derrida explains that Husserl imagined a pre-expressive element to "lived-experience" (2011, p. 13). It is through the difficulty in discerning between the "element of language" and the "element of consciousness" that a certain "indiscernibility" arises: this interdiscernability brings "non-presence and difference" forward, "right into the heart of self-presence" (Derrida 2011, p. 13). Thus, through the voice, there is a sort of mediation that occurs. The non-presence arises through the dismissal of the Mind, of the Ideas, of "ideal objects," which are not ideal objects at all but "historical products" (Derrida 2011, p. 13). Derrida continues, from Ghost Dance: 
Therefore, if I'm a ghost, but believe I'm speaking with my own voice, it's precisely because I believe it's my own voice, that I allow it to be taken over by another's voice. Not just any other voice but that of my own ghosts. So ghosts do exist... and it's the ghosts who will answer you. Perhaps they already have. (McMullen 1983)

Are we ghosts? Can we merely say that Derrida thinks that language gives us life? Are we phantoms floating around in overt subjectivity, hosts to language? To the voice? No, but it is when one believes they are speaking with his or her "own voice" that it can be “taken over by another's voice." What is meant, here? Do we understand this to be a sort of Heideggerian sense of language-in a reduced or reductive sense, where there is ready-made content to our language that we inherit? How is it that the voice does not fall subject to the ideologies already present? Maurice Merleau-Ponty ensures us that language does more than simply carry ideas. He writes in his Phenomenology of Perception that "speech accomplishes thought" (Merleau-Ponty 2012, p. 183). That is, language works reflexively with the world around us. Or is it only language mediated by the voice? No. Merleau-Ponty uses the example of the author who sits down to write a book not knowing what they plan on writing (2012, p. 183). Meaning is not directly transferred outward. Merleau-Ponty argues that words do not carry with them readymade thoughts, that each word we utter is not some "inert envelope" carrying signification (Merleau-Ponty 2012, p 181-83). We are always engaged in an active process of making meaning with these words, which have active meaning in themselves: words are alive. That is, Merleau-Ponty means to say that, almost in a 
memetic fashion, words "import" their "meaning [sens] into the listener's mind" (202, p. 185).

Does not also the performing musician react and respond to the world around him via the "language of music"? Though I much dislike this term, "the language of music," so often thought of as a universal language, a lingua franca, for the code of Western music seems to be a product of Western language itself and not its own language, though this is thought's food for another day. Might we say that this responsivity erupts through the performer's musicality, through the complex network of interactions that occur between audience, instrument, voice, technology, audience, and ghost? Let us return to Derrida's explication in Ghost Dance. Perhaps he means that through the illusion of speaking with what might be our "own" voice we are inhabited by the meanings made by others, by ideologies, but these ready-made constructs preexisting in language. But why is it only in the guise of self-ratified authenticity, of selfassured authentic identity that we are overtaken by the ghosts of ourselves? What, in fact, does it mean to be haunted by our own ghosts? Through the rote repetition and recitation of performance - that is, of playing from a scripted piece, for example, or even from memory-each performance has slight variation but it is in novel invention that we separate ourselves from our self-history. It is through the process of composition that we leave our ghosts behind and take up a voice, a voice that responds to these complex networks and surroundings and emerges as an aleatoric rupture:

The enigma of the voice is rich and profound because of all the things to which it seems to be responding. That the voice simulates the "keeping watch" over presence and that the history of spoken language 
is the archive of this simulation from now on prevents us from considering the "difficulty" to which the voice responds, in Husserl's phenomenology, either as a systematic difficulty or as a contradiction that would be specific to his phenomenology. (Derrida 2011, p. 13) This "keeping watch" - is it a sort of tie between non-presence and presence, or past and present? - is the role of the voice. I have attempted here to bring about this figure of the ghost as a way to understand, perhaps as a metaphor, perhaps as more, the nonpresence of presence, the "being lost in thought" of madness or more than this: that to be not quite here is indeed to be here. Derrida of course is non-phonocentric and the voice should not be here given our attention and priority, but the paradox of the voice.

But for Derrida, meaning comes through the figure of the voice: for there to be meaning, there is a coming together of form and content—of the transcendental and the empirical—so every repetition is both the same and different. The voice cuts across the empirical and transcendental. We are then left with a liminal space for music: is music formed from madness or from conscious composition? If from madness, what right have we, then, to say that the elephant's mourning trumpet is not music? If from conscious composition, where then does inspiration arise? Through Derrida we abandon the simple notion of the present, for it contains with it always our ghosts and of future ghosts to come, and perhaps the very condition of being is that of being ghosts, or of being a being-ghost. Within this notion of the ghost there is, too, the thought of not-being-at-all, of negative being, in the immediate present the ghost appears as the far-past — and perhaps the forever-to-come-but is in the present, if it appears to us, and appears in the voice as both writing and sound. Thus it is for us not 
to see a ghost but to hear it. And to hear it always. There then might be some reconciliation in the figure of the ghost for understanding how it is that humans come by musical composition.

Ghosts mean something else to philosopher Slavoj Žižek, channeling Lacan: The whole point of Lacan is that in order for social reality to establish itself - by social reality I mean social order, social symbolic reality something must be primordially repressed. Something cannot be symbolized, and the spectral apparition emerges to fill up the gap of what cannot be symbolized. So, again, the specter conceals not social reality but what must be primordially repressed in order for social reality to emerge. (1995)

We might be reminded of the Freudian construction of the ghost as a kernel of repressed truth, similar in some sense to the dream. But for Žižek's reading of Lacan, the apparition is not part of the symbolic order: "They are always here as the embodiment of what Lacan would have called a certain symbolic deadlock" (1995).

Through these phenomenological explorations of key thinkers of the $20^{\text {th }}$ century, I have attempted to expand the notions of composing, to think not only of the act of creating music as a deliberate and fully conscious structuring of intellectual content through the technology of an instrument, but also to consider the composition process as one of rapture, response, and tied up in a thousand hands, not just the hands of the performer. It is not that the rhetorical act is unintended or the product of the will of others, but it is in moments of novelty - in the composition of music — that the artist is there self-identifying and imbued with ghosts, that he is haunted. It is through 
this contribution to a rhetoric of music that we might move beyond the stereotype of the mad artist or the Bohemian if we are instead to understand the musician as he who sings with ghosts of his self rather than he who sings alone in a contained madness. We should still be mindful, however, of the ready-made structures in music just as well as the structures which come from pre-existing tropes in our language. But we might learn something here about the analysis of voices, of recordings, and of digital waves. How can we reconcile this Derridean paradox that it is when we believe we are most ourselves that we are most haunted, that we have been inhabited by past selves? How do we reconcile the reality of having to let the voice leave the body, and of letting it be recreated on our speakers: ghosts born from our household technology, and ghosts saved for later days? In the following chapter, we bring the figure of the phantasm to the digital music commodity to better understand those liminal spaces of digitality, between materiality and virtuality, in which the digital music commodity takes shape and, too, shapes us. 


\title{
Chapter 3
}

\section{The Digital Music Commodity: Memory, Notation, Reproduction}

\author{
To my knowledge, the economic organization of this form of production lacking defined goals, \\ and the nature of the new relation it creates between man and matter, consumption-production and \\ pleasure, have never been expressed in theory before. \\ - Jacques Attali
}

\section{Song and Civilization}

In this chapter, I move from issues in inspiration and invention to our attempts toward the solidification of music in its recording and notation, the development of the music commodity in its material and immaterial forms, and our distribution and sharing of music. What happens to music after we create it? What are the places and spaces that music operates in as a digital commodity? Herein we come to understand how the ends of music are now situated in a capitalist framework-while, as Jacques Attali tells us, music and money have always been tied together, we come to see how the particularities of the digital music commodity move us, and how music moves itself across digital networks (Attali 2009). We save our music on scoresheets and in binary code. We access it through the digital Cloud via the Internet. Much has changed in the formats — in the media — through which we access and store our music, and we see 
certain patterns in music sales which hedge toward subscription services of music and the generalized cataloguing of music. We see the ready access to enormous libraries of music through pay-to-access services such as Spotify, and yet the continuity of the album as the primary mode of collectivizing discrete songs still remains. We see, too, the furthered separation of musician from the audience through the flat rate music library access fee. Having addressed the role of rhetoric in the composition and performance of music, we begin to see the role of rhetoric in the instances of the recording, distribution, and ultimately the archivization of music, which now, at the time of writing, most often occurs in these digital phases. Music is recorded using digital audio workstation software (DAWs) such as Avid ProTools, Steinberg Cubase, or Apple Logic Pro in studios or at home. Domestic recording mainstays have expanded recently, as well, in freeware DAWs such as Audacity, or Garageband, which comes ready to use on most Apple computers and mobile devices. In this chapter, I investigate how music is mediated by its recording and distribution as a digital commodity, and the political economy surrounding the digital music commodity; I build on Jacques Attali's framework by calling this the digital-political economy of music. I examine the role of the extant fragments of ancient Greek musical notationsixty-one tattered remnants that remain on papyrus and pottery—-to think about how we now transcribe sound to various visual representations.

Independent music comes as an opposition in more than cultural relations of power: it comes as opposition in economic, systemic, and social relations. This is particularly important, here, when we are trying to stake a claim for rhetoric in the age of mechanical and digital reproduction, and in the independent production of music. 
That is, this occurs in a critical relationship between the musician and recording technology in the domestic sphere, in the bedroom, the basement, the garage, on laptops and with hundred dollar condenser microphones. Apple devices typically come pre-installed with GarageBand, a powerful DAW, and even mobile devices at the time of writing this are equipped with such software, though we won't get into the ethics of Apple at this point. Here is where I make my claim for rhetorical musical considerations by independent musician-producers-where once rhetoric was a significant part of a liberal education, and music in theory and practice was given years of attention in liberal education pedagogy, we now have a population that is surrounded by the tools to create music but lacking the skills to purposefully direct their art and to consider its reach, scope, and long-term political, social, and cultural ramifications.

Perhaps the digital turn in music production, and the ubiquity of home recording technologies, has not yet made a an apparent, immediate dramatic impact on the larger machinery of the music industry. Yet, the various roles of music production, which I have discussed above, have been compressed into the individual: writing, performing, audio engineering, mixing, mastering, manufacturing, marketing, distributing. The independent musician must be more aware now than ever of audience, of how the forms and figures of their audio productions will affect their listeners, and how to write music such that it will ever be heard in the bottomless sea of unsigned, independent artists. Too often the musician turns to pop forms, to write a singular hook that will draw attention from major label interests, or a viral gimmick to amass YouTube views. But we need not follow such a road. An independent music 
reconstituted by the meditative intents of a population might point toward a different sign for the future.

Humans work hard to preserve their music, perhaps because of this perceived understanding of its significant persuasive, political power. Charles Darwin, in his The Descent of Man, and Selection in Relation to Sex, supposes that "musical" vocalizations may have worked as a sort of proto-language, and while theories of the origins of music are still debated widely by evolutionary musicologists and in the archeology of music, we see a strain in Darwin that limits music to the affective dimension:

When we treat of sexual selection we shall see that primeval man, or rather some early progenitor of man, probably first used his voice in producing true musical cadences, that is in singing, as do some of the gibbon-apes at the present day; and we may conclude from a widelyspread analogy, that this power would have been especially exerted during the courtship of the sexes-would have expressed various emotions, such as love, jealousy, triumph—and would have served as a challenge to rivals. It is, therefore, probable that the imitation of musical cries by articulate sounds may have given rise to words expressive of various complex emotions. (Darwin 1871)

Indeed, this should be of much interest to us, as we wonder if this is not an anachronistic or anthropomorphic sentiment that Darwin is suggesting. Contemporary work in bioacoustics demonstrates that even the seemingly musical songs of birds are used to relay significant information, and that the sounds of other animals are used for more purposes than for sharing emotional states. There is a division known to 
historians of music, set in the disciplines, between prehistoric music and ancient music — where ancient music as a demarcation begins with the world's literate societies. What are we to make of this? Early wind instruments, such as the ocarina, have been dated to at least 20,000 years ago. This is still early in the larger view of the human story, and perhaps what we might even deem as late in our protolinguistic development of communication. Given the shells of old ocarinas, we can guess at the tones and timbres that could have been played, and recreate some of these instruments. But we cannot know the melodies that rang out in the early air, or their nature: how they were structured, what they meant, how they were used, and how they were shared over the passing of years and over thousands of miles of migration. The preservation of our early music through memory, through repetition, through communal sharing, sounds much like our early oral histories, our stories.

We have, for millennia, been aware of the incredible power of music as well as its elusive and enigmatic nature: I began the first chapter of this dissertation with an epigraph from Museaus, whose line "Music to mortals of all things the sweetest" is relayed to us via Aristotle (Jowett 2009). Much strange mythology surrounds the creation of music, as artists often explain the composition process as one of divine inspiration —as in Plato's Ion—or moments of maddened passion, as in the stories of the cicada in the Phaedrus. Despite the obscuring cloud of history that hovers around, much has been written on the subject of ancient Greek music. It seems to us, now, that musical innovation flourished in ancient Greece. Not only this, but music was studied by the youth—we should remember, of course, that this was prevailingly an education reserved for young males, exclusively — and much was theorized about its pedagogy 
and role in civilization and the ideal state. Music was not to be regarded as a trivial matter in early democratic society. Scholarship in the area of ancient Greek music is widely dispersed among various fields. Despite the insatiable allure of music to our Western intellectual ancestors, very few remnants of their written musical tradition survives through written symbolization, as notation. We can attribute this to at least two causes: a resistance to confine a musical theory to notation—similar, perhaps, to Plato's distrust of the written word — and the reality of violence and destruction leading to crumbling societies, the burning of libraries, widescale human disagreement and the riotous calamities of nature. But more than anything, it may have been the general attitudes toward musical notation that has left us with so little. Pohlmann elaborates, for us: "Quintilian, for all his high esteem for the role of music in the orator's education, excludes the use of notation from his programme" (i). We must realize, of course, that contemporary recording technologies, and the practice of audio engineering, has not yet and will likely never discover a method to perfectly capture the subjective experience of music in its perfect totality: the monumental difference between live performance and either analog or 24-bit digitally mastered recordings is such that we ought to consider them two very different media, and we shall. The Greeks seemed to have understood this, too: that the technology of writing intervenes with that relationship between the artist and art, the speaker and their words.

So often do the immediate limitations of technology-in storage, in space, in speed-determine our creation and apprehension of media. The American blogger Andy Baio has published the following analysis from the Whitburn Project regarding the surprisingly unchanging nature of the hit song length (2008). The Whitburn Project 
analyses were conducted by collecting data from Billboard top songs from the past 120 years. Baio accessed these records and summarized the findings as such after encountering the documents, where the first column is the decade from which the song length data is derived, the second column is the average length of a Billboard hit song from that decade, and the third column or data point is the number of songs sampled (2008):

$$
\begin{aligned}
& \text { 1950s, 2:30 (95 songs) } \\
& 1960 s, 2: 30 \text { (250 songs) } \\
& \text { 1970s, 3:30 (153 songs) } \\
& \text { 1980s, 3:59 (142 songs) } \\
& \text { 1990s, 4:00 (132 songs) } \\
& 2000 s, 3: 50 \text { (58 songs) }
\end{aligned}
$$

We might wonder, of course, why in the 1970s the average song length jumped beyond the 2:30 mark. Or why the capacity of the original 78rpm record, at 3:30, which debuted in the 1890s, seems to still have left such an incredible mark on popular music, considering the advent of the LP record in 1948, thereby increasing recording and time capacity. Yet, to this day, the average pop song length stays roughly the same as it was in 1890 (when it was around 2:45) (Baio 2008). We can go back further, here, to assess the importance of brevity and memory. The early starts of troubadours with their heroic chanson de gestes of the $12^{\text {th }}-15^{\text {th }}$ century and of course the Grecian epics remind us that the capacity of the mind to recall and remember more than one hundred lines of lyric per musical unit— the song — is not impossible. Yet, with something like La Chanson de Roland, though the stanza lengths are variable, only one stanza in I- 
LXXXVII breaks a thirty-line cap. Though we can only speculate, one might wonder if the modern chorus started as a trope of repetition: a rhetorical and mnemonic technique. A defining characteristic of digital media is its ability to be broken down into units (Manovich 2002). It might be worth drawing, here, a connection to the early German theorists who attempted to break music down into discrete units, too: sizable figures, manageable bits, drawing parallels to rhetorical figures. Like new theories of digital media, these composers understood the significance of the sample size, the rhetorical reproducibility of the stand-alone fragment.

We might turn to Jaron Lanier; in his You Are Not a Gadget: A Manifesto (2010), Lanier views the emergence of MIDI or Musical Instrument Digital Interface-which was standardized in 1982 — as detrimental to the human condition. Worse, still, he writes, is that it has become a concept that is "locked in." That is, he worries that, dependent on human survival, hundreds or thousands of years from now, we will still be stuck with MIDI tones and tunes, all around us. Yet, the limitation of definition has been around for a while. Lanier writes:

People have played musical notes for a very long time. One of the oldest human-hewn extant artifacts is a flute that appears to have been made by Neanderthals about 75,000 years ago. The flute plays approximately in tune. Therefore it is likely that whoever played that old flute had a notion of discrete toots. So the idea of the note goes back very far indeed. (2010)

And yet, while Lanier tells us that the idea of a "single, precise" musical "note" was not a necessary element of the "process of making music until the early 1980s," we know 
of the surviving fragments of ancient Greek musical notation through Pohlmann and West, despite what seems to be a philosophical and cultural disposition against the stagnation of music through a formal codification (2010). The appearance of these early flutes “75,000” years ago with discrete notes perhaps tells us as much about the early desire to solidify musical processes as much as it does about the fluidity of music. Monodic musical arrangements prevailed for millennia in the form of the Greek kithara accompanied by the voice and later the lyre, the guitar, because of the flexibility of the human vocal chords to sing in key with a singular instrument. The rigidity of the frequencies of instruments must be carefully monitored and held to precise standards to play in full concert orchestras - the collective tuning of strings, transposition across instruments to tune to a concert pitch. Here in this apparent conflict of the rigidity and fluidity of music do we see a parallel to the present figure of the digital music commodity, so much like the figure of the ghost: both here and not here, tied up in trans-oceanic cables as binary code to be passed around on the Internet and then immediately in our ears, our minds, in their coming to existence through their reproduction as code as well as their rebirthing through our amplifiers and speakers.

\section{The Physics of Sound}

Let us first think about the immediate, physical properties of sound, what is often called the science of sound. J.W.S. Rayleigh writes in his The Theory of Sound that "sounding bodies are in a state of vibration" (1896, p. 1). Both he and Horace LambLamb, in his The Dynamical Theory of Sound-go on to describe that there is significance 
in distinguishing between sounds that constitute noise, and those that constitute a musical note (Rayleigh 1896, p 2, Lamb 1910, p. 3-5). Both scientists, however, agree that there is extraordinary ambiguity in this distinction, and we are certainly still grappling with this ambiguity today, if anything can be said of contemporary American subgenres such as noise-rock or the growling vocalizations of Swedish Death Metal against its melodic — though often distorted—backing arrangement. Comedically, the Norwegian performing artists Hurra Torpedo use kitchen appliances in their music as percussive instruments, applying force with large hammers or dropping, smashing, and banging them together, to accompany original compositions as well as assumedly parodical renditions of cover songs such as Bonnie Tyler's saccharine "Total Eclipse of the Heart."

Public response to this distinction between noise and note is not new, of course. Looking back to the early 1900s, there are accounts that on the opening night of Stravinsky's Rite of Spring, the dissonant and unexpected tonal characteristics of the piece caused a great stir in the audience, and caused what was almost a "riot" in reaction (Chua 2008, p. 59-61). Though it may have been Nijinsky's choreography of the performance that incited such a violent response in the audience; Nijinksy seemed to have been pleased with the reaction, while Stravinsky was apparently infuriatedthough the musical dissonance, here, had a compositional intent and purpose: "Its basic rhythmic energy and dissonant immediacy, after all, advertises the initial chord as the primal sound from which the material of spring could erupt" (Chua 2008, p. 83). Material interference in the transmission did not cause the confusion, here. 
Yet, while the concert hall is designed to, as accurately as possible, allow sonic curves to travel to the ear through the air with even amplification and clarity, James Jeans in his Science and Music tells us that even when "the only transmitter is the air of the room," in the example of the orchestral performance, the curve of sound still "undergoes a good deal of distortion on its journey from the orchestra to our ears" (Jeans 1937, p. 15). We often forget, as Jeans writes, there are "the walls, the roof and floor, the clothes of the audience, and even the empty seats" and that "a considerable part of the sound we hear may have been reflected dozens of times before it reaches our ears" (1937, p. 15). In the case of the Stravinsky riot, then, I identify at least two types of interference: one is the physical interference from performers to audience, the second is a sort of rhetorical interference, a dissonance between authorial or compositional intent and interpretation.

We can look back further than Stravinsky to see that this relationship between noise and musical note is a tenuous struggle. Aristotle, in his Politics, takes issue with Plato's writings in a similar vein, regarding the use of particular musical modalities: "But Socrates, in Plato's Republic, is very wrong when he permits only the Phrygian music to be used as well as the Doric, particularly as amongst other instruments he banishes the flute..." [1342b] (Jowett 2000). While Plato's Socrates is quite adamant that the Doric mode is the correct mode to be taught to the Athenian youth, Aristotle surprises us with a more open position, pertaining to what we might call a sort of rhetorical parallel between the structures of modes and their purposes (dithyrambic structures falling into Phrygian tonal patterns, for example): 
...for the Phrygian is to the modes what the flute is to musical

instruments—both of them are exciting and emotional. Poetry proves this, for Bacchic frenzy and all similar emotions are most suitably expressed by the flute, and are better set to the Phrygian than to any other harmony. The dithyramb, for example, is acknowledged to be Phrygian, a fact which the connoisseurs of music offer many proofs, saying, among other things, that Philoxenus, having attempted to compose his Tales as a dithyramb in the Dorian mode, found it impossible, and fell back into the more appropriate Phrygian. [1342b] (Jowett 2000).

It might be noted, too, that the William Ellis translation of Politics which I have here been referencing has Aristotle tell us that "the Doric music is most serious, and fittest to inspire courage" while the Benjamin Jowett translation tells us that "the Dorian music is the gravest and manliest" [1342b] (2009, p. 316). Because of the few remaining fragments of ancient Greek musical notation, catalogued by Pohlmann and West in The Documents of Ancient Greek Music: The Extant Fragments, we know very little about what these modes would have sounded like (1970). Scholars seem to agree that the Phrygian mode of contemporary Western music would have little—if any—similarity to the Phrygian mode which Aristotle and Plato were referencing. I argue, here, that Aristotle is as much concerned with aesthetics as he is about the inherent quality of the modality and its ability to influence the performer and listener alike. Yes, Aristotle is attempting to identify those musical qualities which will move the soul to virtue. But he is identifying particular aesthetic qualities of distinct modalities that have the power to do 
so. This is not unlike Horace Lamb's explanation of the "musical note" in contrast to "noise": "the sensation is smooth, continuous, and capable (at least in imagination) of indefinite prolongation without perceptible change" (1910, 3).

The ancient Greeks, though, did not yet envision graphical waveforms of sound. In the Aristotelian treatise "On Things Heard" from Minor Works-the piece was written in the tradition of the Peripatetic School, but most likely not by Aristotle himself - the theory of sound expounded is that of the movement of air: "contraction, expansion and compression" (1955, p. 51). This is very much how we understand the movement of sound through air today: through series of changes in air pressure caused by vibration, comprised of what is now called compression and rarefaction. There is also an early strain of what we now think of as the "physics of sound," in this work; it is noted that the long necks of "geese, cranes and cocks" make "violent sound" because of the length and narrowness of the windpipe, and the widespread use of such stringed instruments as the kithara in ancient Greece demonstrate that mathematical principles were widely applied to music: both in its composition and by luthiers who designed and built the instruments. Anthropologically, some of the earliest discovered instruments — up to 20,000 years ago—worked on similar principles by using stopholes to change the length of the pipe. Although, the early ocarina used what we now call Helmholtz resonance: a sort of intra-reverberatory bouncing of waves to produce a sonorous, almost human-like tone. As we see in the largely unchallenged work of these physicists in the late 1800s and the early 1900s, the transmission of sound through matter by moving matter is still very much how we understand the physicality of sound. 
We should note, too, that sound does not only travel through air, though air has become the sort of normalized medium of sound transmission.

The material nature of sound is evident in our anatomical reception of it, as well. The structure of the ear is a very mechanical one: the eardrum acting as a sort of diaphragm to note the changes in pressure. We can contrast this with other sensory functions which seem to rely more on chemical reactions: touch, smell. The ossiclestiny bones of the inner ear called the malleus, incus, and stapes-are effected by the movement of the drum and create fluid waves in the cochlea that correspond to the pressure changes in the air. Tiny hairs in the cochlea—each with distinctive resonant frequencies - react to the fluid waves and send electrical impulses through the auditory nerve to the brain. Or such is more or less the current understanding. Here it would give me great pleasure to embark on a sort of elementary philosophical inquiry and ask: where $i s$ sound, then? Is there sound independent of the human—or animal—body? And why have we come, through evolutionary processes, to hear this distinct range of frequencies, while other species produce and receive sounds in ranges we call infrasound and ultrasound but are everything natural to them? Still, as little as we know about how the reception—could we say creation?_- of audio works, we will have to save this for another time.

We can ask, though, what happens to the physical sound wave when it is recorded, digitized, and transmitted electronically via our computational technology? As Jeans points out, distortion of sound occurs even in the orchestral hall. Are we dealing with an altogether different phenomenon here, in the electrical transmission of data? Does digital sampling of an analog wave destroy the inherent quality of the 
sound, or is it merely another form of distortion? Is it the brain that makes the note "musical," somehow, from what would otherwise be a simple, trivial disturbance in air pressure? Sound as a physical movement of molecules must be transformed to be stored, whether in memory, on reel, or as digital data. Here is where, traditionally, the digital/analog divide is discussed in recording technologies. But there is much interplay between analog and digital signals, despite audiophiles and purists often arguing for the superiority of such analog recording technologies for music as magnetic tape and vinyl for playback. Here we start to slough around in questions too big for the scope of this immediate project, for all audio begins and ends as analog signals, and subjective tests to determine if listeners could differentiate between high quality analog and digital reproductions are largely inconclusive (Blech \& Yang 2004, p. 1-9). The microphone uses a diaphragm not unlike the inner eardrum to gauge changes in air pressure and render these variations as electrical signals, whether the medium of recording is analog, such as tape, or digital, as in digital audio workstation (DAW) software operating on a computer. Jeans, Lamb, and Rayleigh all find that music constitutes a wave- that is, the collective elements and instruments form a sort of whole, singular arch that excites the listener (or bothers or inspires or so on). Adorno can help us, here, as he writes that "good serious music" is a sort of complete totality, where the details of a musical composition are "cogs in the machine" that work toward a totality (2002, p. 19-20). Adorno writes of popular music, as opposed to serious music: "The composition hears for the listener. This is how popular music divests the listener of his spontaneity and promotes conditioned reflexes" (2002, p. 22). But I propose this dichotomy between serious music and popular music is not unlike the apparent dichotomy between noise 
and note. Here, Adorno is concerned more with the structure and composition of the music than its sonic integrity. Though we might guess that he would find issue with highly compressed digital audio files such as the MP3.

The digital music commodity is both virtual and real, material and immaterial, here and not-here: a curious parallel to the Derridean figure of the ghost, of the self, of the voice. This is a starting point for thinking about the digital music commodity. But we do have some precedent to stake this claim. Lev Manovich, in his The Language of New Media, gives us a sort of framework, which I can here outline. New media, for Manovich, consists of "the digital medium itself, its material and local organization," the "interface" through which we access the media, the "software" that works on this interface, the "Illusions" and "appearance" of the "images created using software applications," and the "conventions" or "Forms" used to organize new media (2002, p. 11). Even in the "material" itself, the code, the signals, the energy of electricity, we come unto a point of physics: energy is not matter. But does not electricity have a sense of materiality: its blue-white appearance, its sparks, its shock? And is it really so that the images on my computer screen are illusions? The pixels are there, and in my case, are being lit up by an LED screen, using light-emitting diodes from behind. What of sound, then? Do the small, tinny speakers on my laptop not produce compressions and rarefactions in the air of my office so that I can be prompted by applications on the computer and hear music?

From the previous discussion of rhetoric as that which moves the soul, and music as that which, in its best form for the ancient Greeks, points toward truth, we should ask, at least in play: What do rhetoric and sound do in a secular world? Of 
course we must account for the indubitable condition that the meaning of soul has changed through time and across cultures. The Greek soul of movement, of selfmoving eternality, is different altogether from the Western Judeo-Christian soul: a sort of actual self inside the corporeal self that after physical death houses itself in an eternal afterlife. But perhaps this retrospective analysis can shed light on our contemporary sonic situation as well as that of the ancient Greeks. We cannot simply see rhetoric as that which leads us to see beyond the outer edges of heaven into the absolute and infinite, as Plato's Socrates suggests in the Phaedrus, nor we can we understand music as that which simply moves the body and moves the emotions, and moves the mortal being.

Could rhetoric be a sort of ordering, as some have suggested that music is an ordering? Yes, we have the canon of Arrangement. Perhaps more than ordering, we can say it is an embodied synthesizing. The theoretical sort of underpinning, here, should not be to equate practices of rhetorical composition and musical composition, but rather to suggest that rhetorical considerations play into and play along with musical choices and performativity. Still, countless problems persist: what do we make of the moment of unexpected inspiration, whether in song or image or word or speech or thought, where there seems to be no source from which it is derived? Must we constantly look for that source, assuming it to be somewhere? Can we be "gifted" by our own inner workings and given "something out of nothing"? 12

\footnotetext{
${ }^{12}$ What I might call the ex nibilo question of musical inspiration. It does seem to assume some grand narrative, though, to think that every song takes after another. If we take either extreme polar position on whether musical inspiration must come from other works of music or that music can come ex nibilo, out of nothing, in the mind of
} 
We do re-materialize digital music. Various processes alter digital music in its transmission: compression, digitization, codification. A sort of intensive listening should help us recognize what has occurred in these stages and be mindful of what happens when audio transverses through wires, just as we should be mindful of old English folk ballads that have survived for eight-hundred years through oral and written form. We must always ask: how has this been transfigured and disfigured? For all we sing, there are only faint echoes. For all we dance, there are only footprints on beachsand washed away in the morning. For all the melodies hummed from mid-day inspiration, there are only the trampling hooves of mass-produced culture: or at least the slight radio annoyances. Perhaps more importantly, I sense some duty in the digital to resurrect what has been lost to the sonicatacomb: the Web, with its nearly infinite tendrily threads, is too often a place for self-published art and song to sit and die, to be lost and unfound.

But from invention our music is then solidified: in its recording, in its notation, in our mind's memory. We must turn to assess the relationship between the music commodity and this disruption of the first invention: all of the twists and turns the song must traverse before it reaches its audience. Where does that brilliance of invention go when the solidity of music prevails and we are left with the digital music commodity? Is it in the moment of hearing the melody by the varied audience, or when

the composer, we are left with a theoretical stalemate on either end: if music is also derived from other music, then wherein does it begin, and how does it change? Or, if music comes from mysterious brilliance or genius, where are those characteristics cultivated, and then is that not the source of the music, and so on? Thus through offering the idea of musica ex materia and the figure of the ghost we can attempt to reconcile these conundrums. 
it is plucked out on the strings by someone learning to cover the song and it reverberates off the basement walls? Or is it forever last, in the moment it is first recorded at home on a cell phone by the composer, so that the song is not forgotten, or when it is first tracked in the studio? Or is it when it is first played back after mixing and mastering and the "final product" is produced? Jacques Attali's return to Attali on the assessment of the music as commodity might help us, here:

When money first appeared, music was inscribed in usage; afterwards, the commodity entraps, produces, exchanges, circulates, and censors it. Music is then no longer an affirmation of existence, it becomes valorized. Its usage did not prevent its entering into exchange: since the time that societies' regulatory codes, prohibitions, and sacrificial rituals broke down, music has been unmoored, like a language whose speakers have forgotten the meaning of its words but not its syntax. (Attali 2009, p.

The valorization of music, like the fetishization, is indicative of its commodification. And so here we transition from the material properties of music and its processes of invention and composition to the digital music commodity and its ephemeral gravity, its reality as data and its reality as sound in our speakers. Musical recordings, whether they consist of data for sonic reproduction or written on papyrus as musical symbolization, allow for our attempts at the performative recreation of music. Inherent in the text of musical scores is the onus of interpretation: and in musical performance, critical and new interpretations of scores are often celebrated. Yet, the historical and symbolic distance fascinates us: what would it have been like to experience the music as 
did the ancient Greeks? Perhaps we crave some semblage, some semblance of the "truth" of historical reality. Fueling our fascination further, no doubt, is that there have been recovered, at the time of writing this work, only sixty-one fragments of Greek musical notation. Many of these papyri scraps are made up of only a few discernible symbols—-short phrases, which may not even be full melodies—and we must know that many of these fragments have been subjected to "imaginative reconstructions" (Pohlmann 5). And yet, they remain as only "a few chance items" that have been passed down to us, and we cannot be sure if they are representative in any way of the sort of sound and music that our ancient friends found themselves theorizing over (Pohlmann 5). Some attempts have been made to create both virtual and physical reconstructions of ancient auditory culture. We have, for example, Hawkins (2011) and his three-dimensional computer graphic model of the Theater District of Pompeii, which we might imagine closely resembled the amphitheaters of ancient Greece. Still, this digital reconstruction, while fascinating and applaudable by all respects, is based on fragmentary and partial knowledge of the period, its music, instruments, people, and culture, among other, perhaps greater unknowns. I have no question in my mind that Hawkins understands this, but I believe we must be cautious in our excitement lest we begin to take modeling for a new, definitive reality. Hawkins in some sense reifies a past for us, but it is just that: some past.

Now, Pohlmann and West's Documents of Ancient Greek Music is oft cited as the most comprehensive scholarship available on surviving Greek music fragments. The work has since been amended, and was published in 2001, as new fragments and pieces of musical notation from the Classical to Roman period of Ancient Greece are 
occasionally uncovered and found, as recently as William A. Johnson's contributions on two tattered papyri in 2000: the Yale fragment, pieces of two vocal notations, and the Michigan fragment—so named because of its shape, which resembles the Lower Peninsula of Michigan—which contains lines of instrumental notation. As of the 2004 edition, Pohlmann and West identify sixty-one remaining works of Ancient Greek music, found on scrolls and pottery and paintings, including instrumental pieces and sung lines of tragedies: found as silent but singing somewhere. How do we access these silenced songs? Or must we reinvent them? Music played an integral role in the lives of the Greeks, in many ways similar and may ways dissimilar to our current cultural atmosphere. Were our ancient friends more musical, and what would that mean? Stefan Hagel notes in his Ancient Greek Music: A New Technical History that “musical notation was already firmly established" by the middle of the $3^{\text {rd }}$ century BC, the period of time from which the oldest surviving documents of ancient Greek music were born (2010). Thus, there are portions of the past which will remain sealed, at least for now: "There is no sense in searching for the secret of what anyone may have known” (Derrida 2011, p. 100). Is there no sense? Do we need sense? The great university of Alexandria, which housed the famed Library of Alexandria-a sort of grand attempt at collecting all the ancient world's written texts—would have also housed works of poetry and music in its “museum” (Liddel \& Scott 1940). The

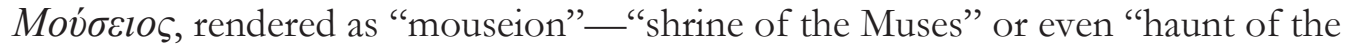
Muses"-would likely have been the dedicated housing place of the collected work of our ancient musicians, though we might wonder about the existence of folk music or "popular" music that may have gone unrecorded, deemed illegitimate or unworthy of 
archiving, in opposition to religious ceremonial works and the art-music of the time reserved for stage productions (Liddel \& Scott 1940). We now attempt some similar projects: the Library of Congress houses the Alan Lomax Collection in its American Folklife archive, and released in 2011 the "National Jukebox": an archive of roughly 10,000 sound recordings performed by Americans in the years 1901-1925. We haunt ourselves through unearthing our past and allow ourselves to commune with these ghosts. Yet, to haunt is to inhabit, and where there is habitation there is life.

\section{The Haunt of the Muses}

Where is the haunt of the song in today's world? Where does the song sleep and slumber to be awakened? The song prevails now as a commodity, though music and money have always been closely related (Attali 2009). With these few fragments of ancient Greek music remaining, we should be interested in Attali's comments about the destruction of a commodity in Noise: The Political-Economy of Music: "the object is produced, sold, consumed, destroyed, worn out" (Attali 2009, p. 37). With the digital music commodity, perhaps it is first worn out on us before it is destroyed — digital storage prolongs the life of a song, though mass distribution ruins our ears to music quickly: the abundance of overplay. Distrust of radio stations to play culturally relevant music, the intrusive, maddening repetition of holiday music in American department stores in November and December- the employees who have to endure hearing the line "I saw mommy kissing Santa Claus" in its hundred different renditions like Sisyphus pushing a giant ginger snap he can never taste up a mountain of candy canes. 
Who makes these decisions regarding the habitations of songs? Not just the immediate decision, but the decision to produce and distribute this music initially? Why was it created?

Here is where_-and why_music as a commodity concerns us: that dissonance between what is perceived to be wanted, and what sells well across a diverse population. This dissonance between the arithmetical mean of desire and subjective desire, if we grant the imagination the ability for such a thing to be quantified. But the supposed mean desire of a large population leads music industry marketers, talent scouts, $A \& R$ representatives, and all levels of managers to make low-risk decisions about the sorts of music — and the sorts of musicians—-which they produce with their funds in the pursuit of profit. And yet we also see the occurrence of such strange entities as that which we might call postmodern joke music: such as Rebecca Black's "Friday," which only becomes so widely known through its distribution and rapid Internet popularity: the "fail" culture. A completely fulfilled desire is the death of the desire itself. Do we stray away from "the perfect song"? Here is where a politics of music matters most, in the intersection of public and private life, in the intersections of our desires and the realities of production and distribution, and in the peculiar role of the musician-citizen as something-of-a-subversive-character [Attali], when we all are continually shaping the sonic realities around us by the very necessity of living. As long as we are alive, we are always sounding. And the sheer number of independent artists who are producing music is, to me, a positive sign of the cultural vitality of the nation but also as a symptom of the state of popular music on a global scale.

To understand what draws us to the digital music commodity, we can look to 
Marx. What is the "mystic character" of commodities that Marx writes of in his Kaptial? It is something "metaphysical" and "transcendent," but Marx does not stop here. We must think, too, of the "social form" of the labor that is involved in music production, and in its performance and in the production of the commodity (Marx 1887). How is performative music commodified? We hang on to our ticket stub from a concert. We retain a memory and we tell a story of the musical performance. We might buy a token — a t-shirt or an album or a poster—-to support our much-loved artists, especially at the smaller, local level. But the performance of live music is also restrained by the expectation of the solid, discrete commodity: we expect, from our popular rock and country and folk and rap and metal artists to hear discrete song units, between three and four minutes of length.

Commodities are "social things" with some "imperceptible" qualities: wherein are the ideological underpinnings of music, in the perceived or imperceived, or both (Marx 1887)? Can this ever be stripped from a commodity: that is, its social nature of production? Is there not something peculiar about the music commodity that lends us to quickly empathize with its production in a way that, say, a coffee cup does not? In the music commodity, we hear the voice, the creak of a chair, the squeak of fingers on oily fiddle strings. Scholar Huw Hallam writes of the Walkman and introducing "layers of private experience" into public life: we all produce sound and organize sound in such a way as to contribute to the music of the world, whether we compose harmoniously or with dissonance or strike out and sing anew (2012, p. 10). We might call this a sort of sonic interpellation. Hallam sees this, too, though, in channeling Xenakis on the explosive sounds of protest (2012). 
Jeremy Wade Morris creates an important distinction with the recent emergence of the digital music commodity (2010). There is not a singular sort of music commodity—vinyl records have even made a resurgence in popularity, and with Morris we see that there is a fluid nature even to the digital music commodity, with countless file formats, such as FLAC and lossless file types for the audiophiles and MP3s for their compressed, smaller file sizes that can be more easily flung around the Internet, and on top of this various sorts of metadata. We here come across the division which sparks much ethical debate: whether we are sharing music or stealing music through the use of Internet torrents and downloads. Adams channels Bataille in exploring the "potlatch" culture and the phenomenon of the gift-giving economy, which precedes, it seems, even barter (Adams 2008, p. 2). And indeed, some musicians do give their digital music out as gifts: with the purchase of a vinyl record, a digital download code is provided, or, in the case of Radiohead's album In Rainbows, the individual can decide how much they want to pay for the music, hosted on the band's official website. Some musical artists elect to offer free downloads of their music across the Internet in hopes of its propagation and widespread distribution, to capitalize on other markets. We use terms such as "piracy" and "stealing" to describe the downloading music, but we also use such terminology as file-sharing. And, indeed, those who choose to allow music to be seeded from their library through file-sharing programs put themselves at serious legal risk.

Yet, when a digital music file is shared, it is not given away, it is replicated. Thus, the overabundance of output that Adams critiques in Bataille as a general economic principle seems slightly off (Adams 2008, p. 2). It does not seem that the independent 
music explosion facilitated by Internet file-sharing and self-publishing on the web cannot really be deemed an overabundance-for there is not a singular type of music commodity. We react differently to songs individually, produced in the same style, or even by the same artist. I am on par with Adams in thinking that this access to free culture is incredibly important in the sovereignty of the individual, in a sort of personal freedom - this is undoubtedly how I began my own interest in philosophy, through finding PDFs of Greek philosophy on the Internet at the Peter White Public Library- I remember Googling “why am I here?” A question still unresolved, of course.

What is distinct about the digital-political economy of music? What has changed? Morris writes that "Music and computing are not interdependent and conflicted bedfellows" (2010, p. 27). Yet, Morris's pessimism about the revolutionary potential of the digital music commodity should be closely regarded:

It is too early to tell how disruptive the Internet, file sharing, and the digital commodity will be relative to other transitions in the history of recorded music. The form and character of the music commodity are currently in flux and, as with previous format changes and innovations, there is hope this instability might re-organize the economics and/or power structure of the music industries. However, for every beacon that change is afoot, there are equal reminders that complete disruption is unlikely, or at least overrated. Models for the retail of digital goods seem strikingly similar to their analog precedents and digitization has provided numerous opportunities for new forms control and power (e.g. surveillance, data mining, advertising) that limit rather than 
enhance the rights of users and musicians. (2010, p. 67)

Is this not a more realistic vision of the digital music commodity? Here we are absolutely right to consider "control and power" and how it manifests surrounding digital music distribution. Attali, too, recognizes that there have been concerns about the plight of the musician as a laborer throughout Western history. How has the digital music commodity changed the way the labor of musicians is understood? Is music now simply a "tool of regulatory power" rather than an "affirmation of existence" (Attali 2009, p. 36)?

To understand this, we must look at the production of the music commodity. We can return to Karl Marx's explication of commodity fetishism from his Capital (1887, p. 46-52). To think of music as a commodity, we must understand it as existing as a sort of material good and consider the labor involved in producing it. To start, the labor of creating the contemporary independent music commodity occurs in multiple stages and across time: there is the home-recording of demos, the performance of music at often unpaying venues or where excessive travel is involved for minimal economic return, and the printing and distribution of this music, where we often see musicians having to act as curators of their own personal websites and storefronts and thus be visual designers in conjunction with their audio creation, production, and distribution. Of course, this is not to say that less work or time is spent in major label music production, though work roles are widely distributed and specialists handle multiple artistic projects of the same vain simultaneously. The music commodity, then, is not simply an aesthetic, sonic production. Yet, whether it is through digital networks or physical media, the replication and distribution of the music commodity —indeed, 
the commodification of music, first-has separated the labor of the production of music and its reception, or consumption. Music, as a commodity, has become fetishized. And the digital music commodity, Jonathan Sterne tells us, presents "fetish qualities" as well: “digital music's packaging and presentation" (Sterne 2009, p. 39). We might wonder if the digital files themselves stored on a user interface such as iTunes might present additional fetish qualities.

The music commodity, like other products of artistic endeavor, is distinct in the initial labor of artistic struggle, of the necessity of inspiration and invention. The independent musician is almost always at-work in other fields, and holds musical creation as a dream or a hobby or a side-art. The inspiration that leads to musical composition does not simply occur always at will: here, there are moments of anxiety and unpredictable highs-and-lows of productivity. There is, too, the necessity of purchasing equipment of varying degrees of quality. Though certain "lo-fi," or lowfidelity genres have emerged_-even in American folk music, an already bare and stripped genre, as we have seen with Sub Pop's representation of Samuel Beam in 2002 - there are audible differences in commercial condenser microphone quality and, perhaps more importantly, in the skill and knowledge applied in mixing and mastering processes in operating complicated digital audio workstation software. And before operation, we must ask: Can the musician-laborer afford a digital audio workstation (DAW) such as Pro Tools and the necessary hardware to run it, including-but never limited to-a computer with significant RAM to run the program and plug-ins, the multi-input interface for processing signals between the computer and equipment, or 
even the lowest-end condenser microphone to capture an appreciable range of signals produced by the subtleties of the voice and our instruments?

It is no wonder, then, that there is such a phenomenon as the "one-hitwonder," when all the factors of creation and cultural reception are considered. Even the most talented and experienced of musicians might only find one point of connectivity in their writing that meets or melds with the expectations of the public and also serves as a meaningful expression of their intent. What can this tell us about the "use value" of the music commodity? For, it is difficult to ascertain the amount of time of labor that is necessary to produce a popular song, so contingent on reception and cultural troughs and crests. And what of the labor to compose a truly novel and revolutionary piece of music which simultaneously captures public interest, in the modality of what Adorno calls "serious music" (2002, 19)? Jacques Attali clarifies, from the outset of his Noise: The Political Economy, that music has been subsumed into this paradigm of commodity fetishism:

Fetishized as a commodity, music is illustrative of the evolution of our entire society: deritualize a social form, repress an activity of the body, specialize its practice, sell it as a spectacle, generalize its consumption, then see to it that it is stockpiled until it loses its meaning. (Attali 2009, p. 5)

Attali goes on to write that this "heralds" a "society of repetition" (2009, p. 5). How is it that we can reclaim music from its commodified form? Can music be given a noncommercial meaning? Popular music, for Adorno, "is manipulated not only by its promoters, but as it were, by the inherent nature of this music itself'- the nature of 
this music being that of the "song-hit," where the composition and structure of the music is modeled after all others, but it will have "at least one feature by which it can be distinguished from any other" (Adorno 2002, p. 21-27). Serious music - that is, "good serious music" —on the other hand, acts as a complete totality, where the details of the composition act as "cogs in the machine," constituting a totality (Adorno 2002, p. 19-20). In the standardized pop song, or "song-hit," or in Adorno's rendering of "popular music" in general, there is nothing "novel" introduced: thus, a cultural repetition with only slight, trivial variation (Adorno 2002, p. 18). Could there be a place in contemporary, independent music production for "serious music"? Can we rework this idea of "serious music" and play with Adorno's formula—could a serious music be that which works toward political rupture, for example? Let us have some help from Walter Benjamin to assess the digital music commodity. Benjamin writes, in his "The Work of Art in the Age of Mechanical Reproduction," that "...the unique value of the 'authentic' work of art has its basis in ritual, the location of its original use value" (1968, p. 5). Ideal music for the ancient Greeks_ - at least in the work of Plato and Aristotlewould move men to virtue, would ascertain some "truth," as has been mentioned. Lesser forms of music might move us to relax, to feel pleasantry. As Attali tells us, music and money are now welded and melded together, and we see this in the digital, as well. The digital turn in independent music production is heralded by the appearance of low-end, inexpensive recording equipment and the ability to sell the music commodity via the Internet. When we examine such self-publishing sites for independent music like BandCamp, we see that the inherent structure is made to act as a virtual storefront. Via BandCamp, musician-entrepreneurs can sell a range of file 
types of their music, from the very compressed MP3 to lossless files—-that is, files which are purported to have retained all of their data and have thus lost nothing through conversion, though we should be skeptical of this. Physical packages can also be sold through BandCamp- which has a transaction system based through PayPal, the sort of Internet standard for payment. A playful problem: If I am the only person to purchase my friend's 4-song LP through digital download via BandCamp, is there a degree of authenticity retained in the files that I then play back? For Benjamin, we ought to say "no," for there may have been nothing authentic in the tracks to begin with: "To an even greater degree the work of art reproduced becomes the work of art designed for reproducibility" (Benjamin 1968, p. 5). With models such as BandCamp, this point seems especially salient. Often our independent music is developed for the purpose of being reproduced: digitally manufactured through replicatory processes, so to speak. Douglas Davis offers a sort of counterpoint, in his “The Work of Art in the Age of Digital Reproduction," in which he argues that the individual copy of a work of art retains this Benjaminian aura, or that it undergoes a process of "transfer" and is embedded in the individual copy (1995, p. 381).

Poetically, Carl Sagan introduces his Pale Blue Dot with a description of the human species as being nomadic (1997). We have explored all of the earth, so we must now move to the stars. It is in our evolutionary profile to move about our planet, to chart, to discover, to migrate. Eventually, though, when "the climate was congenial" and "the food was plentiful, we were willing to stay put" (Sagan 6). Attali tells us, though, of the bard, of the Medieval troubadour, of the traveling court musician. The poet, the musician, the bohemian has seldom found a home in city walls. In popular 
culture, we still have this phenomenon in the touring musician who may be "on the road" for most of a given year, as oppose to the concert musician or studio musician, who might have salaried income and reside in one city or town most of the year. But the digital-music-laborer, the independent recording artist who uses digital spaces to sell their work, is landlocked. The domestic sphere must become a recording studio as well as a place of inspiration and creation.

We can turn to philosopher Slavoj Žižek to frame the political gravity of music in relation to potential for social change. In his Violence: Six Sideways Reflections, Žižek writes:

Adorno's famous saying, it seems, needs correction: it is not poetry that is impossible after Auschwitz, but rather prose. Realistic prose fails, where the poetic evocation of the unbearable atmosphere of a camp succeeds. That is to say, when Adorno declares poetry impossible (or, rather, barbaric) after Auschwitz, this impossibility is an enabling impossibility: poetry is always, by definition, "about" something cannot be addressed directly, only alluded to. One shouldn't be afraid to take this a step further and refer to the old saying that music comes in when words fail. There may well be some truth in the common wisdom that, in a kind of historical premonition, the music of Schoenberg articulated the anxieties and nightmares of Auschwitz before the events took place. (2008, p. 4-5)

Attali and Žižek come together neatly here in thinking about music as a sort of prophecy, that "the music of Schoenberg" anticipated the "nightmares of Auschwitz," 
for example (Žižek 2008, p. 5). We see here, as in Attali, the function of music in its ability to communicate when "words fail" and an even further possibility in music to act as a sort of premonition of both helpful social change and terrible nightmares (Attali 2009). Jeremy Wade Morris writes in his "Sound in the Cloud: Cloud Computing and the Digital Music Commodity that "the music commodity is an increasingly mobile and shape-shifting one" and that "Music in its digital form can arrive on computers or mobile phones but it can equally appear... as a giant floral print in the shape of a horse" (2011, p. 2). Morris is slightly obtuse in his analysis of recent musical trends in the cloud: Pandora is a free service and plays more like a college radio station than anything, while Spotify resembles Netflix in its pay-by-the-month access to what only seems like a limitless selection of content. How can we hope for social change from music when our access to the digital music commodity, already forced to be made for sale in the capitalist society, is even further restricted in the form of the digital music archive? Here we turn directly to these problems of archivization and access: who determines which content is available on services like Spotify, and who gets to access it? If our music is locked behind a paywall and requires Wi-Fi-which is another costly monthly service_ — can we call it still, simply a digital commodity? Morris concludes:

Digital music, like countless other technologies, may never live up to all its promises. It may never fully disrupt the structure of music industries or reduce the number of intermediaries between artists and their listeners. (2011, p. 18) 
I wonder what to think of this, when an easy majority of my composition students openly admit to pirating, discuss their techniques, and despite my warnings and cautions and in-class debates about the involved ethics, licensing, and copyright law involved, grinningly share their techniques for evading university and ISP protocols for monitoring such activity. Here again the problem of archivization: you can't find any album to download freely on the Internet, and with torrenting, access to the content is dependent on the availability of seeders: that is, users who have the files who are willing to risk sharing it over a network. Thus, artists that are popularized by major labels, trend-setters, late-night talk shows, Billboard ratings, and so on, are easier to find. At least, here, the users are the archons. Morris goes on:

As much as digital music promises greater accessibility, mobility, interactivity and control over music selection, this review of cloudbased music services shows that it also lends itself to contingent technologies, data mining, the exposure of personal information and the abridging of personal rights. But digital music's less grandiose promise — to turn our attention back to the meaning and form of the music commodity and to re-engage us with the role of music in our lives — is already being realized. (2011, p. 18)

Sterne can help us, here, from his "The Preservation Paradox in Digital Audio," in which he asks: "Why are some recordings available to us today and others not? The answer has much to do with will and selection choice, but also with broader cultural attitudes about recordings and the sound they contain" (2009, p. 57). Sterne recognizes 
the importance of a sort of forgetting, seen in his "Death and Life of Digital Audio" (2006). We are faced not only with a wide variety of file formats, playback devices, operating systems, and the consistent change of digital technologies, but also the materiality of these objects themselves: our computer's hard disk memories won't last twenty years at best (2006, p. 55-56). But it is not our goal to create some ideal archive of everything ever created, nor should it be, for Sterne.

Much of the data-mining that's done on musical services like Spotify are cashed in on in the eruption of media analyst consultants and related industry positions that have opened up in response to the knowledge economy's pining for pretty data. Paul Lamere's firm, The Echo Nest, sees itself as a Music Intelligence company. A recent TIME Newsfeed article published the sensational title: "Here is a Map of Every State's Favorite Band" based on information published by The Echo Nest (Roy 2014). What Paul Lamere has done, however, is simply shown the relative popularity of fifty artists for each US state, not necessarily the most-listened to artist in each state. This sort of data is interesting, and bridges genres — we see pop artists such as Ciara as well as lesser-known "indie" artists such as Kurt Vile and The Head and the Heart, as well as old mainstream favorites such as George Strait and an apparent fascination with "jambands" Phish and The Grateful Dead in the far Northeast - and yet we should be careful in the application of it, not only because the methodology here is misleading by not looking at a full spectrum of all artists, but selective artists and their relative popularity, but also because of the marketing, distribution, and of course cultural repercussions of such purported facts about aesthetic musical choices in geographical 
regions. This data was collected using Zip codes provided by registered users of music services such as "Rdio, Spotify and MTV," and according to Roy, this constitutes "a ton of data" (2014).

\section{The Archivization of Sound}

Preservation may not have been of the utmost importance to the Greeks, though we cannot make such brash assumptions with any certainty. Anxiety over mortality, and the mortality of our artistic productions, has no doubt been seen throughout history. Leonardo Da Vinci wrote, interestingly, in his work The Art of Painting, a short chapter on the subject: "Chap. ccxxx.- - How to paint a Picture that will last almost for ever" (Da Vinci 1957, p. 141). We might find either humor or great sadness in Da Vinci's fascination with the longevity of his own art, in the fact that only a relatively small number of his works have been preserved. Perhaps Da Vinci's method of "baking" the painting and applying a "varnish" of "nut oil and amber" was simply unsuccessful: or perhaps we must consider the greater social and cultural violence, the catastrophes of civilizations in order to better understand not only our processes of archivization but also to question our re-constitutions of our own history. Archivization is now seen as a critical element in musicology: Philip Bohlman writes:

Each modern institution of ethnomusicology supports some form of archive for the storage and study of data and fosters field study by its staff and students, which in turn enriches the holdings of the archives: 
the locus of the archive, therefore, is inextricably bound to the center of theoretical work. (Bohlman 1986)

Thus, the archive has become a powerful tool for the musicologist. Though, as John Vallier (2010) notes, there is usually an "archival ennui" that surrounds university music archives: a boredom, dissatisfaction, and malaise much unlike Derrida's archive fever. A very different sickness of apathy, which arises perhaps from the ubiquity of online digital music archives and the ability to retrieve endless music. Having access to moremusic-than-we-could-ever-listen-to-in-one-million-life-times might cause some anxiety, it seems. Does the ubiquity of music make it more dangerous, more invisible? I believe so. Which is why we especially need a revised understanding of the political economy of music.

The Library of Alexandria is an interesting point of analysis, then, in that it could have had the archival potential to preserve the music of our ancient Greek cultural ancestors. Though we cannot be so idealistic. Music is never perfectly archived. Indeed, it is fundamentally altered through transcription, and, like Heraclitus, we might realize that no single act can be recreated, especially a musical one, which is so contingent to time and space, always in flux and movement. Yet, in a pragmatic sense, written notation is incredibly helpful in sharing, distributing, and performing music in harmony, in community. Ptolemy's Harmonics was translated most recently into English by Jon Solomon (1999). Ptolemy "seems to have lived in Alexandria" according to Andrew Barker in his Scientific Method in Ptolemy's Harmonics (2000) and we thus might think of him as a messenger between these monoliths of human interest: music and museum, song and star. Ptolemy's primary work was in astronomy, and his empirical 
and spatial approach is evident in his musicological writings, and especially with his geometric diagrams illustrating mathematical, proportional relations between tones. Yet, Ptolemy was more Platonist in the sense that "beauty" was left to be best discerned by the "ear" rather than "theoretical constructions" (Ptolemy 1952, p. 271).

As aforementioned, music was seen by Plato and Aristotle as an incredibly powerful medium that could move the soul to virtue. Yet, the Greek philosophers seemed to be at wit's end as to how to address the widespread fascination with song. Aristotle, in Book Eight of his Politics, affirms the necessity of teaching music to our youth, especially because of its incredible emotional power (Jowett 2000). And this power has not been lost through time. Since at least the time of Ancient Greece, and surely earlier, humans have been well aware of the special capacity of music to move the mind. It is no wonder that both Aristotle and Plato were concerned with the pedagogy of music_-something we've shed entirely from American public education, or have attempted to waive off with once-a-week out-of-tune tooting session on cheap, plastic "recorder" flutes. I make a connection, here, though, with the ancient Greek mystification with music and their resilience to classify notation and to create a standardized notation system. Song was likely to be of greater cultural importance to the Greeks than it is now to us-usually reserved for celebration, ceremony, funeral (though this may have heightened its thoughtless re-use, replication, and ideological entrenchment)—yet they had no systematized process of recording, storing, or distributing their music. It thus necessitated live performance and embodiment. Music, in our world, is more often found in its recorded, digital state than in instruments and 
bodies and fingertips. Or were our Greek friends playing music in the streets, was every inch of Athens alive with song? We cannot know certainly.

Here is where the difficulty with the archivization of music, and of culture, comes into play. If the ancient Greeks stressed the process of musical composition as one of creation - that is, a process that blesses kairotic moments, improvisation, and even aleatoric gestures and movements - then how can it be archived? How can it survive through time? Is it possible to archive an attitude toward music? It is lucky, perhaps, that there are at least some surviving theoretical/reflective writings on ancient music, such as Ptolemy's Harmonics. Strange, though, that our contemporary pedagogical approach to musical education in America stresses the reading and even memorization of notation rather than creative composition. Yes, the archivization of music poses many difficulties. This is evidenced by the example of ancient Greek music I have here provided, but it remains the case even today. Music is often a collaborative and performative experience. Still, these problems exist in all archives: how do we stabilize and preserve what is alive? More importantly, we must ask ourselves for what purpose we attempt to archive the sounds we produce, and why we produce these sounds. Music, like writing, emerges from particular social and cultural climates and is understood in the contexts from which it is born. Yet this feels trite and not entirely true: perhaps it is simply a movement in academia whose blender I've tripped into. Oftentimes music taken out of its "original context" can be more meaningful and more elucidating, not just historically interesting but genuinely moving. Yet again, there is something trite, I think, about the widespread study of "classical" music and even classical literature: the romanticizing of the canon. Musicologist Bujic tells us more: 
In music history there existed for a long time a deeply entrenched belief that because music (by which I mean European, primiarly written, music) is a universal language, there is less danger there of falling into the trap of ideologized or narrowly localized views, since there was an implication that the language of music transcends the linguistic and political barriers. But cosmopolital and trans-national as it might have been, music has always been a part of its world and those writing about it brought into their historical accounts all the beliefs and prejudices of their time or nation. (Bujic 2006, p. 68)

And as Pohlmann ensures us in the introduction to his DAGM, his collection is "not published with the intention of providing materials for the reconstruction of the sound of ancient music" (1970, p. i). We cannot revive entire civilizations, and thus must let the ideal of the archive die in some sense with the phantasm of a past that stays with us only through lingering lights and flickers, a few notes. So frustrating, though, that we know we must have so much in common with those specters singing beside us.

Our anxiety over our music is not unique. The Hornsleth Deep Storage Project is such an example of a general or universal archive that hopes to preserve the human species for future generations. Kristian Von Hornsleth, the Danish artist responsible for this intriguing venture, explains the drive behind the pointed, star-shaped sculpture which houses human and animal DNA:

My idea with Deep Storage Project was to create an art project investigating the concept of eternity. One of my first questions to 
myself in the initial phases was, how and why do we humans store our cultural identity in the hope of passing ourselves on to further times? (Hornsleth 2012)

While contemporary work in archive science demonstrates that we must be mindful of the ideological sway of the archivist, Hornsleth conjectures that "maybe the genes of art lovers wouldn't be the worst building material for a new human race" (2012). We must be highly critical of this position. Though I find the desire to preserve humankind in some capacity rather hubristic but quite admirable, we must understand that no full truths or whole kernels survive time and always pass. The archive is not a lie, but it is an illusion built to satisfy.

Hornsleth continues to describe the rational behind his alluring and enigmatic, albeit problematic, Deep Storage Project:

Think about the cavepaintings, the pyramids, and all the other great voices from the past, why was it so important for them to save and secure their cultural identity? Was it mere vanity or maybe a survival instinct related to evolutionary psychology? Will we have problems with saving the human race as such? Who will be here in 30.000 years to read our signals and we enjoy the signals from former times? (2012)

Any archivist must seriously ask a similar question: why are we driven to store, to preserve, to catalog and save? Yet, we cannot be so certain that remembrance after-theevent-of-catastrophe were the driving goals behind "cavepaintings" and "pyramids" (or, for example, our remaining sixty-one fragments of Greek musical notation). But can we say they are simply the accidents of culture? Does every civilization expect to 
live forever, or do we only now understand the ghosts and tombs we will leave after death for others to stumble upon? Is there not some strange deviation from history in this desire to protect ourselves from global catastrophe? For, to attempt to archive our civilization is to recognize that we are not only mortal as individuals, but that we are mortal as a multitude. In the humbling words of Carl Sagan, on our "mote of dust suspended in a sunbeam," that is, our astronomically insignificant planet, can continue onward without us (1997). This is, perhaps, the great philosophical and political divide of the techno-optimists and the radical ecologists: there is a rough intellectual circle who believe we can control the earth and a rough intellectual circle who argue that we are subservient to the earth. This debate is not irrelevant but it is dismissible. For, we are the progenitors of our own demise. And we know it.

There is a growing cultural consciousness; it is exemplified at its extreme by the ridiculous Roland Emmerich film 2012 which feeds our fascination with apocalypse, as if to alleviate that very guilt which we feel by externalizing it to a mis-reading of an ancient Mayan astronomical calendar that is then hogwashed into 'prophecy' and mutated into a feature length abomination of virtually rendered explosions and metropolitan flood and fire (2009). We are as afraid of natural disaster as our ancients, who ascribed these phenomenae to disgruntled gods and goddesses. We know no better if we do not take these signs into our responsibility and, rather than resort to mere archivization, allow our archives to become centers of public knowledge in temporal spaces. We must accept our mortality and the feeble, transient nature of paper and circuitry. Roots and wires. 
Derrida, in his Archive Fever, unburies the Freudian notion of the ghost and how the specter is involved in the "carrying of truth" (Derrida 1998, p. 86-7). The archive is a haunted place, where dead voices still sing. And with the advent of musical recording technology — and now its widespread use and relative inexpensiveness in the United States and throughout much of the world-we haunt ourselves daily. Each musical act recorded is in itself an archive: carrying not only truths but ideologies. Carrying not only ideologies but human breath. But perhaps there needn't be a biological death for our music to haunt us. The very act of recording is to reify a ghost, and allow a secular spirit to leave the body. Perhaps, we can follow this further and attest that every performance is, every communicative act is, at once, both the taking and giving of life. The notes come together to form the ghost, which relay back to us the sea-salt and rosebuds. History, then, is our greatest ghost. To construct an archive is to build a haunting ground for dead voices, and we are born, not always already interpolated-we think in ways with Althusser, here-but always already in the presence of specters. This, in turn, allows us to wonder what ghosts we will leave behind.

Foucault, in his "Of Other Spaces," criticizes the "general archive" (Foucault 1986, p. 26). For Foucault, these attempts we have made to catalog and archive the entirety of humanity — all our arts and letters and science and history—is characteristic of modernity. Yet, the great museum of Alexandria made similar attempts to store all the world's knowledge in a physical location, on a single substrate. What ghost will this give breath to? And in what many have deemed the postmodern era-though I have never been comfortable with this designation, so we might refute it later-we still have made such attempts at universal archivization. The Voyager Golden Records, 
phonograph records which were launched with the Voyager space probe in 1977, were inscribed with sound and images to demonstrate a representative picture of life on our planet. Though the possibility of a distant civilization coming across the Golden Records is incredibly unlikely, this was known by its designers, as it's known by us. This interesting example of archive-as-communicative-device demonstrates, I believe, a counter-argument to Derrida's rendering of the archive as that which must be situated on a permanent and singular substrate (1998, p. 13). It is also telling of our coming-toterms with our potential mortality as a global civilization. Due, perhaps, to the manifold, latent leftovers of a global economy and communication technology, we are ever-more tied to the fates of others, to all of us. As we become more interconnected we become more anxious, and more involved in pending global catastrophe. The reality of the smallness of the world becomes apparent, and the fragility of our global civilization.

There might be something distinctly anti-postmodern about Lorene Scafaria's Seeking a Friend for the End of the World (2012). It is not depicted as a farcical account of some great imaginative scenario. A man hears on his radio that the last attempt of the astronauts to save the planet from a giant asteroid named "Matilda" has failed: their shuttle has exploded, and society unravels in contemplative and at times, even selfreflective dignity. Keira Knightley finds love in Carrel, and the film ends with a bright, unbearable light flashing-as to signify the end of all the world, of course it would be two explosions followed by a bright, white light—while the man and woman stare in each others' eyes and speak of their inner peace, how it will be okay. This is a topic for anti-postmodernity: how does the human function in the wake of global apocalypse? 
This film is classified by IMBD as a "Romance/Sci-Fi/Drama," while it features prominent comedic actor Steve Carell in the primary role of the male protagonist. What does this juxtaposition of the seriousness of the end of the world with a comedian acting in a dramatic position have to say about our current cultural climate? Nothing, because this would be a misreading. Rather, Carell here churns reality from comedy; he makes the transition into post-postmodernism by throwing out the joke and waking up from the pervasive illusion that was Finnigan and drugs and Courtney Love. This bridging from the comedic to the actual, to the reification of our fears and the facing of them with self-discovered truth and meaning: this is the generative essence of what I understand as the anti-postmodern. And certainly it needs a name that is not less critical but more explanatory. We will return to the naming of names in another time, on another page, or another space.

The possibility of apocalypse is part of our everyday consciousness and appears throughout our Western popular culture: film, literature, and video games (Bethesda's popular Fallout series among others). Though there has been, throughout human history, various end-of-the-world tales, and the anxiety of the nuclear age was absolute and real, it seems we have in some sense accepted our own individual mortality through sensing the fragility of civilization as a whole. We have found ourselves through finding each other. Rather than scare ourselves with the tremors of mythological eschatology, we might consider what ghosts we will leave behind, whether we are in our last days or whether we will colonize other worlds over vast expanses of space. If the obvious isn't already implied: we cannot "make guilty our disasters the sun, the moon, and the stars," we must make guilty ourselves. 


\section{That Which Is Not Seen}

From ancient Greek musical notation to the present binary codification of music and its travels through virtual space, we have for millennia been attempting to keep still our songs: to quiet them on paper, to house them in archives, to save them as files. And this recent change to the music commodity as a digital entity is beginning to have significant effects on the music industry. The state of the desire for digital music at present times can superficially be understood through industry reports. We must start here to grasp a picture of market trends and to see where the digital music commodity is headed, and what it means to have our music wrapped into the digitalpolitical economy of music. From the International Federation of the Phonographic Industry, we have the following account:

Growing digital revenues were the driving force behind the industry's positive result in 2012. Digital revenues increased by 8 per cent to US $\$ 5.8$ billion. There was continued expansion of the download model, acceleration in the take-up of subscription services, better monetisation around music videos and growth in digital radio audiences.

More than 20 million people paid for music subscription services in 2012, an increase of 44 percent on 2011. Meanwhile, download sales continued to grow in 2012, increasing by 12 per cent to 4.3 billion units globally (combining digital singles and albums). 
Although the industry is less reliant on income from physical format sales, with their share declining from 61 per cent in 2011 to 57 per cent In 2012, they still account for the majority of industry revenues. (2014) Subscription services, independent services for artists like BandCamp: what does the increase in digital music consumption mean for us? In his Essays on Political Economy, Frederic Bastiat told writes that an "act" within "the economic sphere" has a "series of effects": in which "it is seen" and in which the effects "are not seen" (Bastiat 1848, p. 6). He writes that it is the "bad economist" who "confines himself to the visible effect," and indeed, we must try to look for this effects which might be "foreseen" (Bastiat 1848, p. 6). Mirroring, to some extent, Attali's argument regarding the prophetic significance of music, we might learn here to think about the potentialities-both the helpful and harmful - that have arisen from the shift to the digital-political economy of music, the digitization of sound, and the methods through which we now most commonly access our music. With projected—-though seldom doubted—growth rates for the digital sector of the music industry, and the coupling of physical sales with digital downloads, we should be wary of what the digital-political economy of music means for the listener. And it is hardly right to think of digital music sales as being in any way sectored off from physical sales_-for, we so often come to first contact with song through the digital interface, or as a result of its digitization and its sharing through social media. And, music has been for some time subsumed in advertising, and indeed the careers of many artists have been launched and supported by television commercial royalties: the group Freelance Whales found further network television support after their song "Generator ^ First Floor" was used by Chevrolet in a 2011 television 
advertisement for the Chevy Volt. Though music is so often seen as an add-on in advertisement—a secondary feature-it sells itself through its attachment to other commodities: in this case, an automobile.

Andre Nusselder, in Interface Fantasy: A Lacanian Cyborg Ontology, identifies three fundamental domains of the world following the "digital revolution": there is 1) the "matrix," the sort of invisible dimension of "zeros and ones" in which "codified objects" reside and exist as signals which are imperceptible to us, 2) the "mental space of the conceptualization or representation of code objects," the mind's rendering of the information we receive, the experience of the "codified objects" themselves, and 3) the "interface," the "crucial medium" of these objects which acts as the "gate leading humans into cyberspace" while ultimately "still separating us from it [the matrix] as a whole" and "thereby preventing the psychotic realization of desire" (Nusselder 2009, p. 4). This matrix, what Nusselder also conflates to "cyberspace," can be seen as an extension of the base-superstructure model (2009, p. 11). In the same sense in which the political economy of music, for Attali, shows "the possibility of a superstructure to anticipate historical developments," so too might we look to music in the digital age as a way to read potentialities_ of both the "dystopic" and "utopic" variety, as well as all and whatever may rest between—in such a light (Jameson 2009, p. xi-xii). The phantasmic character of the digital music commodity — seen in its codification, its immediate invisibility, its quick and ceaseless reproduction through replication, its shape-shifting reification through the interface-is not unlike Derrida's figure of the phantom. But this does not entail that we should adopt a superstition and fear the ghosts that haunt us, but rather that we should adopt a critical lens with which we view 
the changing scope and nature of the creation and distribution of digital music, in all its manifestations. Though Attali was writing at the beginning of the widespread adoption of computer technologies in the domestic sphere, he notes that the proliferation of music in society is a relatively recent occurrence:

Among sounds, music as autonomous production is a recent invention. Even as late as the eighteenth century, it was effectively submerged within a larger totality. Ambiguous and fragile, ostensibly secondary and of minor importance, it has invaded our world and daily life. Today, it is unavoidable, as if, in a world now devoid of meaning, a background noise were increasingly necessary to give people a sense of security. And today, wherever there is music, there is money. Looking only at the numbers, in certain countries more money is spent on music than on reading, drinking, or keeping clean. Music, an immaterial pleasure turned commodity, now heralds a society of the sign, of the immaterial up for sale, of the social relation unified in money. (Attali 2009, p. 3-4)

The immaterial pleasure is turned into the material commodity, and so "heralds a society of the sign," of the "immaterial up for sale" (Attali 2009). And yet, our digital music retains immaterial properties itself, and so we are faced with a sort of paradox, of the immaterial pleasure turned immaterial. In such, we further that distance between understanding the conditions of labor under which the commodity is produced and so further distance our understanding of music. In the following chapter, I discuss the violence of sound. From the material and immaterial properties of the digital music commodity and the way it moves itself, we turn to look to the way that music in the 
ideologies it carries moves us politically_ through the immediate, subjective violence of musical torture to the role of silence in the suppression of the political protest. 


\section{Chapter 4}

\section{The Violence of Sound}

Music is not ideology pure and simple...

-Frederic Jameson

\section{Sonic Bullets and Objective Violence}

Those aforementioned classical attitudes toward music — such as those by Plato and Aristotle - in which music is described as that which moves men to virtue through instructing them how to experience emotions properly, and perhaps even to truth, are complicated by the widespread distribution of music and its many forms. This merely emotional dimension of music has carried through into contemporary conceptions of music as that which incites in us particular emotional reactions-similar to that Grecian notion of music imitating the emotions - or that which allows us to experience new palettes and dimensions of subjective psychological experience: music as transcendence or music for escapism. Yet, music also moves us physically_in simple and complex choreography, but also in organized revolt, in the march of the drum, in the formation and dispension of the political protest. This chapter seeks to expand our understanding of music beyond the emotions by demonstrating the subjective and objective properties of violence as it is demonstrated through music. In this coupling of rhetoric and music, one such approach to build on our understanding of the argumentative 
power of music is to understand its political and ideological implications and applications. In this chapter I will explore how government-sanctioned violence through the use of sound has been legitimated and challenged. The extraordinary persuasive power of sound and music has been appropriated by military and police forces to attack those deemed as enemies as well as to subdue protest and quell urban riots. I will explore issues in sovereignty through Carl Schmitt and Agambensovereignty as I see it here, as a suspension of law, as a decision on an exception of when sound transverses from the aesthetic to the violent-and the rhetoric of music and see how this relates to contemporary understandings of subjective and objective violence in Žižek (2008). The goal, in this chapter, is to examine how sound functions in these spaces, and especially spaces of torture: who is the sonically tortured subject? And, then, who is the musician-citizen, who through the independent production of music in opposition to the music-industrial-complex is able to resist the objective violence of music and make songs anew? In this chapter I aim to shed light on how music is being used in acts of violence and to better understand the ways in which the power of sound is both misused and misunderstood. I ask: what are the forms in which sound and music are appropriated by violent activities: in both subjective and objective violence? How can this help us build up a framework for understanding the contemporary relationship between rhetoric and music-to understand how music works persuasively_ by moving to a profound understanding of musical influence, beyond the apparent emotional surface?

An ABC News article by Judy Muller from July 16" ${ }^{\text {th }}$,2012, titled “Sonic Bullets to Be Acoustic Weapon of the Future" describes new developments by the American 
Technology Corporation in "ultrasound technology": they have "developed a nonlethal acoustic weapon that stops people in their tracks." Muller describes that the device projects "sonic bullets along a narrow, intense beam up to 145 decibels, 50 times the human threshold of pain" (2012). This device is operated by a computer, on which an "annoying sound" is picked—-such as the sound of a baby crying—and then is played backward and amplified (2012). The United States army plans to adopt this technology for use in Afghanistan in the form of a handheld model and a mounted model for armored vehicles. The use of sound to induce and facilitate violence is not a new phenomenon. The roar of a tiger has been studied by Elizabeth von Muggenthaler, who explored how the infrasound produced by a tiger- that is, sound produced and projected at frequencies that are lower than the $20 \mathrm{hz}$ bottom range of human hearing — can be used to quite literally freeze small prey (2000). Infrasound travels farther and more easily permeates dense environments because of the naturally longer waveform of lower frequencies.

The violence of the sonic bullet technology expands further, however. Muller explains how the ultrasound technologies of American Technology Corporation are being used to persuade consumers toward purchasing commodities:

Not all the applications of this new technology are pain-inducing. Norris has invented a related acoustic device called the Hypersonic Sound System. Only when he turns the speaker in your direction, do you hear the message. For instance, liquid being poured over ice was the sound requested by a soda company to inspire people within earshot of a vending machine to quench their thirst. Norris tried out the 
acoustic beam at a mall near his office and passers-by all stopped to listen when the sound was aimed at them. "That is absolutely amazing," said one woman, "it sounds like the sound is inside your head." (2012) Here we can see how invasive uses of sound enact a different sort of violence. We can turn to Žižek's work on Violence to better understand how systemic violences affect us (2008). Žižek writes that "Objective violence is invisible since it sustains the very zerolevel standard against which we perceive something as subjectively violent" (2008, p. 2). Žižek creates a framework in this work that distinguishes between subjective and objective violence. Subjective violence is an immediate, visible, physical enactment of violence. Yet, Žižek is more concerned with the underlying, systemic violence. This objective violence establishes the "zero-level" of normality from which subjective violence is determined in a sort of relativistic relationship (2008, p. 2). I am particularly interested in Žižek's rendering of Heidegger, here, in thinking about a symbolic violence that is "embodied in language and its forms" (2008, p. 1). Heidegger, in his "Letter on Humanism," describes how in language, in the very formulation of "grammar" and syntax there is a sort of ready-made metaphysics (1947). This metaphysics of presence holds a presupposition of reality. This seems closely related to Žižek's notion of ideology and his reading of Althusser's interpellation, in that there are predetermined forms and orders that impose upon us and enact a sort of violence upon us systemically. ${ }^{13}$ Ultimately, we must "resist the fascination" with subjective

\footnotetext{
${ }^{13}$ The notion of interpellation is significant for understanding how we are addressed by ideology in music and how the subject is constituted by ready-made meanings in music. We are faced with, in the musical-industrial society, sorts of music which are pre-
} 
violence and come to understand objective violence (2008, p. 11). How does music work to contribute to an objective violence?

This is, of course, a difficult question. However, we can start with something like the notion of noise-especially something like the notion of noise pollution in an urban environment. We can recall our discussion of the limited nature of the soundscape from Chapter 1. Here, we are faced with a sort of zero level of violent noise even in the given soundscape of the urban subject's life. Beyond this, there is the pervasive inclusion of the radio in every automobile and the broadcasting of radio waves throughout society: the normalization of noise. The advertising jingle that we “can't get out of our heads." These are simple examples of how the objective violence of the greater structures of capitalism have normalized violent and invasive sonic realities into everyday life. And, as in the above example by Muller's interviewee, with advanced sound technologies being targeted at individuals, the song goes from being "stuck in the head" to quite literally having the song incorporated into the living experience: "it sounds like the sound is inside your head" (2012). More can be said about how violent sonic scapes become ideological and thus utilized by an objective violence-not that we can say that there is a singular architect who is orchestrating this objective violence, but perhaps we can say that it is the product of a pervasive capitalism. We live in spaces which are expected to be always sounding, and take silence as an absence of some normalized level. Here we have a conundrum, for we

existing and "hail" us as a mechanism of appropriating the subject into the dominant ideology. Yet, if we come to understand the persuasive power of music and its political gravity, we can better understand how it attempts to interpellate the subject and be critical and mindful of its uses. 
wish for silence to better engage in self-reflection, to separate ourselves from the dominant structures and to attempt to reclaim some semblance of self, and yet we also seek a new silence within which we can compose for ourselves the sounds of our lives. Yet, it is not impossible to compose anew from the given backdrop.

Perhaps we can better begin to understand this rendering of objective violence through an analysis of instances of subjective violence. How does sound appear in instances of subjective, observable, immediate violence, and how do they relate to the normalization of violent sounds? Clive Stafford Smith wrote a 2008 article for The Guardian about the use of music in torture at Guantanamo Bay:

Binyam Mohamed, the British resident who is still held in Guantánamo Bay, knows a bit about such torture. The CIA rendered him to Morocco, where his torturers repeatedly took a razor blade to his penis throughout an 18-month ordeal.

When I later sat across from him in the cell, he described how psyops methods were worse than this. He could anticipate physical pain, he said, and know that it would eventually end. But the experience of slipping into madness as a result of torture by music was something quite different. (2008)

Another account, relayed by Andy Worthington in his "A History of Music Torture in the War on Terror" tells a similar story:

Describing how he experienced music torture "on many occasions," Ahmed said, "I can bear being beaten up, it's not a problem. Once you 
accept that you're going to go into the interrogation room and be beaten up, it's fine. You can prepare yourself mentally. But when you're being psychologically tortured, you can't." He added, however, that when music was introduced, at the end of 2003, "It makes you feel like you are going mad. You lose the plot and it's very scary to think that you might go crazy because of all the music, because of the loud noise, and because after a while you don't hear the lyrics at all, all you hear is heavy banging." (2008)

There might be a strange phenomenological area we could discuss, here. The experience becomes unbearable when the music is no longer recognized as music by the mind or the body or the collaborative listening of the two-if even want to bother with a mind-body distinction at all. What I mean to say is that we seem to place forms on the experiences that we encounter, such as with the stringing together of what are altogether separate, individual notes into a complete melody. In both experiences, the stripping away of the meaning through intense repetition and amplification leads to an incredibly violent and disturbing experience of hearing only "heavy banging" and no longer recognizing that this is music at all. And perhaps it is not music to begin with, for those being tortured. Western rock, heavy metal, and rap music is often used in music torture, which are forms that are already unfamiliar to many detainees.

This sort of music torture is not new to American tactics. Worthington assess a report by the Senate Armed Services Committee that looked into the torture and breaking techniques that have been employed during the War on Terror, which seems 
to place their origin—or at least inspiration—in Chinese Communist techniques "used during the Korean War":

During the resistance phase of SERE training, U.S. military personnel are exposed to physical and psychological pressures ... designed to simulate conditions to which they might be subject if taken prisoner by enemies that did not abide by the Geneva Conventions. As one ... instructor explained, SERE training is "based on illegal exploitation (under the rules listed in the 1949 Geneva Convention Relative to the Treatment of Prisoners of War) of prisoners over the last 50 years." The techniques used in SERE school, based, in part, on Chinese Communist techniques used during the Korean war to elicit false confessions, include stripping detainees of their clothing, placing them in stress positions, putting hoods over their heads, disrupting their sleep, treating them like animals, subjecting them to loud music and flashing lights, and exposing them to extreme temperatures. It can also include face and body slaps, and until recently, for some who attended the Navy's SERE school, it included waterboarding. (2010)

The efficacy of these techniques is thus under question. Prisoners from these torture and detention facilities describe hearing the screams of fellow torturees and the sound of banging their heads on the wall. The use of music torture, Worthington describes, was also used in simultaneity with visual sensory deprivation in dark prisons which were said to have resembled Medieval torture chambers. Chained to the wall, forced to listen to blaring rock and rap music for sometimes weeks or longer with no stop-not 
even to sleep-Mohammed and Vance, two former captives, describe how they were not even able to form thoughts. This sort of subjective violence becomes an objective violence. Music is at times employed biopolitically and most often without our knowing, beyond the torture chamber. We too are often subjected to a sort of cultural infection that is produced in the music-industrial-complex in the form of the pop song or even in the national anthem. I do not mean to downplay the extraordinary suffering that was endured and is still being endured by so many detainees, but the message here is strong. The violence of music in these instances steals minds and destroys identities.

Baudelaire writes in the preface to his Flowers of Evil: "How can poetry become music through prosody whose roots dig farther into the human soul than any classical theory might claim?” (2008).

\section{Who Orchestrates Musical Torture?}

Who is the sovereign who decides when sound can be used as torture, and, at times, are we ourselves to blame for the violences of sounds? For Carl Schmitt, the sovereign is he who decides on the exception: "He decides whether there is an extreme emergency as well as what must be done to eliminate it" (2005, p. 7). What is the emergency which warrants a state-sanctioned use of musical torture? The War on Terror seems to be one of retribution veiled as an attempt to extract what could be deemed as critical information about the enemy from detainees. But as we have already discussed above, the use of music torture works more as a means of psychological debilitation than one of extraction. Madness does not produce clarity nor cooperation 
in the instances that we have seen. However, without more information about the success of these methods of tortures, we cannot be sure. This is not to say that we should condone such methods even if they are proven to produce situations in which critical information or information that concerns "national security" appears. This controversial notion of national security often employed by state powers to defend acts of torture might be further analyzed. We can even return to the Hobbesian notion of security. The violence of torture is normalized in public discourse because of this play on the idea of security: Chapter 17 of Leviathan begins by attempting to define the nature of man—his "final cause" and "design"—which he argues is centered around "preservation" (1962, p. 129). We can return again to the figure of the sovereign in Hobbes: In order for humankind to find "security," men must: confer all their power and strength upon one man, or upon one assembly of men, that may reduce all their wills, by plurality of voices, unto one will... and therein submit their wills, every one to his will, and their judgments, to his judgment. (1962, p. 132)

The spectral figure of the terrorist—especially in a post-9/11 America-has allowed our submission to the deciders of unjust practices — such as musical torture-in military and government positions. For Judith Butler, this is where sovereignty reappears-for her, traditional sovereignty has all but vanished-in contemporary political fields: in the bureaucracy of the military. In this paradigm, and in the example of indefinite detention she provides, we see that decisions are made by "governmental bureaucrat[s]" rather than legitimate, accountable individuals or elected officials. Sovereign power finds itself in the hands of "managerial officials with no clear claim to 
legitimacy" (2006, p. 54). We can think of this in biopolitical terms. We may even wonder how this new form of control might appear in new contexts. In the new literary trope of The Matrix, there is complete biopolitical control as the body is plugged into a sort of virtual environment. This is perhaps the greatest enactment of ideology, where the present conditions are so veiled they are not present at all: an absolute false consciousness. Yet, we are already enacting and enabling this sort of psychological torture in the War on Terror through musical means: these prisoners describe in their experience of music torture the inability to think, to sleep, to live. It is quite like Agamben's homo sacer in that the prisoner can be murdered without committing homicide. But instead of murder we allow the prisoner to live but only in a state beyond absolute agony, in a state where the self is no longer the self and the sensory experience of the individual is manipulated absolutely and entirely by whoever here wields sovereign power, usually some commanding officer who would issue permission for a torture method.

In responding in a dialogue with Lucien Price who claims that "music is a mathematics of aesthetic," Alfred North Whitehead writes:

I would accept that definition... for I think we take in quite as much through our sense of hearing as by our sense of sight, perhaps more. Mind you, I don't mean to compare our dependency on the two senses, for we are more dependent on sight, since we have mobility. But I think we respond more to a solemn sound, to music, or to a great bell. It establishes the emotion almost instantaneously, and we think about it only later... Your national anthem, which I hear frequently over the 
radio, does not, fortunately, lend itself to being shouted by mobs in unison, but it admirably serves its purpose and, hearing it, I am more moved than I am by the sight of your flag... The point I am making is that, with the sense of sight, the idea communicates the emotion, whereas, with sound, the emotion communicates the idea, which is more direct and therefore more powerful. (2001) Whitehead here understands the extraordinary rhetorical power of music. So, too, did Walter Ong, who writes in his Orality and Literacy about the centering nature of sound: that is, we become ensounded in environments and are always at the origin of our sound-world, whereas with vision we are always dissecting the world around us (2002). This might be a mere biological reality or it might mean something more. Perhaps this absolute centering nature of sound can help explain why musical torture is indeed so effective, because it places the victim in a state of existential crisis as well as immediate, physical pain. Psychological suffering, rather than the gaining of meaningful counterterrorist information, seems to be the sadistic goal of musical torture. Further, the national anthem, as here discussed, is perhaps the most pervasive of all forms of musical violence and an example of how the power of music is employed by states on not just those deemed as the enemy, but also the public. The national anthem gives security and unity to populations - we see similar figures in religious hymns, which are shared experiences of groups, or in folk music of particular localities and regions. The national anthem, however, goes beyond these instances and attempts to unify all citizens into its argument: and it is unpatriotic not to stand and stare at the flag while it is being played, say, even at a small-town sporting event. It is the training of a 
population through song to unquestionably admire and follow the actions of the state, and are we not in some way to blame, that is, the people of a nation, for so eagerly and willingly standing in obedience to the melodies crafted for us? Do we not have the power to write our own anthemic proclamations in search of new liberties and in envisioning new worlds and political realities? In the following section, I hope to look at how this power of music and all its intricacies and capacities for violence are appropriated by revolutionary groups and draw on some conclusions from this analysis.

\section{The Political Spaces of Sound}

Can we re-think the noise-ordinance as a wall, and as a wall-against-revolution? How can we sound out against both these literal and figurative sound-barriers? Leyshon, Matless, and Revill describe in "The Place of Music," through channeling and interpreting works by Lawrence Grossberg and David Harvey, that in geographical studies we must re-think the role of music (1995). The role of ethnomusicology, for example, or of geographers of music, has been to track the "diffusion" of particular styles or genres of music and to think about how they work in various local, regional, and national environments (1995, p. 425). Leyshon et. al suggest, instead that we think re-think space and place not "as sites where or about which music happens to be made, or over which music has diffused, but rather different spatialities are suggested as being formative of the sounding and resounding of music"; they write that this would provide a "richer sense of geography" that could "highlight the spatiality of music and the mutually generative relations of music and place (1995, p. 425). 
Space and place are central to the framework of occupation. Yet, the concrete spaces of modernity — and I intend to mean both the material concrete of urban environments as well as their visually determined concreteness in lines and grids and geometry, the walls of Wendy Brown are perhaps more prevalent than she even construes them in her $W$ alled States, $W$ aning Sovereignty, so much so that every street is a wall, leaving citizens of urban environments in a state of always-being-in-Frogger and so on-these concrete spaces of modernity are ideological constructions and perhaps more liminal than concrete (2010). The Arab Spring might point to how revolutionary movements of the strategy of occupation transcended the borders of the nation state. Though I am not a techno-optimist, and each revolution procured a different style of protest - a different song in each nation being sung — there is a sort of universality here in the movement of occupy, both the inhabiting of a space in its concrete terms in its sort of spatial reality as well as the theory of inhabiting, delimited by territoriality. It is in these very capitalistic spaces of urban environments—-the actual streets of Wall Street and their edifices as well as the "parks," Zuccotti for example, an intended public space—which are reified and dominated by a corporation's independently contracted security guards as much as by the state-sanctioned police force that attempt to subdue protest and feeble but good-willed attempts at occupation. We can return, then, to the role of argumentation via music in movements such as occupy. We might start with examining Slavoj Žižek in his recent declaration that we need a new "Master" of the Left (2013). Žižek's prolific writing and his insistence on veering from linear argument leaves many contradictions in his trajectory as a philosopher and political thinker, which many writers find problematic, the least but most recent reaction of Jereme 
Roos in his attempt at a response to Žižek's "The Simple Courage of a Decision" in the New Statesman (2013). We must be critical of what we can call democraticocentricismthe unquestioned narrative of democracy as the final and complete political realityand the apparent inadequacies of a democracy to preserve fundamental human rights, and often not even a feasible element of human safety. We are more endangered now than ever by international corporate influence and by inflictive ideologies. Such I say knowing well there is the risk of seeming polemical—though not such a folly would that be.

A common criticism of the American Occupy movement is its lack of leadership and centrality, and so might think again about how sovereignty plays a role in revolution. Arendt warns of the dangers and inefficiency of the "professional revolutionist," who does not cause revolution to occur-his or her influence here is almost insignificant - but the professional revolutionist rises to power in the springs of revolution (2003, p. 520-521). Žižek warned at his address to the Occupy Wall Street movement at Liberty Square in NYC that:

The only thing I'm afraid of is that we will someday just go home and then we will meet once a year, drinking beer, and nostalgically remembering "What a nice time we had here." Promise yourselves that this will not be the case. We know that people often desire something but do not really want it. Don't be afraid to really want what you desire. (2012)

Other influential thinkers appeared at American OWS protests, such as Judy Butler, Astra Taylor — who directed a documentary on Žižek and the popular interview-based 
"philosophical" documentary Examined Life (2008)—as well as Taylor's wife, the revered North American folk-rock legend Jeff Mangum, who played songs from the 1998 In the Aeroplane Over the Sea, a concept-album reflecting on the Holocaust. What can we make of this intersection of protest, protest against capitalist practices as well as Capitalism, in defined, concrete spaces? Are we still thinking too often in terms of nonliminal spaces and thus letting sound, which is seldom defined by visual boundaries which we construct — the wall, the street — to be condemned as a power of protest? And who is the sovereign sound-maker in these situations?

We can turn this analysis into the astounding loudness and silence of the American Occupy movement. Because of particular ordinances in New York City, amplification and sound systems were not permitted in public protests. Yet, silence did not prevail. For these aforementioned speeches and performances, a relay system was used by the protestors to repeat back the messages of the orator. This rhetoric of repetition is a strong current of Western communication which can be at least traced to ancient Greece-repetition and parallelism as employable rhetorical structures, as in Phaedrus - yet this is a collective sense of repetition. I am critical, here, still, however, of how the logic of repetition is also a logic of ideology, of recreating rather than critically assessing a message. Still, here it was used as a means of transmitting a message to a gathered crowd, throughout the occupied space. Perhaps there is an objective violence in the logic of repetition, but there is an immediate subjective celebration of repetition when collective voices can be used as a technology of amplification. The speaker pronounces his message and it is echoed by the wave of sometimes thousands of listeners, who, in this instance, also become speakers. 
What can we say of our contemporary folk music and the appearance of Jeff Mangum at the Occupy Wall Street movement and the appearance of reflections from the camp tragedies of 1940s Europe? In returning to Žižek's notion of needing a new "Master" of the Left—a notion also introduced by Lawrence Grossberg, of needing a new "song" for the Left and collectivization-we might be nostalgic about the folk protest songs of the 1960s in the figure of Bob Dylan or return to the Americana of Woody Guthrie to attempt to conceptualize an authentic American folk, but this is problematic. The American folk tradition draws heavily on musical tropes from English folk ballads, and is not in any way an authentic source of protest. But may there have been something that we are now lacking: do we not see our contemporary folk being forced into being only pastoral, a sort of unequivocal praise of nature and the self (as in American Grammy award winners Bon Iver, whose empty, bucolic lyrics and self-deprecation are more whiningly postmodern than revolutionary?), in comparison to something like Pete Seeger's songs of solidarity? Contemporary folk and "country" music is more often an extension for the justification of military violence and thus constitutive of an objective violence through the establishment of an ideology through the industrial-musical-complex. See, here the lyrics from the bridge of "Chicken Fried," from the Zac Brown Band's album Home Grown, 2005:

Salute the ones who died The ones that give their lives So we don't have to sacrifice All the things we love. (2008) 
Is this the far reaches of the right's ideology? Or something more serious? I am skeptical of this left/right traditional political distinction. Is this not the extension of the ideological justification of murder, of the constitution of homo sacer and a veiling of not just the "sacrifice" but also the self-evident murder of military service?

I move on: What would it mean to have a voice for the left? Did Jeff Mangum's appearance at the Occupy Wall Street movement signal some hope for the future of American folk music as a sovereign source of inspiring revolutionary thought and for thinking outside the spaces of capitalism? Is the performer some sort of sovereign, in his ability to decide on the exception, or to at least recognize moments of exception and call public attention to these ruptures? Could the aleatoric moment of musical composition be related to the possibility of revolutionary rupture? Or am I too optimistic?

I'll end, here, with a lyrical analysis from Neutral Milk Hotel's "In the Aereoplane over the Sea," the title-track from their 1998 album:

What a beautiful face I have found in this place That is circling all round the sun And when we meet on a cloud I'll be laughing out loud I'll be laughing with everyone I see I can't believe how strange it is to be anything at all (1998) Is this empty or fruitful? Must we not first break through immediate ideologies and realize the "strange" reality of existence, to begin to question what it means to "be anything at all" before we can protest meaningfully or envision new possibilities beyond the modern nation-state, beyond Hardt and Negri's Empire, beyond Capitalism 
(2001)? Sound is limited by the noise-ordinance: not just the laws of municipalities of the suburban West where tickets are issued after 10pm for excessive noise in a residential neighborhood, but the greater noise ordinances that constitute an objective violence. We are skeptical of sound, of chants of protests. And yet we are also most indoctrinated by the rhetorical power of music such as in the figure of the national anthem. We allow the noise pollution of capitalism in the revving of engines and clicking clacks of trains which transport workers and citizens, yet we do not allow the noise of protest and of revolution. There are some private revolutions occurring, digitally. The Occupy Wall Street protest speeches by Žižek, Butler, and the performances of Mangum were not allowed-to-be-amplified for the public to hear, though we readily broadcast into our private homes the television and radio waves of the music-industrial-complex: here lies so much more to be analyzed and much of further research. But where these public protests were silenced, they were also repeated not just in the immediate echoing of the audience but in the echoing of sharing in digital spaces. How else would a sixth-generation Upper Peninsula native as the author be able to watch and listen to this movement? The Logic of Occupy perhaps did not rely enough on this idea of sound as a possibility for transcending immediate geographical spatialities. Where do these sounds come from? Perhaps in the sovereign composer, the orator: but we need responsive and responsible orators, a new configuration of the sovereign as those for us to echo and to whom we can respond. 


\section{Ode to Whom?}

In understanding the particular political gravity of music, we must wonder where the process of musical composition is then situated. Susan McClary ties notions of the objective violence of music and its ideological stakes neatly back into musical invention, recitation, and composition, in her video lecture "On Why Cultural Context Matters to Understanding the Music You Play":

So many of the things that otherwise just pass as playing the notes on the page, just a mechanical exercise, how to execute those, how to make sure you're playing in tune - sometimes that is what musicians think their task is: don't make mistakes, make it as beautiful as possible. When you understand the context within which the music was composed - the aesthetic priorities, the sorts of, even, cultural tensions that are articulated in the music, the ability to perform, I think, rises exponentially. To take something like Beethoven's $9^{\text {th }}$ Symphony, for instance, we're very accustomed to thinking of the last movement as the "Ode to Joy." There is a hymn that many people sing in church services, in English, that just has the tune. And the use of the $9^{\text {th }}$ symphony, politically, for purposes of celebration, such as the fall of the Berlin wall, has made people hear that piece in exclusively celebratory terms. Now, in order to hear it that way, you have to ignore a lot of the things that made that piece so difficult to play when it was first performed. It was regarded even as unperformable for quite a long time 
after the premiere. And it was thought to be that way not just because of the enormous performing forces that it takes, but also because of the ruptures that take place, because of the really shocking events. (2010)

Such is why I began this chapter with an epigraph from Frederic Jameson, which reads "Music is not ideology pure and simple..." (2009). We cannot simply say that music functions in the ideological realm and thus should be avoided or immediately criticized. Music is pervasive and takes on endless forms, and in the digital age it is presented to us across media. Music, too, is so often reappropriated, that we must be willing to examine its various levels of functioning. We can relate this to the ground covered in Chapter 2 in the sense of musical invention_of the indeterminancy of "finding" inspiration, in understanding that musical invention occurs from our interactions with the materiality of sound and the world. Susan McClary here understands that musical composition arises from particular tensions in social, cultural, and political situations, and it is in these situations that a composition arises. McClary continues:

....I sometimes tell my students who want there to be a single right way of performing a piece of classical music that that is probably the wrong question. There have been hundreds, thousands of productions of Hamlet, each one with a completely different take on that very, very complex text. Each one imagining a different motivation for Hamlet, a different motivation for Ophelia, and we go to see productions of Hamlet not because it will duplicate the one that Laurence Olivier did on film, but because it will give us new insights, because it will cause us to see not only Hamlet differently, but will allow us to experience our 
own lives in a different way. And that's what the performance of a great piece of classical music ought to do, also. That's why I think that we have to think about what is being said, what is the nature of the meaning of these pieces, and how is that meaning being articulated in the very smallest details of articulation, of bowing, of dynamic marks, or anything else, I think all of these things must be brought together. (2010)

For McClary, a musical text is tied into the social, cultural, and political pressures which formulated the exigency out of which it arose. And for McClary, the reconstruction of the musical reality from notation must be done with a close reading, to think about the initial purpose of the piece, and to think about its current positioning in new political realities. To extend this to the music commodity, we recall in Attali that "music is not innocent: unquantifiable and unproductive, a pure sign that is now for sale, it provides a rough sketch of the society under construction, a society in which the informal is mass produced and consumed, in which difference is artificially recreated in the multiplication of semi-identical objects" (Attali 2009, p. 5). As we have herein seen, music is certainly not innocent, nor are we who use music for the purpose of subject violence in torture, or even in the subjective violence of instances of Muzak. Tied into these subjective acts of violence, however, is an objective violence. The subsumption of musical culture into the music-industrial-complex and the facilitation of this through the digital-political economy of music should leave us to be even more aware of the argumentative power that music holds on us, its ideological lurkings. We must perk our ears to these sonic workings. 


\title{
Chapter 5
}

\section{The Significant Function of Music}

\author{
At first there's hardly anything, and then nothing. \\ Then some more, and then nothing again. \\ And then in the end there's just an inferno. \\ -Marten Hagstrom ${ }^{14}$
}

\section{Beyond "Figures of Rhetoric"}

Joddy Murray, in his Non-Discursive Rhetoric: Image and Affect in Multimodal Composition, writes that "By considering non-discursive texts, all possibilities of symbolization become tools for the rhetor: the symbols of math, music, textiles, food, poetry, commerce, violence, inaction, and even silence” (2009, p. 12). Further, for Murray, "human social life depends on our ability to use various symbol systems to communicate meanings to one another" (2009, p. 191) The question therein turns to whether we best understand music as a symbolic system, or whether it might be a reduction to think of music in terms of Sausserian semiotics. And the posing of this question leads us to the driving question of this section, which is to wonder what currently sits on our knotted and tangled pile of ropes at these particular cross sections of human interest: what is the current state of scholarship regarding rhetoric and

${ }^{14}$ From the documentary Konstrukting the Koloss, by Anders Bjorler and Owe Lingvall, 2012. 
music? Stedman, in Musical Rhetoric and Sonic Composing Processes, has situated a "musical rhetoric" in the framework of Aristotle's five canons-Invention, Arrangement, Style, Memory, Delivery_though I find this limiting and limited in scope (2012). We see certain pitfalls in the attempt of a direct application of this framework to the prerecorded, discrete digital music commodity. So we must ask: should a rhetoric of music account for both performative aspects of music, as Stedman addressed—such as with "Memory," where Stedman considers the musical performer's adhering to the written transcription of music or "Delivery" where improvisation is considered, but might not this be as easily fitted into the canon of "Style"? — as well as the recorded music?

$$
\text { Quintilian, in Ch. X of Book One, "Education of an Orator" in his Institutes of }
$$
Oratory, writes:

Music, however, by means of the tone and modulation of the voice, expresses sublime thoughts with grandeur, pleasant ones with sweetness, and ordinary ones with calmness, and sympathises in its whole art with the feelings attendant on what is expressed. 25. In oratory, accordingly, the raising, lowering, or other inflexion of the voice, tends to move the feelings of the hearers; and we try to excite the indignation of the judges in one modulation of phrase and voice, (that I may again use the same term,) and their pity in another; for we see that minds are affected in different ways even by musical instruments, though no words cannot be uttered by them. (Watson 2006, p. 82-3) 
Through Quintilian, we return to the problem of Murray: do we take music to be something of Quintilian's rendering: that there are no words that music cannot express, that "no words cannot be uttered" by "musical instruments" (Watson 2006, p. 83)? Brian Vickers, in his "Figures of rhetoric/Figures of music?" asks: "how far can the terms of rhetoric be applied directly to music? How far can one aesthetic system, a linguistic one, be adapted to another, non-linguistic?” (1984, p. 2). Vickers answers himself: "It is surely in the nature of things that we can describe one art in the language of another only up to a point" (1984, p. 18). And Roland Barthes tells us, too: "No doubt the moment we turn an art into a subject (for an article, for a conversation) there is nothing left but to give it predicates; in the case of music, however, such predication unfailingly takes the most facile and trivial form, that of the epithet" in his Image, Music, Text (Barthes 1978, p.179). In other words, to speak of music, to offer critique of music, is, for Barthes, to reduce it to the level of the adjective. This conflagration of language and music was seen especially in the Renaissance treatises which attempted to identify and apply "specific musical-rhetorical figures," beginning with Joachim Burmeister in 1599, up to Unger, who gave "tables listening up to 163 figures of rhetoric, or music, or both" (Vickers 1984, p. 21). It seems to me, too, that it is quite simple to attempt to create parallels between common rhetorical figures and particular tropes in musical composition: we see anaphora-the repetition of a sequence of words in neighboring clauses: "We seek in our minds the truth. We seek in our hearts the everlasting!"- - both in the lyrical content of songs as well as in the repetition of melodic phrases beginning with parallel structures and concluding with variation: 


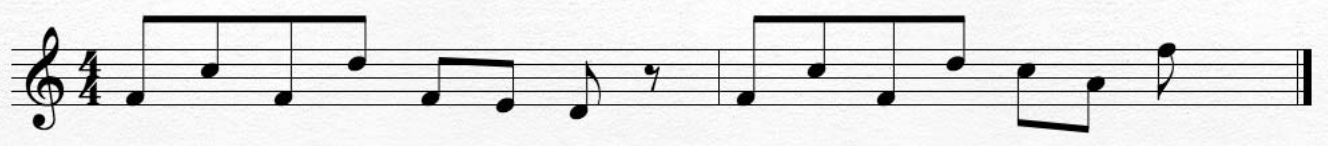

Figure 6.1: Simple illustration of the application of the rhetorical device of anaphora to musical composition. The first four eighth notes of each measure are the same, both in their discrete notes, in their rhythm, and key. If, in this case, we equate each measure to a sentence-and we can even call the eighth note rest at the end of each measure a sort of "punctuation," much like the orator pauses in his speech to create a sense of suspense, or gravity - we can see how this common trope of a variation on a melody looks similar to the syntactic construction of anaphora.

However, we must ask: what is the significance of this? What does this actually help us understand? We can reverse, in part, the above structure and see how we can just as easily say it resembles epistrophe, or the repetition of a sequence of words at the end of neighboring clauses, or in this case the repetition of a sequence of notes at the end of neighboring measures: 


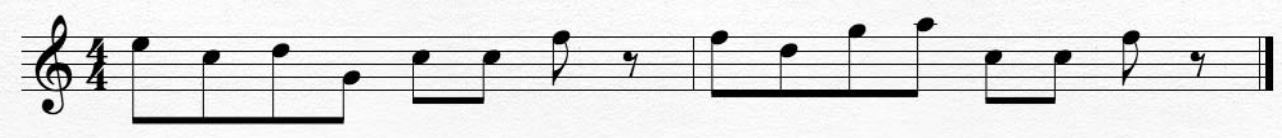

Figure 6.2: Here we see a repetition in the second half of the measure with variation in the first half. Such a model might be said to imitate epistrophe. As Vickers writes: "To modern students, even well-informed historians of rhetoric, the doctrine of the figures can seem incomprehensible, tedious, distasteful" (20). I suspect, too, to most composers, such direct applications between rhetorical figures and musical figures is largely unhelpful either in the composition or the analysis of music. Certain tropes exist in musical composition as in rhetorical composition, and there is something to be said about this. The relationship between repetition and memory, for example, is important: we repeat phrases and vary phrases to remind listeners of what ground has already been covered, what turns and twists a piece has taken. But what should be of concern to us is why these tropes function to incite affect, to stir the reader or listener, across both written and musical composition.

We return to our initial question of whether we should regard music as a sort of signal system in which particular arrangements of sounds-whether in figure, form, timbre, pitch, or otherwise_-signify particular meanings. We must rephrase our question, here. For, music has a certain syntactical system, although there are variations from it and outliers from the apparent rules. But we know that certain musical-syntactical structures — that is, certain arrangements of certain notes in a certain order-often have 
a particular emotional response for the listener, or at least cue certain learned responses from our cultural saturation. The question of whether music is a semantic system, one imbued with meanings, is easily answered with a "yes": we regard music as one of the most meaningful of our art forms. But the question on these hands formulates itself as such: from where is the meaning in music derived? Is it chiefly derived in the arrangement of units, as is language? And here we must answer no, and here is where the direct application of rhetorical figures to music falls apart, and why it must fall apart, for it is not helpful to a musical-rhetorical framework. Words of course are slippery, too, and we change their meanings with and in different contexts—but we allow for certain, more or less, accepted denotations. Music lacks a broad denotative structurewe have only a handful of learned, cultural reactions to music which might be predictive of our response.

In figure 6.3, below, I have composed a very bare, monodic arrangement in Am for voice and accompaniment. The top staff represents the vocal melody and the bottom staff is made up of whole note cords, held for four counts each. This fundamental structure is representative of the skeleton underneath most of Western contemporary pop music as well as other genres: folk, rock, country, even metal and punk. The primary variations between these genres as we now know them tend to manifest in vocal timbre-metal "growls" or country "twang" — and in the instruments and signal processing used, as well as varying percussive styles. But what we see across these genres, typically, is chordal accompaniment to the voice, which sings lyrical lines, typically in Verse-Chorus-Verse-Chorus-Bridge-Chorus fashion, wherein the voice carries the dominant melody and is mixed more loudly than the accompaniment. I have 
provided what would account for a bit of a verse in this figure. We would then likely see a switch to the relative major, in this case $C$, for an uplifting chorus with long, drawn out notes and a reassuring change of melody. If we are lucky the chorus will follow thematically from the verse, but often we are left with a perplexing non-sequitor: listen to "Rule the World" by the popular UK group Take That, for an example. Something about astral phenomenonae and human love in the verse, and then taking over control of the entire human population in the chorus. Well, perhaps I just don't "get it," as is said. Yet, the monodic arrangement is so prevalent in Western music for many reasons that we can guess at. Firstly, it takes little effort to compose such an arrangement: we are almost always working in 4/4 time with no key changes throughout a song unit. Four chords are played for the verse, a different set of four chords are played in the chorus, and a vocal melody is sung on top. More than this, though, we are culturally accustomed to this form, and it is a very accessible way to relate an idea or an emotion through lyrics, which take the primary focus in a monadic arrangement featuring the voice. 

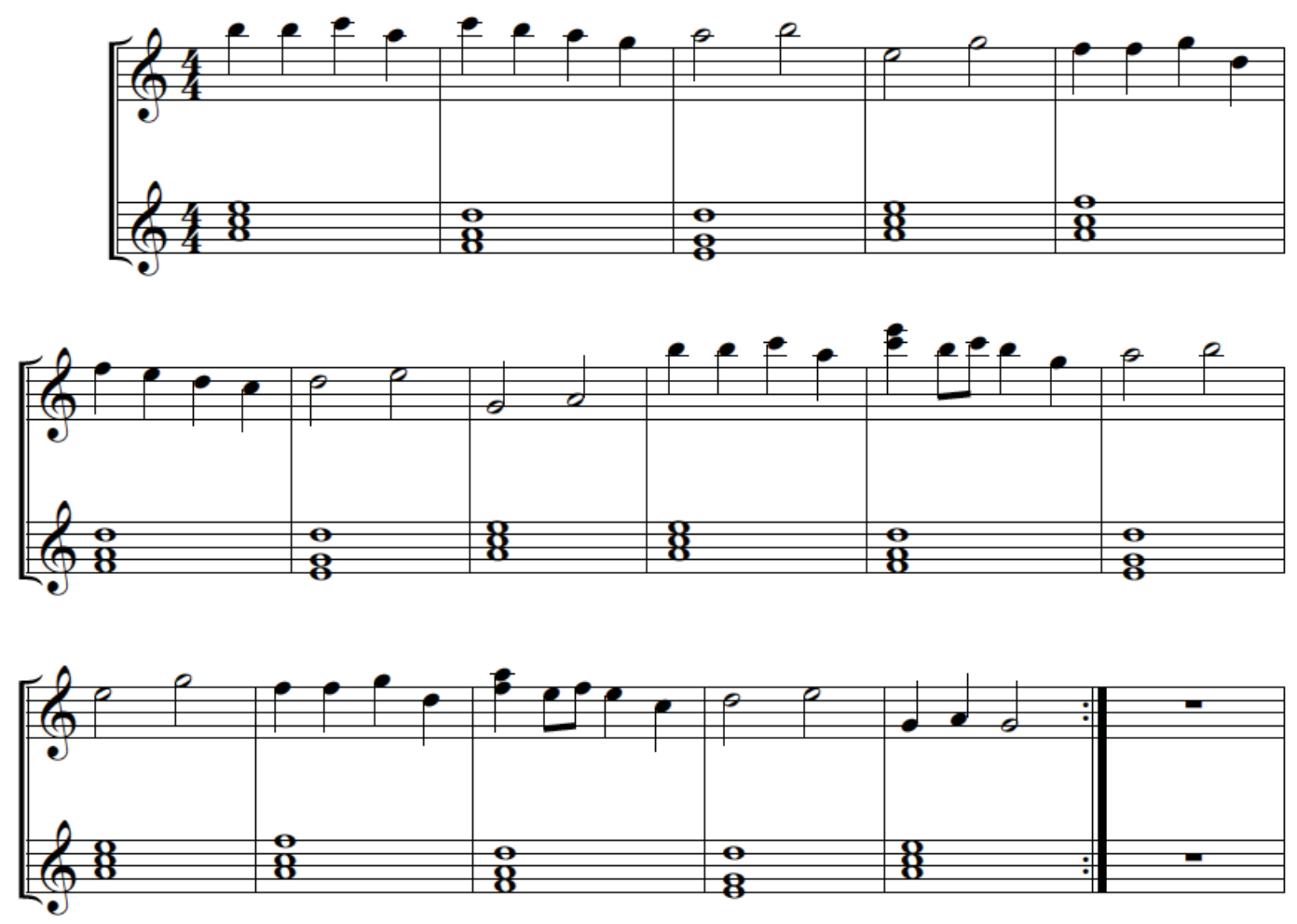

Figure 6.3: A monodic arrangement in A minor. Most popular genres of contemporary Western popular music are written in the format of the monody, which is to say that there is a prevalent vocal melody with instrumental, chordal accompaniment. Monodic arrangements are often homophonic as well, in that there is kept a direct rhythmic relationship between the melody and accompaniment. 
Adorno, as we have discussed, in his critique of popular music, suggests that these types of variations are superficial, compared to serious music (2002). However, symphonic composition follows certain forms and guidelines and patterns as well, and I do not see how we might praise one or the other based on its apparent complexity, for we know that many monodic arrangements allow musicians to demonstrate complex technical skills—say, in the form of an instrumental rock solo or in detailed fingerpicking patterns of folk — and that we find many examples of insightful lyrical content embedded over simple, derivative chordal structures. We can see, for example, in Neutral Milk Hotel's "In the Aeroplane Over the Sea," a simple strumming of the "cowboy chords" G-Em-C-D, a pattern we see in pop music from Taylor Swift to Katy Perry, yet "In the Aeroplane Over the Sea" we have the wonderful, existential closing line: "How strange it is to be anything at all!" (1998). And perhaps the recognition of rhetorical figures in musical composition might help us identify certain patterns in Adorno's idea of "serious music," where these rhetorical figures play into the totality of the whole arrangement (2002). Yet, we must abandon this simple transference of lingual figures of argument to musical figures of argument to understand the persuasive power of music.

A rhetorical-musical framework for the analysis of song must take into consideration the material and immaterial properties of music, as aforementioned and explored, as well as the diverse digital and analog networks through which the digital music commodity is shared and transferred. It must also consider the non-linear process of music composition. We cannot simplify the musical process into a chart: "Creation-Notation-Recording-Signal Processing-Publishing" or some variation 
of this, for it has never been so simple, even before widely available digital recording technologies, and it is not so simple now. Here is where I echo Vicks in his assessment of previous attempts at establishing disciplinary connectivity between rhetoric and music, for the rhetorical-musical figures that many authors have recorded, such as Unger, there seems to be no theory as to why these figures function, what they are suggesting semantically, or from where they come. A framework for the rhetoric of music must look beyond creating parallels between figures of music and figures of rhetoric and instead address the situations out of which music is composed, the networks it is distributed in, and the contexts in which it is played back. For such a project, we may look to the work of Llyod Bitzer, who defines rhetoric for us as that which initiates change, "a mode of altering reality":

...a work of rhetoric is pragmatic; it comes into existence for the sake of something beyond itself; it functions ultimately to produce action or change in the world; it performs some task. In short, rhetoric is a mode of altering reality, not by the direct application of energy to objects, but by the creation of discourse which changes reality through the mediation of thought and action. The rhetor alters reality by bringing into existence a discourse of such a character that the audience, in thought and action, is so engaged that it becomes mediator of change. In this sense rhetoric is always persuasive. (1968, p. 3-4)

And, as we have seen, works of music come out of complex social, cultural, and political scapes which effect their composition, their structures, their arrangements. Music carries political gravity and arises from conditions, from a rhetorical situation, 
into which it is called into moments to not only comment on the world but also to foresee that which can occur, to prophesize, to permit for new ruptures. As Bitzer tells us: "a work is rhetorical because it is a response to a situation of a certain kind," as a “response to a situation” (1968, p. 3-5)

Though I have paid much attention to independent musical composition, we must note, too, that musical groups that are supported by the music-industrial-complex are also experimenting with new ways of creating music, and this is documented especially well in the film Konstrukting the Koloss, by Anders Bjorler and Owe Lingvall, 2012.

You both have budget constraints and a time frame to work with. So, you can never fully do the things you want. I mean, in your head. In the end it will be awesome, and you're pleased, but it's not really what you aimed for. (2012)

The rhetorical-musical analytical process, as I here suggest it, ought begin with a listening. The particular pieces of music I have here used for analysis are discrete songs. These studies may certainly be expanded into future research on such entities as the music video, wherein proxemics, gestures, visual arguments, and so on act together with the music to shape particular stances and arguments. I herein, however, focus on this coming-together of the social, cultural, and political realities surrounding exigencies for musical composition, production, and distribution. 


\section{Rhetorical Listening}

It is a very real sort of ethical responsibility to listen to and to react to the world around us. Joanna Demers channels Adorno's Aesthetic Theory in her work Listening through the Noise: The Aesthetics of Experimental Electronic Music and writes that "musical material engages in a dialectic with surrounding society, never completely reflective while never completely autonomous, either" (Demers 2010, p. 11). She argues, too, that we have seen a shift in framing with the advent of electronic music. And we must remember, with musical technologies in the $21^{\text {st }}$ century, that almost all of our musicat this moment of writing-whether live or recorded, is mediated to some extent by digital technology: in the studio by DAWs (Digital Audio Workstations), microphones, pre-amps, cables, computers, and appears to us on monitor screens as waveforms. Or on stage, the DI boxes, effect pedals, amplifiers, and audio projection systems. With this turn of electronic music, Demers argues that we have lost many of the framing devices of "Western art music" such as tropes in "tonality, dance rhythms, predictable forms, standard orchestration, and concert venues" though not all of this entirely true, and many musical paradigm shifts have occurred throughout Western history: Stravinsky is a quick go-to as a herald of a new spring of innovation (2010, p. 12). Demers is right in saying, though, that with the disappearance of some of these old restrictions, we also began to see that we lost our "reasons for regarding music as separate from the outside world" (Demers 2010, p. 12). This regarding of music as an external entity is criticized in Tim Ingold's Being Alive in his section on "Four Objections to Concept of Soundscape" (2011). 
Tim Ingold criticizes the notion of the soundscape by saying that we are in the sound. Sound is a medium itself through which we live, much like weather is a medium through which we live. I will outline now my understanding of Ingold's four objections to this idea of an acoustic ecology, which I understand to have "originated"-a problematic thing, to try to trace an origin, and an unthought-of part of our Western tradition of scholarship, at times-from R. Murray Schafer. Ingold objects to the idea of thinking of sound as a "soundscape" because: 1) We are an individual center, so to have multiple "scapes" is insensible. 2) We are active listeners through our ears-they're not just "holes in the skull" (2011, p.137). The ears are not instruments of playback, not in the recording. 3. Sound is a medium. It's what we hear in. Like weather. We're in it. 4. A medium has materiality. Just as air is not in our imagination, sound has a very immediate sort of reality (2011). Ingold's objection immediately reminded me of this passage from "The interiority of sound" in Orality and Literacy by Walter Ong, who is discussing how sight "dissects" while sound "harmonizes" in a sort of phenomenological sense:

When I hear, however, I gather sound simultaneously from every direction at once: I am at the center of my auditory world, which envelopes me, establishing me at a kind of core of sensation and existence. This centering effect of sound is what high-fidelity sound reproduction exploits with intense sophistication. You can immerse yourself in hearing, in sound. There is no way to immerse yourself in sight. (2002) 
Strange, though, that we often do seem to immerse ourselves in sight: early silent films in dark theaters, quiet meditation on a walk through the woods. Still, I am immediately skeptical of how biological restrictions play into Ong's notion of sound. If we had "360 degree vision" for example, would we think of vision more as centering? Even so, binaural hearing is often inconsistent and unreliable. This is why we have learned to tilt our heads in confusion — as we often see a dog do-to help us locate the source sound and hear "better" by accentuating the spatial difference between our ears in creating vertical difference to accompany the biological horizontal separation. Yet, I think this is exactly Ingold's point. In a sense, we do feel in every direction, just as we see in every direction, or the "direction" we see is every direction for us. Thus, the idea of having separate scapes_-scapes of vision, scapes of sound, etc.-inherently dissects our perception of reality, which is, really, centered by the individual. We do not sense, we are the sensing.

This is a phenomenological strain of thought that stems, perhaps, from critiques of Kant's formulation of the transcendental unity of apperception, which is no doubt part of the Platonic tradition. That is, thinkers such as Merleau-Ponty and Derrida have objected to the notion of a self before the sensing, that there is a "mind" behind all of our thoughts that then decides, and acts out upon the world. We might take issue to this with the problem of selective listening and of focus. We seem to be able to direct our attention. Or do the sounds of the world call out to us? Yes, we can purchase ear plugs or roll up paper towel into our ears if the neighbors are having a late night party and we are bothered by the sounds. We have some control. But in a panicked state, for example, most mammals will have "heightened" aural attunement- 
a physiological reaction to the threat of a predator — which is accompanied by a fuzzied vision, a de-focusing of sight to better detect movement in the surroundings, as Cassano et. al explain in their "Derealization and panic attacks: A clinical evaluation on 150 patients with Panic Disorder/agoraphobia” (1989). Thus, we cannot forget that there is a sort of violence to sound. We make sound to convey meaning, but we also call out in distress, we sob, we scream. Other animals, too, cry out in pain and bark for our attention. The agitated squeals of a blue jay help scare off predatorial birds looking for eggs. The roar of a tiger can create a bioacoustic, physiological response in its pray, using infrasound to "freeze" its victim. Yes, there is a violence in animal sound, as there is a violence in human sounds: our screams, our cries, our passionate expressions of unrequited love or lost life even in popular radio music, across genres. Further, we are limited in the frequencies we produce and reproduce. As aforementioned, Aristotle wrote of the involvement of the organs in creating sound, in the voice, as a very bodily experience, in his "On Things Heard." For Aristotle, sound rises up from the lungs and throat and clashes with the air. This is true in our "scientific" understanding of sound as vibrations that are transferred through molecules in the air. But there must be a listener to perceive the movements in the air, there must be an ear somewhere. For Sartre:

listening to music is an experience built out of the relations between and among the notes, and it is an active experience in the sense that it requires a well-prepared and engaged listener (via Russon 2003, p. 14) If we return to Derrida's apparent paradox of the voice in his Voice and Phenomenon, we can begin to explain this (2011). For Derrida, the voice is something that comes from 
us, but we are our own listener, as well. This creates a problematic construction. The practicing musician is not performing for another, but performing for the self to hear. Or the solitary musician invents. For, the stage is a place of pre-written, scripted performance. So, too, can be the practice room. But in the practice room-or whatever spot the musician might find themself in, perhaps an old couch in an unkempt apartment in Hancock-there are aleatoric moments. It is often when there is no audience, when there is no one to hear but the self, that improvisation and invention occur. Here is where I see Ingold's objections to the notion of soundscape to be incomplete. Is there not a difference in listening to music as an audience and listening as a performer? Some musicians, perhaps, do not entirely hear themselves alone, such as the orchestra violinist who is part of a whole, and must hear themselves in the music and not as just those notes which are being played, in time with the conductor, from the script. Yet, the solitary musician might also imagine an accompaniment while they perform to the self. What sense can we make of this distinction between listening as a performer and listening as one "in the audience"?

In rhetorical studies we often speak of the audience. The etymology here is not exact but this stems in part from the Latin audire, to hear, but further back relates to the Greek root au, to perceive, and perhaps even to grasp. In the $14^{\text {th }}$ or $15^{\text {th }}$ century it came to mean "persons within hearing range" or an "assembly of listeners," and recorded in 1855 is the sense where it means, close to our common contemporary understanding, as a "reader of a book" (Harper 2013). From this we see where the split has occurred. For, the author, the writer, does not hear a voice come up and out from the lungs, does not hear the own-voice, the self-voice. The voice, here, is heard in 
silence - a rich sort of paradox, as in the internal monologue, as the words come to the page. Perhaps later the piece is vocalized, read aloud. But the orator, the musician, the performer: they must hear the self. The self is thus part of the audience, of those who are within hearing range, for the performer is at once the source of the sound and the most immediate reactor and responder to the sound. In order to perform, we must hear ourselves closely and attentively. There is a strange phenomenon, though, that occurs, where we are not precisely present. It is not as though we stop and think about each note, or each word that emits from our mouth or sings from the contact with strings in our hands. We retain—or in phenomenological terms, synthesize - the immediate past, the present, and the immediate future. We allow the melody we are producing to pull us somewhere, even though we are the architect of that melody.

I will turn to the example of Colonel Chris Hadfield, a Canadian astronaut who has a public SoundCloud page onto which he publishes sound recordings from the International Space Station. One upload, "Ambient noise of the International Space Station" gives listeners an idea of what it might "sound like" to be aboard the space station: the clicks and hums. He has also uploaded original songs, such as "Jewel in the Night Sky," a singer-songwriter style acoustic guitar piece with vocals. Yet, these socalled ambient noises of the space station are still present in the latter recording. It has become part of contemporary recording practice to find isolated areas with nonintrusive sounds: the recording studio is padded, sound-proofed: sound isolation booths, insulation, acoustic panels, barriers. Who is listening to Colonel Chris Hadfield? There is the tagline-perhaps popularized by the 1979 science-fiction film Alien - that "no one can hear you scream in space." Yet, Hadfield hears himself as he 
performs, and through various manipulations of the electromagnetic spectrum, these recorded transmissions were broadcast back to earth and published to the Internet for public listening. To flip this notion over and around: it is precisely in space, and in spaces, that we are heard. Here, perhaps, is the definitive difference in listening as a performer over listening as a "traditional" audience member. There is a delay. The performer is in rapture, in a moment of creation as well as performance. The performer has access to the immediate future of the song-to-come through responding with the self. I would like to problematize my own account. What if the audience member, the listener, has heard this piece before? Not all performances are alike, but in many cases, especially large orchestral demonstrations, there is a sort of robotic recitation of music rather than a process of active aleatoric creation. Does not the listener then hear in advance the immediate future of the melody to come? Perhaps in these instances, differencesthese aleatoric moments—-might be even more dramatic. I am not sure. I will problematize my account further. I have provided some agency to the melody itself. I say it "pulls" the musician. Is this not just a re-externalization of the melody? Perhaps this is problematic. I have not yet fully made sense of this, yet. For more insight, let us examine the case of varying rhythms in live music. Whereas recorded music is often set to a click track - a sort of metronomic device-to maintain consistency and for ease of adding overdubbed tracks, the live performance is a dynamic performance. The musician—even the speaker, we can say, here-enjoys transcendental moments in which these aleatoric moments of notes held out of time, jumps in the voice, new emergences of grain, incite excitement in the performer. Yet, each experience of recorded music varies, too, depending on where we are and how we hear the music, the 
medium through which it comes to us and what others might be present in our hearing: the same songs which move us to dance might also precipitate deep introspection.

\section{Significant Function}

Whitehead might help us parse out this difficult area between the rigidity of music as a mathematics and the persuasive nature of music. Price says to Whitehead, in conversation recorded in the Dialogues of Alfred North Whitehead:

For the past year I have been spending evenings with the last quartets and piano sonatas of Beethoven, which are some of the most abtruse music ever written. I don't pretend that I understand them except in parts, but they, too, like the beauty of a star, gain from the grandeur of their surrounding immensities of thought. They plunge one for hours at a time into a world of abstract values, like higher mathematics, and I actually think they have made me better able to comprehend some of the higher mathematics of abstract thought which I hear from you. Music is of course highly mathematical and it is also abstract. It is peculiar, too, in having at one and the same time an emotional and an intellectual content. I do not presume to define music, but I do think that music is a mathematics of aesthetic. (2001, p. 227)

Whitehead responds: 
...with the sense of sight, the idea communicates the emotion, whereas, with sound, the emotion communicates the idea, which more direct and therefore more powerful (2001, p. 228).

We can relate this notion to Barthes's concept of the grain of the voice in his Image, Music, Text, where he discusses the place where sound and semiotics meet: in the grain of the voice (1978). Could the "intellectual content" of music, in the terms used here, just as well be ideological content? Music and language harbor deep ideologies that constrain and command us. This is the role of the rhetoric of music, to explain places of rupture and creation, and this is what I have attempted to lay out as a groundwork, to explain how listening to the self can cause aleatoric moments of creation, and to argue that we must avoid the machination of musical performance. So, too, is it true that as orators we often fall victim to machination and repetition, of inanities begot of rearticulations of premeditated empty phrases. I am as guilty as any. Perhaps looking beyond human music and song can help us understand these issues further. Are there ideologies present in animal sounds? Is there "intellectual content" in the songs of the humpback whale? The humpback whale uses tones that range beyond even the full extent of human hearing, and are long, complex structures imbued with repetition, and, undoubtedly, meaning. This is why we call them songs. Are they more than songs? What would it mean to have our primary mode of communication to be more like Homeric epics than short bits of exchange? Richard Dawkins, from his The Selfish Gene, in which he coins the word "meme" for a unit of cultural transmission, writes:

Cultural transmission is not unique to man. The best non-human example that I know has recently been described by P.F. Jenkins in the 
song of a bird called the saddleback which lives on islands off $\mathrm{New}$

Zealand... By comparing the songs of fathers and sons, Jenkins showed that song patterns were not inherited genetically. Each young male was likely to adopt songs from his territorial neighbours by imitation, in an analogous way to human language.... occasionally Jenkins was privileged to witness the 'invention' of a new song, which occurred by mistake in the imitation of an old one. (1989, p. 189-190)

Dawkins concludes: "Song in the saddleback truly evolves by non-genetic means" (1989, p. 190). But can we be so sure that these variations are the product of "mistake" alone? There are several problems, here: agency, authorship, expression, will, among others that occur to me immediately. Do we perceive the sounds of birds as musical only because human melodic phrases tend to be similar in length? Can we learn from Dawkins, here, and think about how rhetoric and memetics relate? Perhaps there is something rhetorically effective in the short, repetitive nature of bird song, much like we have repetition in popular music: often just four repetitions of the same melody with parallel lyric patterns, sometimes with a variation on the fourth to signal a transition back to the verse or to a bridge between a final repetition of the whole chorus structure. We can ask further questions, here: why have we labeled the call of the "mourning dove" as such: a sound of profound sadness that seems to resonate with us? Have we only retroactively applied this label after certain musical tropes defined sounds of sadness for us? Or is there something intrinsically mournful about this sound? Perhaps we are not listening to the mourning dove at all, but anthropomorphizing it, falling into this mythologization that Derrida discusses through 
Haraway, here. There is clearly a difference between Emily Howell, the "robot" classical composer created by David Cope—really a work of software, or program— that composes "original" material based on the canon of classical music that it has analyzed, and the bird, who calls upon the history of its hearing, and not data. Or could it be that what Jenkins saw as "mistakes" and the song-differences created by Emily Howell are more similar than we might first think? Is all our music a "mistake"? [And as a side note, how do we even credit such a piece of music: who is the author, Cope or Howell? Or is there something more at stake here?] The songbird is perhaps a prime example of the biotechnologization of an animal, and both the commodification of song and animal (Haraway 2007, p. 56). Why does the caged bird sing? To turn this literary trope around: might it actually be singing to us, and not for us? Or to ghosts of birds that are unseen to it? To go back to Dawkins, and to relate to Haraway's question of “Can animals play?”, I turn to Johan Huizinga (1950, p. 22). Huizinga writes in Homo Ludens in a section entitled "Nature and Significance of Play as a cultural Phenomenon":

Play is older than culture... Animals play just like men... And-what is most important-in all these doings they plainly experience tremendous fun and enjoyment. Such rompings of young dogs are only one of the simpler forms of animal play. There are other, much more highly developed forms: regular contests and beautiful performances before an admiring public. (1950, p. 1)

Huizinga goes on: 
...even in its simplest forms on the animal level, play is more than a mere physiological phenomenon or a psychological reflex. It goes beyond the confines of purely physical or purely biological activity. It is a significant function- that is to say, there is some sense to it. In play there is something "at play" which transcends the immediate needs of life and imparts meaning to the action. All play means something. (1950, p. 1)

Here is where I will mark a difference, then. The robot composer does not seem to play. And it is play — which seems to be something like a variation from expected behaviors, at least in a human sense, but we see this too in animals who know they are being observed, who have an audience - that contributes to creation and innovation and change in music. We are too quick to say that musicians "play" their instrument, when they are only repeating or reading scripted songs. This is not play, at least in Huizinga's sense. What do I mean to say? We must expand our understanding of audience to include the self, so that we can play and create alone. Through understanding that music has a significant function, we learn to play differently, to cultivate musicality over rote repetition, and to learn to cultivate the aleatoric moment in which forms can be broken and new musical—and followingly, political—ruptures can ensue.

Who is listening? It's not just the self, of course, but we can start, here. And with so much music published in digital spaces, we ask ourselves, what should we listen to? Do we listen too much? Silence, too, is important. What can we say of ethics and responsibility in sound? Let us "listen" to John Donne’s "Meditation XVII": 
No man is an island, entire of itself; every man is a piece of the continent, a part of the main. If a clod be washed away by the sea, Europe is the less, as well as if a promontory were, as well as if a manor of thy friend's or of thine own were: any man's death diminishes me, because I am involved in mankind, and therefore never send to know for whom the bells tolls; it tolls for thee. (1624)

The author here forgets that the bell tolls for me, the self-same author, as well as thee. For reader and author alike. Is there, perhaps, some greater continuity between performer and audience that we have forgotten? We have ushered in an era of the "death of the author" too readily. We are all authors and all singing songs. Before this famous passage, the work reads:

Who casts not up his eye to the sun when it rises? But who takes off his eye from a comet when that breaks out? Who bends not his ear to any bell which upon any occasion rings? But who can remove it from that bell which is passing a piece of himself out of this world? (1624) With each sound we make are we letting some piece of ourselves escape into the world? No, the living thing is not a closed system. Though, as Walter Ong notes in his Aurality and Literacy that words are always leaving us - that we cannot say the word "existence" without losing the "exis-" by the time we get to the phonetic utterance of "tence"-we must ask, to where do they go? We do not lose the self through the expulsion of sound and meaning, but gather more through our emission. We let some air go and take some in. We sometimes, too, speak to ourselves, as if we are drawn to make sound for comfort. A breathy sigh. The angered individual can erupt into a 
frenzy over hearing the sound of his own voice escalating - this, too, can be cathartic, a primal scream therapy. And so we are responsible in listening as performing, in knowing that the bells toll for us, and that we have always the dream through which to build and build over again the carillon.

\section{Conclusion: Musical Locality in the Digital Age}

At last, I will here look at the particular situatedness of musical argument in a localalized, cultural occurrence. We must first set the stage of Upper Peninsular musical culture in Michigan. An article appeared in The Atlantic Cities in October 2012 titled “How Far Can You Live From an Interstate Highway?”. In the piece, Henry Grabar hunts for rural America's most remote locations - in terms of vehicular transportation, at least. As a sixth-generation 'Yooper," I wasn't surprised to read the following: I found that the farthest places from the Interstate are actually east of the Mississippi, on a peninsula that juts north into Lake Superior from Upper Michigan. (Grabar 2011)

Yet, music in the remote Upper Peninsula city of Marquette, Michigan, flourishes because of its localized nature. Local musicians write and sing their own songs. They draw on old traditions and inflect with the new. Marquette has dedicated, talented artists who have been strumming and howling for decades. New bands and acts and recordings springing up in basements, on cassette tapes, and in downtown bars. One can hear Heather Evans at the Wild Rover restaurant at an afternoon, or Troy Graham at the Ramada Inn's little bar at night. Michael Beauchamp hosts a summer concert 
series at the Presque Isle Bandshell, overlooking Lake Superior. I remember seeing Sycamore Smith singing at Breaker's Roadhouse some chance night I was wandering, and there's a certain house where music lives on into the morning. There's endless springing up from the little city. There's a real reason to sing, up in the far north: to make it through the winter, to celebrate the sun, to look back into time and into the self. To look ahead. Many genres can be heard in the Upper Peninsula, but there is so much in common across them, so much to be heard. Yet again, the geographically remote is no longer the disconnected. President Barack Obama visited Northern Michigan University, in February 2011 to applaud their WiMAX initiative, a city-wide wireless Internet service for no cost to students. The service now covers an incredibly expansive area: “the cities of Marquette, Gwinn, Ishpeming, Negaunee, K.I. Sawyer, and Chocolay township" all have access to NMU's WiMAX network (NMU 2012). Tuition wasn't raised, and the entire system was installed by six people in four days. Obama commended this connectivity, and went on to discuss the role of infrastructure in economy, even at the local level, using Marquette's Getz's Clothiers as an example:

This is a third-generation, family-owned, Marquette institution. They've occupied the same downtown store for more than a century -- but with the help of broadband, they were recently listed as one of America's 5,000 fastest-growing companies. Now how did they pull that off? (Applause.) Obviously they've got great products, great service. But what's also true is online sales now make up more than two-thirds of their annual revenue. Think about that. You got a downtown department store; now two-thirds of its sales are online. It 
can process more than 1,000 orders a day, and its workforce has more than doubled. So you've got a local business with a global footprint because of technology. Now, if you can do this in snowy U.P. -(laughter) -- we can do it all across America. (Obama 2011)

The message is clear is clear: digital networks in remote geographical locations are facilitating all sorts of human interactions. And this is true beyond economic transactions.

Universities work as physical centers of access to popular culture in the Upper Peninsula. There are no major commercial music venues. However, there is a thoughtful and reflective collective of musicians who live in the distant, snowy north and have been producing, distributing, and performing their music for decades. The physical substrate of this collective was, for some time, Marquette's 231 "House of Muses” on West Washington Street, until a January 2007 fire rendered the building uninhabitable and left few remnants of several lives' collections of audio and musical equipment (Diem 2008). A hardwood-floor that once packed two-hundred bodies to see Michigan legends Sah, Sycamore Smith, and Hell Town Trio on stage now stands as an empty shell in Marquette. My own silly teenage band, Tommy Kilometer and the Nautical Mile, a rocky, surf-pop confusion, frequently performed at the House of Muses and other small venues in the Upper Peninsula: He-Brews coffee shop in Iron River, a music store in Calumet. When the thing disbanded-and I'm thankful it's buried-I began producing and recording my own acoustic-oriented, experimental, digital music using a laptop and a cheap condenser microphone. I published to hosts online, as many local musicians did, and a collective was reunited in the fires and sparks 
of wired and wireless networks. Digital musical networks and communities provide a cultural infrastructure to connect the Upper Peninsula folk and independent music scene not only across the region but across the world. Independent record label Van Party Tapes run by Marquette native Jeremy Moran sells its home-made "split cassettes" via BandCamp and regularly sells out of its limited edition runs. This juxtaposition of antiquated technology, the cassette, and the virtual marketplace is the controversial oven of the analog-digital debate.

Yet, we need not tire ourselves with the old "which is better: a CD or vinyl?" Rather, we have to be conscious of how these new virtual spaces are having an effect on the music being produced and distributed, as well as its reception. This is why I have advocated for a rhetoric of music in the past and why I continue today: I dare to clash with a titan. Marshall Mcluhan wrote that the medium is more significant than the message itself — though of course not so simply, and I don't intend to reduce his argument, here-yet I hold that the message is in the invisible, in the ideological realm of what we produce and consume (McLuhan 1967). Can we access this ideological realm? Perhaps. Yet philosopher Slavoj Žižek warns that when we believe we have escaped from ideology, we are most entrenched in it (Žižek 1989). Music is commendable in its ability to resist the throes of capitalism. It is shared, celebrated, and produced as part of a general, universal counter-culture. But in its ubiquity it can become silent.

Žižek writes, on finding the location of ideology:

The crucial thing is to locate ideology where it belongs. Let's take a clear example: the well known song "Tomorrow Belongs to Me" from 
the film Cabaret. Some of my friends, after seeing the film, Bob Fosse's Cabaret, thought that after they heard this song they finally understood what at its deepest as to its emotional impact, what fascism is. But I think this is precisely the mistake to be avoided. This song is rather ordinary, popular song, incidentally it was composed, when they were shooting the movie, by a Jewish couple. Nice irony. If you look not only at the music, at the way it is sung, but even at the words, "awakening of a nation," "tomorrow belongs to me," one can well imagine with a slight change of words, [a] radically leftist, communist song. (2012)

And herein is where I see the potential in the digital-political economy of music to revitalize the process of musical composition —although of course with such potential to revitalize is also the potential to condemn. Jacques Attali, too, envisions this twosided potentiality in the political-economy of music, in telling us "what composition can mean: each person dreaming up his own criteria, and at the same time his way of conforming to them" (Attali 2009, p. 145). We see, in Marquette music, in the geographically remote but digitally connected culture of the Upper Peninsula, such songsters as Sycamore Smith whose music calls upon both local traditions in songs such as "The Man With the Skeleton Arms," tales of drinking, death, and Flanniganweaving local fables with mythology, commentary on religion, the machinations of society, and the human condition in the wintry north. Here, in Sycamore's "Hokum All Ye Faithful," we see in the lyrics a dry-witted atheistic tone: 
Tell me, have you heard the one

About the prophet with the perfect soul?

The heavenly bastard with his own slasher flick-

The greatest fairytale ever told

Weekly he receives

A kneeling ovation from a sleepy nation

They're swallowing the old routine, the holy saltine, And backwash from the cup of salvation

Have you heard the legend sweeping the land?

They're saying we all sprung from some invisible man

And when he finished up, he took a little rest

And he's been resting ever since I guess... (2014)

Sycamore's lyrics, with all the other dimensions of his musical performance-the use of a shiny, brass kazoo over the traditional singer-songwriter's harmonica, devil horns adorned on his acoustic guitar-come together as a non-discursive argument, and, if we understand further the biography of the musician, the growing rate of atheistic and agnostic demographics in the United States, the we come to see the complex relations that situate the music commodity. If we take Tolstoy's reckoning of history in his epilogue to $W$ ar and Peace, that historical events are not the result of the actions of what historians deem to be significant people — the apparent genius of Napoleon Bonaparte is but an illusion, for Tolstoy-but rather that history is determined by the wills of individuals who are sometimes swayed to various actions rather than commanded, that 
power is only illusory in those who give commands and that they are merely acting some small part in the greater movement of human events, we can come to understand the intricacies of the political-economy of music and its further complications in the digital interconnectedness of a global economy (1869). Through Tolstoy's struggles with the concept of free will—and, as he writes, so it should be a struggle for anyone who has ever given the notion a worthwhile dedication of thought—he reasons ultimately that freedom, the essence of the life of a human, lies somewhere between absolute free will and absolute inevitability. Though the composition of music may be tied up in the current economic structures of human making, and so they may have always been, we still retain the agency to write our music anew and to sing some new song for ourselves. As Tolstoy tells us, it is not that the Bonapartes who make history, they are only remembered as such because the course of human events seem to align with those decisions that have been recorded and retrospectively selected as being fitthe illusion of the genius of a historical figure is constructed through chance, through the writings of historians. So, too, with our musical history, with Western stardom and Grammy Awards, we attempt to identify particular moments in the progression of music as being definitive ruptures, changes, and significant genius. Yet, there are always working underneath this illusion the efforts, creations, and genius of a civilization that is constantly reshaping itself, throwing wood on the fire and stoking the flames. We remember that Jacques Attali tells us that music is prophetic, that, again, the superstructure is not determined indefinitely by the base of society, that indeed our musical culture can play reciprocally back into the base, then we might think that in the present digital-political topography of music, we have the same opportunity —and 
altogether the same dangers ahead of us. Yet what is certain is that the onus is on us to be mindful, to listen to ourselves, to understand the persuasive power of music and to appropriate it for the foundation and shaping of new political realities. So here we have mapped the digital-political topography of music, and so we may now use this renewed understanding of the power of music in its many ways of moving us: in the composition of music, in its performance, and in our listening and sharing of our songs across our societies. 


\section{References}

\section{Chapter 1}

Adorno, Theodor W. “On Popular Music.” Essays on Music. Gillespie, Susan H., translator, and Leppert, Richard, editor. University of California Press. 2002.

Aristotle. “On Things Heard." Minor Works. Harvard University Press. Printed in Great Britain. 1955.

Aristotle. Politics. Jowett, Benjamin, translator. Dover Publications, Inc. Mineola, New York. 2000.

Aristotle. Politics: A Treatise on Government. Ellis, William, translator. Project Gutenberg. June, 2009. http://www.gutenberg.org/files/6762/6762-h/6762-h.htm

Aristotle. Rhetoric. W. Rhys Roberts, translator. The Internet Classics Archive. 1994.

Babich, Babette, "Mousike techne: The Philosophical Practice of Music in Plato, Nietzsche, and Heidegger." Between Philosophy and Poetry: Writing, Rhythm, History. Continuum. 2002.

Blech, Dominik and Yang, Min-Chi. "Perceptual Discrimination of Digital Audio Coding Formats.” Audio Engineering Society. Presented at the 116th Convention. Berlin, Germany. May 8-11, 2004.

Casal, David Plans. "Crowdsourcing the Corpus: Using Collective Intelligence as a Method for Composition.” Leonardo Music Journal. 21. 25-28. December 2011.

Congreve, William. The Mourning Bride. In The Dramatic Works of Wycherley, Congreve, Vanbrugh, and Farquhar. Hunt, Leigh (ed.) Edward Moxon, Dover Street. 1855. Dawkins, Richard. The Selfish Gene. Oxford University Press. 1976. 
Fiennes, Sophie. The Pervert's Guide to Ideology. P Guide Productions. 2012. Film.

Goldman, Richard Franko. "Varèse: Ionisation; Density 21.5; Intégrales; Octandre; Hyperprism; Poème Electronique. Instrumentalists, cond. Robert Craft. Columbia MS 6146 (stereo).” Musical Quarterly. 47.1. January 1961. 133-34.

Gorgias. Encomium of Helen. The Rhetorical Tradition: Readings from Classical Times to the Present. Bizzell, Patricia, and Herzberg, Bruce, editors. Second edition. Bedford/St. Martin’s. 2001.

Hawhee, Debra. "Bodily Pedagogies: Rhetoric, Athletics, and the Sophists' Three Rs." College English. 65.2. 2002.

Jastreboff, Margaret M and Pawel J. "Decreased sound tolerance and Tinnitus Retraining Therapy (TRT)." Australian and New Zealand Journal of Audiology. 24.2. November 2002. 74-84.

Krause, Bernie. The Great Animal Orchestra: Finding the Origins of Music in the World's Wild Places. Little Brown. 2012.

Mann, Charles Riborg and Twiss, George Ransom. Physics. Scott, Foresman and Company. 1910.

Mathiesen, Thomas J. "Harmonia and Ethos in Ancient Greek Music.” The Journal of Musicology. 3.3. Summer, 1984. 264-279.

McClary, Susan. "The Politics of Silence and Sound." Afterword. In Attali, Jacques. Noise: The Political Economy of Music. Massumi, Brian, translator. Tenth printing. The University of Minnesota Press. Minneapolis, MN. 2009. 149-156. 
Murray, Joddy. Non-Discursive Rhetoric: Image and Affect in Multimodal Composition. State University of New York Press. 2009.

Petrisor, Alexandru-Ionut. "Multi-, Trans- and Inter- Disciplinarity, Essential Conditions for the Sustainable Development of Human Habitat." Urbanism. Arbitectură. Construcții. 4.2: 2013. 43-50.

Plato. Laws. Jowett, Benjamin, translator. The Internet Classics Archive. 2009. http://classics.mit.edu/Plato/laws.html

Plato. Phaedrus. Nehamas, Alexander and Woodruff, Paul, translators. Hackett. 1995. Pohlmann, Egert and West, Martin L. Documents of Ancient Greek Music: The Extant Melodies and Fragments. Oxford University Press, US. New York, NY. 2001.

Salmons J., Wilson L. (2007), “Crossing a Line: An Interdisciplinary Conversation about Working Across Disciplines, Models and Notes. A Trainerspod Webinar, August 23, 2007.

Schafer, R. Murray. The Tuning of the World. Random House, Inc. 1977.

Schoen-Nazzaro, Mary B. "Plato and Aristotle on the Ends of Music." Laval theologique et philosophique. 34.3. 1978. 261-273.

Quintilian. Institutes of Oratory. Ed. Lee Honeycutt, translator. John Selby Watson. 2006. Iowa State. 15 March 2014. <http://rhetoric.eserver.org/quintilian/>. Uzdavinys, Algis. The Golden Chain : An Anthology of Pythagorean and Platonic Philosophy. World Wisdom. 2004.

\section{Chapter 2}

Chua, Daniel K. L. "Rioting with Stravinsky: A Particular Analysis of the Rite of Spring." Music Analysis. 26. 1. July 2008. 59-109 
Crowley, Sharon. The Methodical Memory: Invention in Current-Traditional Rhetoric. Southern Illinois University Press. 2010.

Derrida, Jacques. Of Grammatology. Gayatri Chakravorty Spivak, (translator). Originally published 1967. The John Hopkins University Press. 1997.

Derrida, Jacques. Voice and Phenomenon: Introduction to the Problem of the Sign in Husserl's Phenomenology. Leonard Lawler, (translator). Originally published 1967. Northwestern University Studies in Phenomenology and Existential Philosophy edition. Northwestern University Press, Evanston, Illinois. 2011.

Ferrari, G.R.F. “Listening to the Cicadas: A Study of Plato’s Phaedrus.” Cambridge University Press. 1990.

Hawhee, Debra. "Bodily Pedagogies: Rhetoric, Athletics, and the Sophists' Three Rs." College English. 65.2. 2002.

Heraclitus. Fragments. The Online Classics Archive. MIT. Last accessed 24 April 2013.

Hurra Torpedo. "Total Eclipse of the Heart." Kollossus of Makedonia. Duplex Records. Originally written by Jim Steinman. 2006.

Lamb, Horace. The Dynamical Theory of Sound. Edward Arnold: London. 1910.

Lidell, H.G. and Scott, R. Greek-English Lexicon. Oxford University Press. 1940.

Listenius, Nicholas. Rudimenta Muscae Planea. Wittenberg, Germany. 1533.

Matsson, Kristian. “The Tallest Man on Earth Interview.” FaceCulture. Transcribed from YouTube.com. March 25 2010.

McMullen, Ken, (director). Ghost Dance. 1983.

Merlau-Ponty, Maurice. Phenomenology of Perception. Donald A. Landes (translator). Originally published 1945. Routledge. New York, NY. 2012. 
Ong, Walter J. Orality and Literacy. First published 1982. Routledge edition, 2002.

Plato, Phaedrus. Nehamas, Alexander and Woodruff, Paul, (translators). Hackett. 1995.

Quintilian. Institutes of Oratory. Ed. Lee Honeycutt. Trans. John Selby Watson. 2006. Iowa State. 26 Feb. 2014. <http://rhetoric.eserver.org/quintilian/>.

Schoen-Nazarro, Mary B. "Plato and Aristotle on the Ends of Music." Laval theologique etphilosophique. 34. 3. 1978. 261-273.

Shakespeare, William. 1 Henry IV. The Norton Shakespeare. W. W. Norton \& Company. New York, NY. 1997. 1151, 1190-94.

Žižek, Slavoj. "Connections of the Freudian Field to Philosophy and Popular Culture. Lacan.com. First presented at the Eighth Annual Conference of the Australian Center for Psychoanalysis in the Freudian Field, Melbourne, 13 August 1994. Published in Agenda: Australian Contemporary Art. 44. 1995.

\section{Chapter 3}

Adorno, Theodor W. “On Popular Music.” Essays on Music. Gillespie, Susan H., translator, and Leppert, Richard, editor. University of California Press. 2002.

Aristotle. Politics. Jowett, Benjamin, translator, and Stevenson, Daniel C., editor. The Internet Classics Archive. 2009. Original text written 350 BCE. Accessed November $23^{\text {rd }}, 2012$.

Attali, Jacques. Noise: The Political Economy of Music. Massumi, Brian, translator. Tenth printing. The University of Minnesota Press. Minneapolis, MN. 2009. 
Barker, Andrew. Greek Musical Writings: Volume II, Harmonic and Acoustic Theory. Cambridge University Press. Cambridge, Great Britain. 1989.

Bastiat, Frederic. Essays on Political Economy. G.P. Putnam and Sons. 1874. http://www.econlib.org/library/Bastiat/basEss1.html\#Chapter\%201

Benjamin, Walter. "The Work of Art in the Age of Mechanical Reproduction." Illuminations. Hartcourt, Brace, and World. 1968.

Bohlman, Philip V. "Traditional Music and Cultural Identity: Persistent Paradigm in the History of Ethnomusicology". Yearbook for Traditional Music. 20. 38. 1998.

Bujic, Bojan. "Navigating through the Past: Issues Facing an Historian of Music in Bosnia." International Review of the Aesthetics and Sociology of Music. Published by the Croatian Musicological Society. 37.1. June 2006. 67-84.

Christopher Adams “The Sovereignty of Free Culture: Georges Bataille and The Accursed Share.” April 26, 2008 First Interdisciplinary Research Workshop on Free Culture iSummit 2008. 29 July\{1 August, 2008. Sapporo, Japan.

Da Vinci, Leonardo. The Art of Painting. Philosophical Library. New York, NY. 1957.

Dalquist, Janet Anuta. "Pipe Organs of the Keweenaw: Houghton County, Michigan." The Diapason. February 2007.

Darwin, Charles._The Descent of Man, and Selection in Relation to Sex. 1871.

Davis, Douglas. "The Work of Art in the Age of Digital Reproduction (An Evolving Thesis: 1991-1995)." Leonardo. 28.5. 1995. 381-386.

Derrida, Jacques. Archive Fever: A Freudian Impression. University of Chicago Press. Chicago, IL. Paperback edition. 1998.

Foucault, Michel. "Of Other Spaces”. Diacritics. 16.1. 1986. 22-27. 
Hagel. Stefan. Ancient Greek Music: A New Technical History. Cambridge University Press. Cambridge, UK. 2010.

Hallam, Huw. “THE PRODUCTION OF LISTENING: on Biopolitical Sound and the Commonplaces of Aurality.” Journal of Sonic Studies. 2.1. May 2012.

Hawkins, et. al. "Greco-Roman Music in Context; Bringing Sound and Music to Virtual Pompeii”. Pre-Publication Draft. PublicV R. Retrieved from archive.org on November $25^{\text {th }}$, 2012. Uploaded 2011.

Hornsleth, Kristian Von. “Why Deep Storage Project?”. Deep Storage Project. Accessed Nov. $15^{\text {th }}$ 2012. Re-accessed Dec. $5^{\text {th }}, 2012$. http://www.deepstorageproject.com/Deep-Storage/TEXTS/WHY-HDSP-

International Federation of the Phonographic Industry. "Facts and Stats." Last accessed June 11, 2014. http://www.ifpi.org/facts-and-stats.php

Liddell, Henry George and Scott, Robert. A Lexicon Abridged from Liddell and Scott's Greek-English Lexicon. Nabu Press. 2010.

Lorene Scafaria's Seeking a Friend for the End of the World (2012)

Marx, Karl. Capital: A Critique of Political Economy. Volume 1. First English Edition. Aveling and Moore (translators). Progress Publishers. 1887.

Morris, Jeremy Wade. Understanding the Digital Music Commodity. A thesis submitted to McGill University in partial fulfillment of the requirements of the degree of Doctor of Philosophy in Communication Studies. June 2010.

Nusselder, Andre. Interface Fantasy: A Lacanian Cyborg Ontology. MIT Press. 2009.

Olivetti, Paola. "Musical Features of the Ritual Lament in Ancient Greece." Rosetta. 2, 21-31. 
Oswell, Michelle. "Digital Image Archive of Medieval Music." Review. Notes.

December 2011.

Patterson, Nick. "The Archives of the Columbia-Princeton Electronic Music Center." Notes. March, 2011.

Plato. Ion. Jowett, Benjamin, translator, and Stevenson, Daniel C., editor. The Internet Classics Archive. 2009. Original text written 380 BCE. Accessed November $23^{\text {rd }}, 2012$.

Plato. Laws. Benardete, Seth, editor. University of Chicago Press. Chicago, IL. 2001.

Plato. Republic. Jowett, Benjamin, translator. Stevenson, Daniel C., editor. The Internet Classics Archive. 2009. Original text written 360 BCE. Accessed November $23^{\text {rd }}, 2012$.

Pohlman, Egert and West, Martin L. Documents of Ancient Greek Music: The extant melodies and fragments edited and transcribed with commentary. Clarendon Press, Oxford. 2001.

Roy, Jessica. "Here is a Map of Every State's Favorite Band: Unsurprisingly, Illinois is super into Sufjan Stevens.” TIME Newsfeed. 25 Feb, 2014. http:/ / newsfeed.time.com/2014/02/25/here-is-a-map-of-every-states-favoriteband/

Sagan, Carl. Pale Blue Dot. A Vision of the Human Future in Space. Ballantine Books. 1997.

Seeger, Anthony. "The Role of Sound Archives in Ethnomusicology Today." Ethnomusicology. 30.2. 1986. 
Shakespeare, William. The Norton Shakespeare: Based on the Oxford Edition. Greenblatt et al., editors. W. W. Norton \& Company. 1997. 2336.

Sterne, Jonathan. "The Preservation Paradox in Digital Audio." Sound Souvenirs: Audio Technologies, Memory and Cultural Practices. Bijsterveld, Karin, and van Dijck, Jose, editors. Amsterdam University Press, Amsterdam. 2009.

Vallier, John. "Sound Archiving Close to Home: Why Community Partnerships Matter." Notes. 2010.

Watts, Richard J. "Using folk songs as a source for dialect change? The pervasive effects of attitudes". Multilingua. 29. 2010. 307-335.

Will, Uffe Kock. Computer Music Modeling and Retrieval. Second International Symposium, CMMR 2004. Esbjerg, Denmark, May 26-29, 2004.

Žižek, Slavoj. Living in the End Times. Verso. New York, NY. 2010.

Žižek, Slavoj. Violence: Six Sideways Reflections. Picador. New York, NY. 2008.

\section{Chapter 4}

Agamben, Giorgio. Homo Sacer: Sovereign Power and Bare Life. Stanford University Press. Stanford, CA. 1998.

Arendt, Hannah. "The Revolutionary Tradition and its Lost Treasure." The Portable Hannah Arendt. Penguin Books. 2003.

Baudelaire, Charles. Flowers of Evil. (Les Fleurs du Mal). Creative Commons Edition. Collected by Josef Nygrin. 2008.

Boon et al., editors. Terrorism: Commentary on Security Documents Volume 109. Oceana. Oxford University Press, 2010. 
Butler, Judith. Precarious Life: The Powers of Mourning and Violence. Verso. New York, NY. 2006.

Brown, Wendy. W alled States, W aning Sovereignty. The MIT Press. 2010.

Heidegger, Martin. "Letter on Humanism.” Basic Writings: Martin Heidegger. Original 1947. 1977.

Hardt, Michael, and Negri, Antonio. Empire. Harvard University Press. 2001.

Hobbes, Thomas. Leviathan: Or the Matter, Forme and Power of a Commonwealth Ecclesiastical and Civil. Original 1651. Simon and Schuster: New York, NY. 1962.

Leyshon, et. al. "The Place of Music" (Introduction). Transactions of the Institute of British Geographers. 20.4. 1995.

Mangum, Jeff. "In the Aeroplane Over the Sea." In the Aeroplane Over the Sea. Merge Records. 1998.

McClary, Susan. 2010. "On Why Cultural Context Matters to Understanding the Music You Play.” Public video lecture. https://www.youtube.com/watch?v=b64cWimEIo

Muggenthaler, Elizabeth von. "Low Frequency and Infrasonic Vocalizations from Tigers." Presented December 6 ${ }^{\text {th }}, 2000$. ASA/NOISE-CON 2000 Meeting, Newport Beach, CA.

Muller, Judy. "Sonic Bullets to be Acoustic Weapons of the Future." ABC News Online. July 16 ${ }^{\text {th }}$, 2012. Last accessed April 24, 2013.

Ong, Walter J. Orality and Literacy. First published 1982. Routledge edition, 2002. Plato. Phaedrus. The Internet Classics Archive. MIT. Last accessed April 24, 2013. 
Schmitt, Carl. Political Theology: Four Chapters on the Concept of Sovereignty. Original published 1922. The University of Chicago Press. Chicago, IL. 2005.

Smith, Clive Stafford. 'Welcome to 'the disco': How US interrogators use music as a tool of torture." 2008. The Guardian. Last accessed April 24, 2013.

Taylor, Astra, director. Examined Life. Zeitgeist Films. 2008. Film.

Wachowski, Andy and Lana, directors. The Matrix. 1999.

Whitehead, Alfred. Dialogues of Alfred North Whitehead. Recorded by Lucien Price. 1954 original: copyright by the Executors of the Estate of Alfred North Whitehead. Nonpareil Book edition. David R. Godine, Publisher. Jaffrey, New Hampshire. 2001.

Worthington, Andy. "A History of Music Torture in the War on Terror." Antiwar.com. 2008. http://www.antiwar.com/worthington/?articleid=13908

Zac Brown Band. “Chicken Fried” (Single). Atlantic Records. 2008.

Žižek, Slavoj. Violence: Six Sideways Reflections. Picador. New York, NY. 2008.

Žižek, Slavoj. "The simple courage of decision: a Leftist tribute to Thatcher." New Statesman. April $17^{\text {th }}, 2013$.

Žižek, Slavoj. Transcription of his address to the Occupy Wall Street movement. Published in Impose Magazine, October $25^{\text {th }}$ 2012. Speech delivered on October $9^{\text {th }}, 2012$. 


\section{Chapter 5}

Adorno, Theodor W. “On Popular Music.” Essays on Music. Gillespie, Susan H., translator, and Leppert, Richard, editor. University of California Press. 2002.

Aristotle. "On Things Heard." Minor Works. Harvard University Press. Printed in Great Britain. 1955.

Barthes, Roland. Image, Music, Text. Hill and Wang. 1978.

Bitzer, Lloyd. “The Rhetorical Situation.” Philosophy \& Rhetoric. January 1968.

Bjorler, Anders, and Lingvall, Owe. Konstruking the Koloss. 2012. Film.

Blistein, Ryan. “The Triumph of the Cyborg Composer.” Pacific Standard. Online edition. Last accessed April 10, 2013. http://www.psmag.com/culturesociety/triumph-of-the-cyborg-composer-8507/

Cassano, et. al. "Derealization and panic attacks: A clinical evaluation on 150 patients with Panic Disorder/agoraphobia.” Psychiatric Clinic II, University of Pisa, Rome, Italy. Elsevier, Inc., 1989.

Dawkins, Richard. The Selfish Gene. Oxford University Press. 1976.

Demers, Joanna. Listening through the Noise: The Aesthetics of Experimental Electronic Music. Oxford University Press. 2010. 
Derrida, Jacques. Voice and Phenomenon: Introduction to the Problem of the Sign in Husserl's Phenomenology. Northwestern University. 2010.

Donne, John. "Meditation XVII.” The Online Literature Network. First published 1624. Last accessed April 23, 2013. http://www.online-literature.com/donne/409/

Farnsworth, Rodney. "How the Other Half Sounds: An Historical Survey of Musical Rhetoric during the Baroque and After.” Rhetoric Society Quarterly. 20.3. 1990. 207-224.

Hadfield, Chris. "Ambient noise of the International Space Station" and "Jewel in the Night Sky” via Soundcloud.com. Last accessed April 12, 2013. https://soundcloud.com/tags/Chris $\% 20$ Hadfield

Haraway, Donna. When Species Meet. University of Minnesota Press. 2007.

Harper, Douglas. Entry on “Audience.” Online Etymology Dictionary. 2001-2012. Last accessed April 23, 2013. Web. http://www.etymonline.com/index.php?term=audience

Huizinga, Johan. "Nature and Significance of Play as a cultural Phenomenon." Homo Ludens: A Study of the Play-Element in Culture. First published 1944. Roy Publishers edition, 1950.

Ingold, Tim. Being Alive: Essays and Movement, Knowledge, and Description. Routledge. 2011.

Murray, Joddy. Non-Discursive Rhetoric: Image and Affect in Multimodal Composition. State University of New York Press. 2009.

Ong, Walter. Orality and Literacy. First published 1982. Routledge edition. 2002. 
Quintilian. Institutes of Oratory. Ed. Lee Honeycutt. Trans. John Selby Watson. Iowa State. 2006. Accessed 15 March 2014.

<http://rhetoric.eserver.org/quintilian/>.

Russon, John. Human Experience: Philosophy, Neurosis, and the Elements of Everyday

Life. State University of New York Press. 2003.

Stedman, Kyle. Musical Rhetoric and Sonic Composing Processes. Graduate Theses and Dissertations. University of South Florida. 2012.

Tolstoy, Leo. W ar and Peace. Vintage Classics. First published 1869. 2008.

Turkle, Sherry. Alone Together: Why We Expect More from Technology and Less from Each Other. Basic Books. 2011.

Vickers. "Figures of rhetoric/Figures of music?" Rhetorica: A Journal of the History of Rhetoric. 2.1. 1984. 1-44.

Whitehead, Alfred. Dialogues of Alfred North Whitehead. Recorded by Lucien Price. 1954 original: copyright by the Executors of the Estate of Alfred North Whitehead. Nonpareil Book edition. David R. Godine, Publisher. Jaffrey, New Hampshire. 2001. 